Portland State University

PDXScholar

$1-1-1984$

\title{
Stepfamily adjustment: a balance theory analysis including the noncustodial parent as a member of the family system
}

Margaret L. Fujita

Portland State University

Follow this and additional works at: https://pdxscholar.library.pdx.edu/open_access_etds Let us know how access to this document benefits you.

\section{Recommended Citation}

Fujita, Margaret L., "Stepfamily adjustment: a balance theory analysis including the noncustodial parent as a member of the family system" (1984). Dissertations and Theses. Paper 376.

https://doi.org/10.15760/etd.376

This Dissertation is brought to you for free and open access. It has been accepted for inclusion in Dissertations and Theses by an authorized administrator of PDXScholar. Please contact us if we can make this document more accessible: pdxscholar@pdx.edu. 


\title{
STEPFAMILY ADJUSTMENT: A BALANCE THEORY ANALYSIS \\ INCLUDING THE NONCUSTODIAL PARENT AS A MEMBER \\ OF THE FAMILY SYSTEM
}

\author{
by \\ MARGARET L. FUJITA
}

A dissertation submitted in partial fulfillment of the requirements for the degree of

\author{
DOCTOR OF PHILOSOPHY \\ in \\ URBAN STUDIES
}

Portland State University

(C) 1984 Margaret L. Fujita 
TO THE OFFICE OF GRADUATE STUDIES AND RESEARCH:

The members of the Committee approve the dissertation of Margaret L. Fujita presented August 7, 1984.

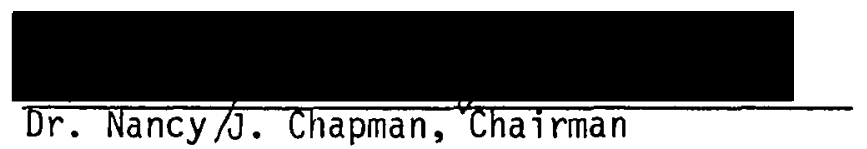

Dr. Nancy/J. Chapman, Chairman

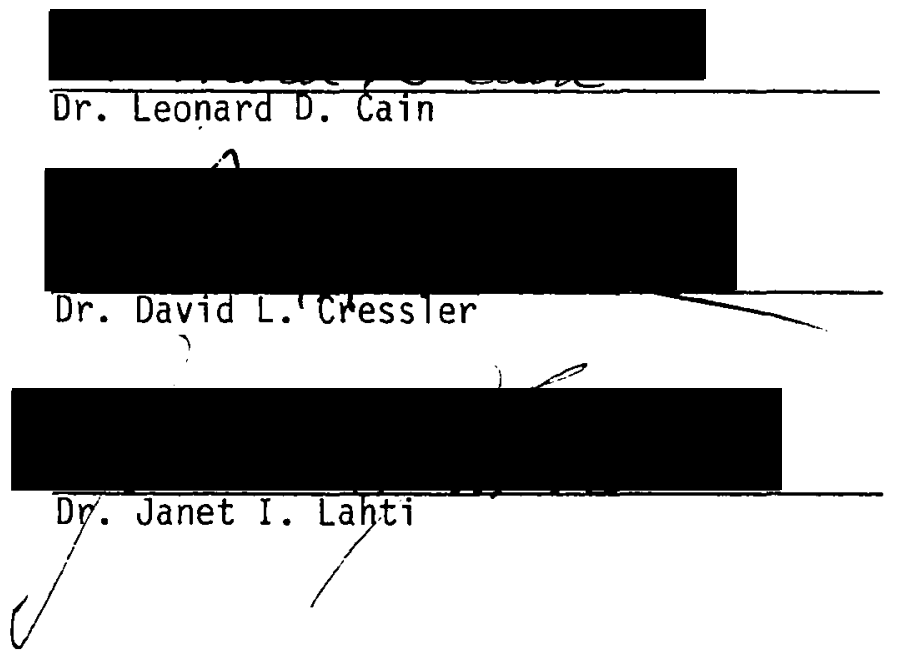

APPROVED:

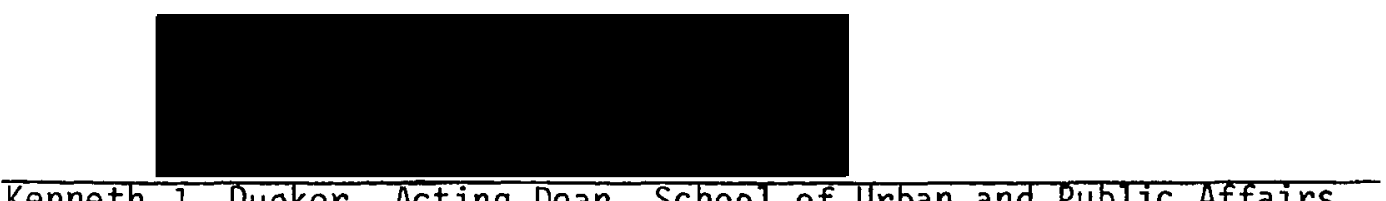

Kenneth J. Dueker, Acting Dean, School of Urban and Public Affairs

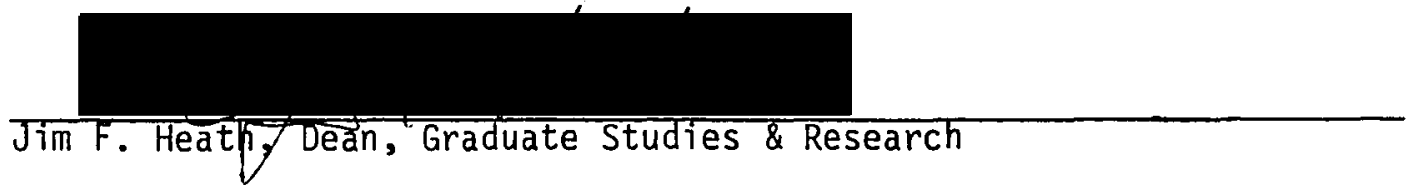


AN ABSTRACT OF THE DISSERTATION OF Margaret L. Fujita for the Doctor of Philosophy in Urban Studies presented August 7, 1984.

Title: Stepfamily Adjustment: A Balance Theory Analysis Including the Noncustodial Parent as a Member of the Family System.

APPROVED BY MEMBERS OF THE DISSERTATION COMMITTEE:

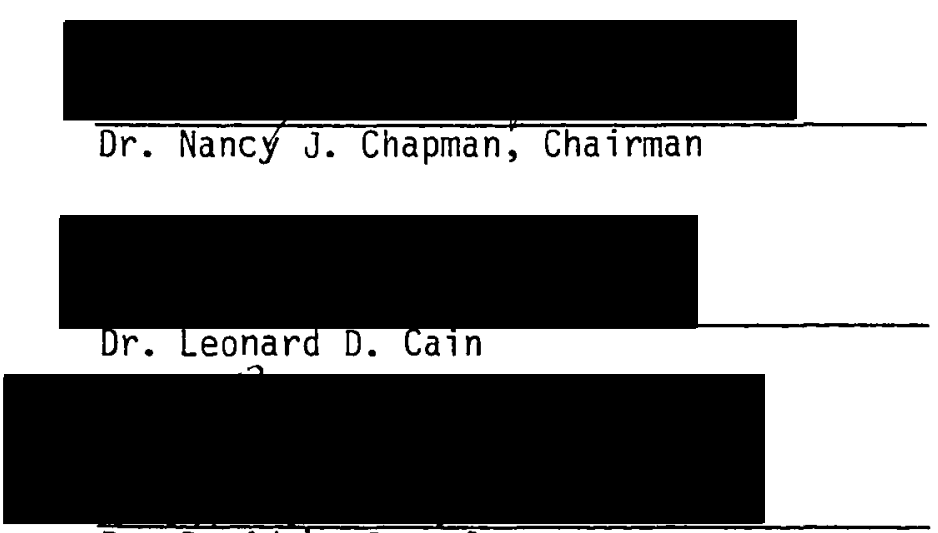

Dr. David L. Cresster

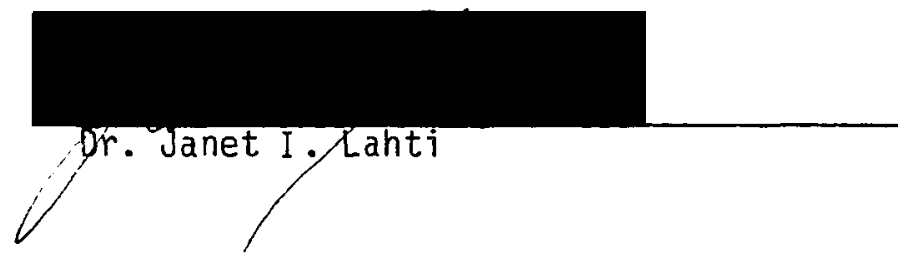

Stepfamilies are an increasingly common family form in modern urban

life. As such families increase in number, it becomes important to understand the factors involved in their successful functioning.

This study developed a balance theory analys is of stepfamily relationships in order to understand family adjustment and empirically tested hypotheses derived from that analysis. The analysis included the 
intrafamily relationships among stepparent, natural parent, and child and the extrafamily relationships between family members and the nonresident natural parent.

Balance theory originated with Heider's (1958) concepts of unit formation, sentiment, and balanced state. Unit formation refers to a relation of belonging together. In this study, residence within the stepfamily household was defined as a positive (+) unit relation; residence outside the household was a negative (-) unit relation. Sentiment refers to the affective relation between two persons.

The assumption of balance theory is that unit relations and sentiment relations tend toward a balanced state. Balanced states are systems of relations in which the algebraic product of the signs of the relations is positive. If a balanced state does not exist, the imbalance will produce tension. Given the above definition of unit relations, a completely balanced family system is possible only when the sentiment relations with the absent natural parent are negative.

The general hypothesis tested was that the degree of balance of the stepfamily system of relations is associated with stepfamily adjustment indicated by family members' feelings about satisfaction with family life, acceptance by other family members, and expected permanence of the stepfamily, as well as with individual adjustment indicated by family members' self-esteem. Balance indices were calculated based both on individual sentiment relations and on unit relations.

Thirty-seven newly formed stepfamilies with a resident adolescent child provided the data for the study. Questionnaire data were obtained 
from the natural parent, the stepparent, and the child in regard to intrafamily communications, extrafamily relationships with the absent natural parent, and the family and individual adjustment variables.

The results supported the hypothesis of an association between balance and family members' feelings indicative of stepfamily adjustment. For the child, the association between balance and feelings indicative of stepfamily adjustment was stronger when unit relations were included in the calculation of system balance than when balance was based on sentiment relations alone. For adults, the balance calculation based on sentiment relations alone produced the stronger associations with family adjustment.

Self-esteem was not associated with family system balance. It was associated with the number of positive dyadic sentiment relations in the family system to which a member was a party.

Implications of the results for research are that balance theory is a fruitful approach to understanding stepfamily adjustment and functioning.

Policy implications of the research point to possible trade-offs in custody issues. Joint custody, while providing the benefit of continuing relationships with both natural parents, also may make more difficult the child's adjustment in the stepfamily. 


\section{ACKNOWLEDGMENTS}

The help of many people has made this achievement possible. There are too many to list every person, but the contribution of some has been so invaluable that I wish to thank them individually.

First, I wish to thank my Chairperson, Nancy Chapman. She first suggested balance theory to me. Her patient and thoughtful criticism encouraged me to do my best work, and without her this dissertation would never have been written.

Each of my committee members has made a unique contribution to this endeavor. On innumerable occasions, David Cressler has given to me the emotional or intellectual support that I needed at that particular moment. Janet Lahti's aid as I worked with the Stepfamily Project of the Regional Research Institute expedited the solution of many practical problems, including my first introduction to the computer terminal. Leonard Cain has contributed a broader intellectual perspective to my thought, with his focus upon the urban implications of the research.

I wish to acknowledge the assistance of the Stepfamily Project, whose data I used in this study. Paul Koren, Janet Lahti, Carol Sadler, and Priscilla Kimboko collected the data. The Regional Research Institute provided needed working space for which I thank its director, Arthur C. Emlen.

Others have made invaluable contributions. Darey Shell taught me how to use the computer. Alta Beebe deciphered my handwriting to type 
the first draft. Sally Lopez typed the final drafts and urged me on when I was discouraged.

My family sustained me throughout this endeavor. My daughter, Anne, took over many household responsibilities during the major work of writing. My husband, Ben, made intellectual contributions in our many discussions. I thank both of then for their support.

I thank Thomas C. Burgess for his special assistance. 
TABLE OF CONTENTS

PAGE

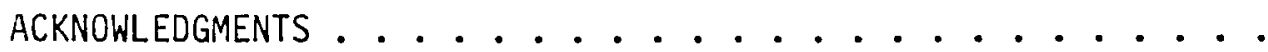

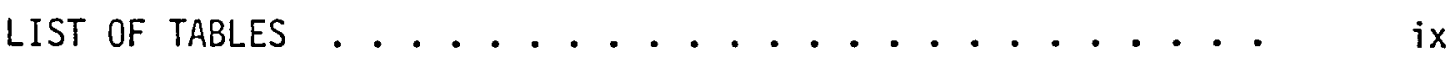

LIST OF FIGURES . .................. . .

CHAPTER

I INTRUDUCTION ................... 1

Research Problem ............ 1

Theoretical Basis

Balance Theory Model ..........

Definition of Concepts

Conceptual Model

Hypothesis .................. 6

Significance of the Research Problem . . . . 6

Organization of this Report ........ 9

II A BALANCE THEORY OF STEPFAMILY ADJUSTMENT . . . . . 10

Stepfamily Research .......... 10

Variables Associated With Stepfamily Adjus tment

Urban Context

Rationale for Using Balance Theory 
Balance Theory ..............

Balanced States

Graph Theory Model of Balance

Balance Theory Applications

Balance Model of the Stepfamily System . . .

Unit Relations

Sentiment Relations

Child-Absent Parent Dyad

Resident Parent-Absent Parent Dyad

Development of the Hypotheses

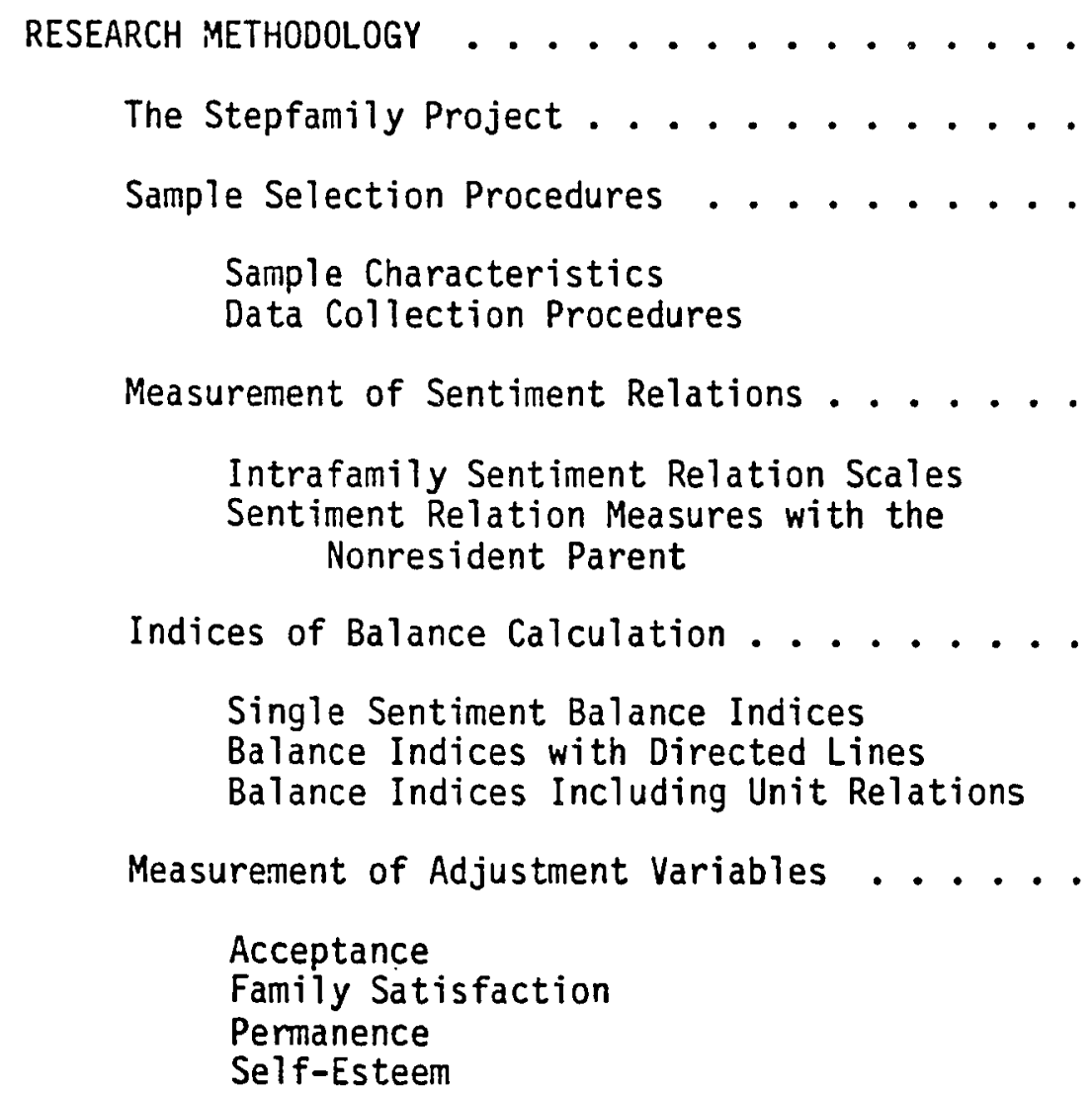

Intrafamily Sentiment Relation Scales

Sentiment Relation Measures with the Nonresident Parent

Indices of Balance Calculation . . . . . .

Single Sentiment Balance Indices

Balance Indices with Directed Lines

Balance Indices Including Unit Relations

Measurement of Adjustment Variables . . . .

Acceptance

Family Satisfaction

Permanence

Self-Esteem 
Hypothesis Testing Procedures ........

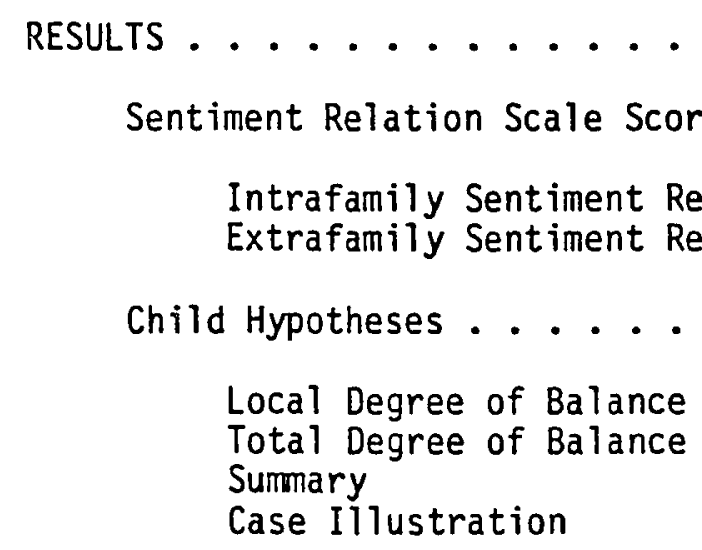

Local Degree of Balance

Total Degree of Balance

Summary

Case Illustration

Stepparent Hypotheses . . . . . . . .

Local Degree of Balance

Total Degree of Balance

Summary

Natural Parent Hypotheses . . . . . . .

Local Degree of Balance

Total Degree of Balance

Summary

Case IIlustrations

Alternate Hypothesis Exploration . . . . .

Overall Summary of Results ......... 81

Balance Theory Analys is . . . . . . .

Asymmetric Relations

Unit Relations

Self-Esteem

Limitations of the Research ......... 
viii

CHAPTER

PAGE

Implications of the Results ........

Research Implications

Policy and Clinical Implications

Summary ...............

94

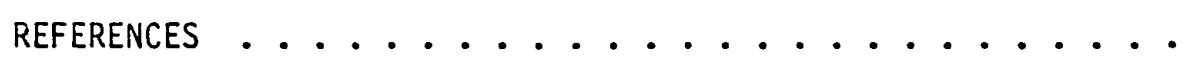

96

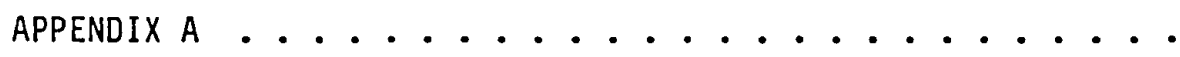

99

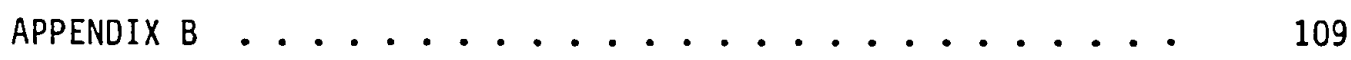

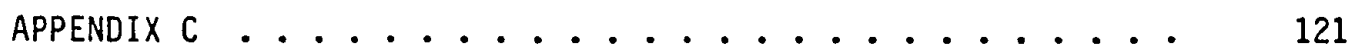

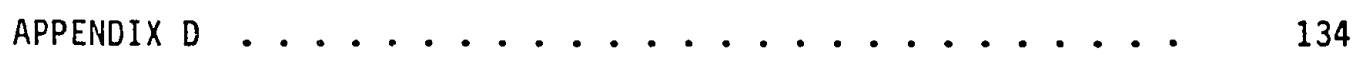




\section{LIST OF TABLES}

TABLE

PAGE

I Reliability of the Communication Subscales . . . 36

II Degree of Balance Calculations with Simple Sentiments 49

II Reliability of the Adjustment Scales . . . . . . 58

IV Correlations Between Balance Indices and Adjustment Scales for the Child.......... . . 64

$V$ Correlations Between Balances Indices and Adjustment Scales for the Stepparent . . . . . . .

VI Correlations Between Balance Indices and Adjustment Scales for the Natural Parent ........

VII Comparison of Correlations of Adjustment Scales With

Balance and With Positivity ........

VIII Computer Names, Means, and Standard Deviations of Sentiment Relation Scales ........

IX Means and Standard Deviations of Adjustment Scales.

$X$ Conceptual Variables with Corresponding Items in 


\section{LIST OF FIGURES}

FIGURE

PAGE

1. Balance Theory Model of Stepfamily Adjustment . . . 7

2. Balanced and Unbalanced Triads . . . . . . . 18

3. Relationship System .............. 19

4. Stepfamily Relationship System Depicting both unit and Sentiment Relations ........ 22

5. A Signed Relationship System ............ 44

6. A Stepfamily System of Sentiment Relations . . . . 46

7. Illustration of the Difficulty With the Degree of

Balance Index Using Four Cycles ....... 48

8. A Stepfamily System With Directed Lines Representing Reciprocity of Sentiment Relations ......

9. A Stepfamily System With Sentiment Relations and Signed Unit Relations ............

10. The Stepfamily System With Unit Relations and Directed Lines Representing Reciprocity of Sentiment Relations...............

11. Stepfamily System With Directed Lines With Low Degree of Balance Index for Child.........

12. Absent Parent, Resident Parent, and Child Triads ... 
13. Frequency Distribution of Marital Sentiment Relation from Natural Parent's Perspective (NMREL) ...

14. Frequency Distribution of Marital Sentiment Relation from Stepparent's Perspective (SMREL) ....

15. Frequency Distribution of Stepparent-Child Sentiment Relation from Parental Perspective (SCREL) ...

16. Frequency Distribution of Stepparent-Child Sentiment Relation from Child's Perspective (CSCREL) . . .

17. Frequency Distribution of Natural Parent-Child

Sentiment Relation from Parental Perspective $(N C R E L) \ldots \ldots \ldots \ldots$

18. Frequency Distribution of Natural Parent-Child Sentiment Relation from Child's Perspective

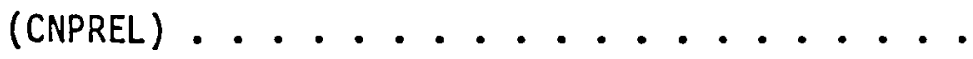

19. Frequency Distribution of Absent Natural ParentStepparent Sentiment Relation (STEPREL) ....

20. Frequency Distribution of Absent Parent-Child Sentiment Relation (CHIREL).......

21. Frequency Distribution of Ex-spousal Sentiment Relation (NATREL) .......... 


\section{CHAPTER I}

\section{INTRODUCTION}

Stepfamilies are an increasingly common family form in modern urban life. It is now estimated that $25 \%$ of all children will have a stepparent before they reach the age of 18 (Glick, 1980). As stepfamilies become more prevalent, it is important to study them in order to understand the process of adjustment, particularly the factors which facilitate it and those which impede it.

This research developed and empirically tested a balance theory analysis of stepfamily relationships and adjustment. The focus was the adjustment to the new family of family members residing within the remarriage household. The absent natural parent was included as an influence upon this adjustment.

\section{RESEARCH PROBLEM}

For stepfamilies, relationships with persons outside the household are more complex than for first families. There are persons outside the household who can enter into a parental or parent-like relationship with the children. There are more sets of grandparents, aunts, uncles and other kin. There may be friends connected through previous marriages. Research in social networks led to the recognition that these relationships influence family interaction and functioning.

Two investigators, Bernard (1971) and Duberman (1975), reported 
that the attitudes of significant others toward the remarriage are associated with the adjustment and success of the new family. While their studies are suggestive of the importance of the social context, a critical literature review (Walker, Rogers, and Messinger, 1977: 281) concluded that:

An additional shortcoming in the research literature is the lack of a focus on relationships of remarriage famiiy household members with relatives and friends connected through a former marriage.

This research addresses the above shortcoming by investigating the relationships between the absent natural parent and remarriage household family members and relating them to stepfamily functioning. These particular relationships were chosen to be a point of focus because at one time in the past this now-absent parent was highly significant to the resident household parent, probably was highly significant to the child, and potentially remains so for both of them.

Theoretical Basis

The fields of social network analysis and family therapy converge in that both proceed by examining systems of relationships. This convergence suggested the potential fruitfulness of an approach to understanding adjustment of the remarriage family based upon an examination of the relationship system. This examination included study of the intrafamily relationships among stepparent, natural parent, and child and the extrafamily relationships between family members and the nonresident (absent natural) parent. For a stepfamily with three 
members, this relationship system includes six dyadic relationships: the marital relationship between stepparent and natural parent, the natural parent-child dyad, the stepparent-child dyad, the ex-spousal relationship, the absent parent-child dyad, and the absent parentstepparent dyad.

The potential for loyalty conflicts is high here. Within the family, the natural parent may be torn between the well-established relationship with the child and the newer one with the stepparent. The child may feel conflict between loyalty to the absent parent and affection for the stepparent, or conflict over feelings of belonging to the new stepfamily. If the two natural parents do not get along, the child may feel caught in conflicting loyalties.

Balance theory, originating with Heider's (1958) concepts of unit formation, sentiment, and balanced states, appeared to be a possible theoretical basis for understanding stepfamily functioning as a system. This system is assumed to be interdependent. The arrangement of the relationships is not accidental or unconnected, but is under the influence of a balancing force. A change in one relationship is an influence for change in another relationship in the system. As will be described in detail later, that model fits situations involving loyalty conflicts. This research developed a balance theory analysis of stepfamily relationships and adjustment and empirically tested hypotheses derived from that analysis. The research focused upon the adjustment of the stepfamily household members (natural parent, stepparent, and child), while including the absent natural parent as a 
member of the interdependent family system.

\section{BALANCE THEORY MODEL}

\section{Definition of Concepts}

Before presenting the conceptual model of stepfamily adjustment based upon balance theory, definitions of Heider's (1958) concepts of sentiment, unit formation, and balanced state will be given as an aid to understanding the model. Sentiment refers to an affective relation between a focal person, $P$, and another person, 0 . Sentiments may be classified as either positive or negative.

Unit formation refers to the perception of a relation of belonging together. For example, traditionally members of a family are seen as a unit. Thus, they have a positive unit relation with each other, while persons outside the family have negative unit relations with family members.

A balanced state is

a situation in which the relations concerning the entities fit together harmoniously, there is no stress toward change. A basic assumption is that sentiment relations and unit relations tend toward a balanced state ... . Sentiments and unit relations are mutually interdependent. It also means that if a balanced state does not exist, then forces toward this state will arise. If a change is not possible, the state of imbalance will produce tension (Heider, 1958: 201).

Heider then proceeds to formulate conditions of balance. At this point in the discussion, it will suffice to know that relationship systems are made up of sentiment relations and unit relations that tend toward balanced states. Balanced states are not always attainable. Balance 
indices have been developed to measure the degree of balance of a relationhip system. Imbalance in the relationship system produces tension for the persons involved. With these concepts, the application of balance theory to stepfamily adjustment can be presented.

\section{Conceptual Model}

In the balance theory model of stepfamily adjustment presented in Figure 1, the stepfamily relationship system consists of the following: a) the dyadic relationships among household family members (i.e., the marital dyad, the natural parent-child dyad, and the stepparent-child dyad), all of which are positive unit relations and are shown inside the household boundary; and b) the three dyadic relationships that each (the child, the resident natural parent, and the stepparent) has with the nonresident (absent natural) parent. These latter categories are negative unit relations and cross the household boundary.

A sentiment relation exists between each dyad in addition to the unit relation. Each particular arrangement of sentiment relations and unit relations in a stepfamily relationship system can be characterized by the degree of balance of the system. This degree of balance is indicated in Figure 1 by the arrow connecting the stepfamily system to system balance.

Lack of balance in the stepfamily relationship system produces tension for the family members. In contrast, family members in balanced systems experience little tension. The degree of tension experienced is manifested in the members' feelings of family satisfaction, acceptance in the stepfamily, expected permanence of the family, and self-esteem. 
Such tension is a force toward changing a relation with another family member in a direction toward balance in the system (indicated in Figure 1 by the feedback loop from the tension box to the stepfamily relationship system). This aspect of the model has interesting implications for understanding change in stepfamily relationships which will be discussed in later chapters.

\section{HYPOTHESIS}

In general, the expectation is that the degree of balance of the stepfamily system of relationships will be associated with stepfamily adjustment indicated by feelings of stepfamily members about satisfaction with family life, acceptance in the stepfamily, and expected permanence of the stepfamily and with individual adjustment indicated by family members' self-esteem. The reasoning underlying this expectation is as follows: Though balance is the preferred state in interpersonal systems, the complexities surrounding stepfamilies at times preclude the attainment of balanced states. States of imbalance result in tension which is manifested in family members' feelings about the stepfamily.

\section{SIGNIFICANCE OF THE RESEARCH PROBLEM}

As the number of stepfamilies grows, it becomes more important to understand the factors involved in successful functioning. One aspect of successful family functioning is that family members feel satisfied with their family, accepted by other family members, secure in the 


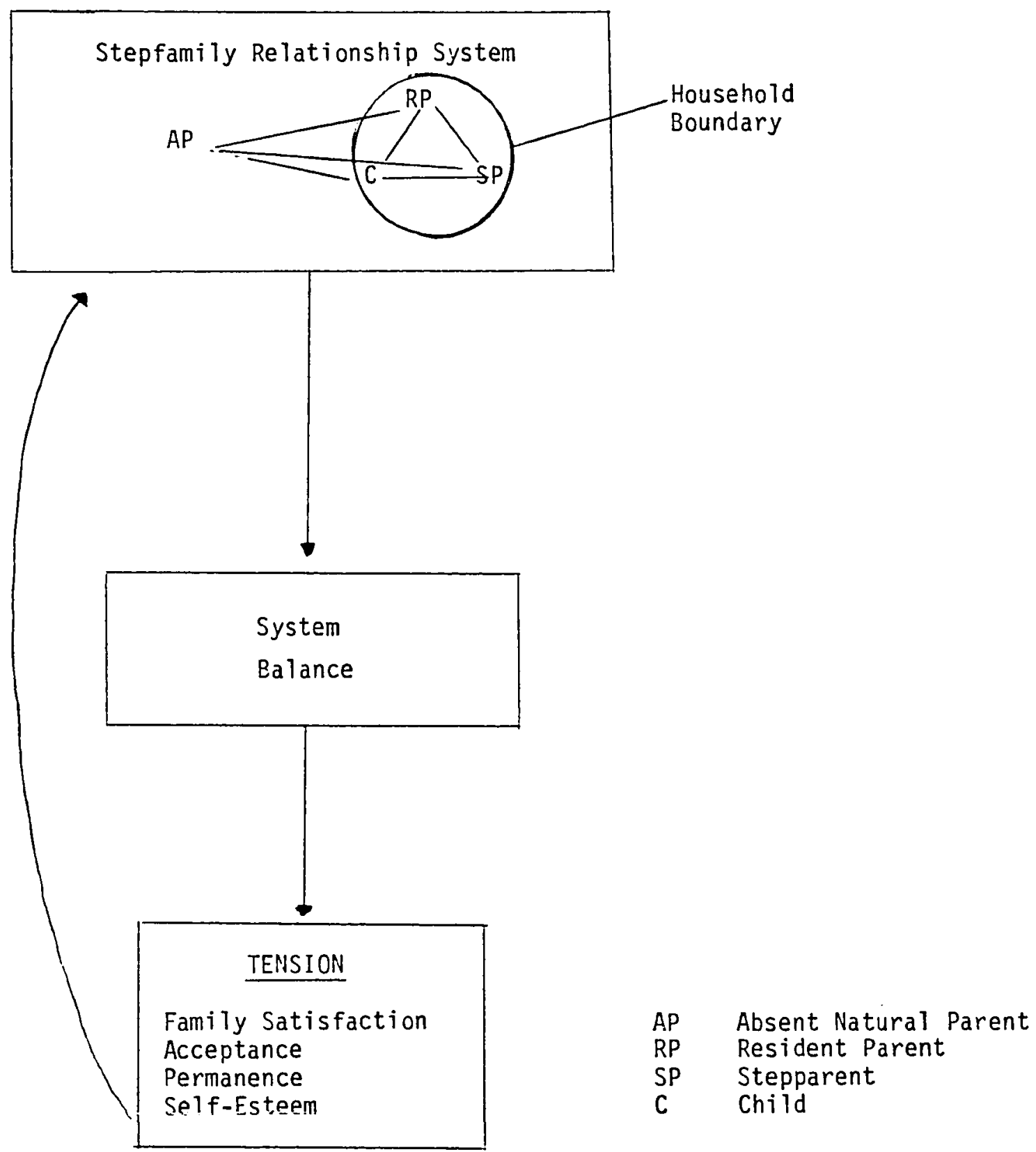

Figure 1. Balance theory model of stepfamily adjustment. 
expected permanence of the family, and sure of their own self-worth. In our society, these are socially-valued outcomes. Both mental health professionals working with dysfunctional families and social policy experts could benefit from information relevant to attaining these goals.

Borrowing from Bronfenbrenner's $(1977,1979)$ ecological framework, the balance theory model is the inner part of an interconnected nested system of levels of analysis. The household family is the microsystem, and the relationships with the nonresident parent are the mesosystem; both are embedded within the broader social-cultural context or macrosystem, defined as the "overarching patterns of ideology and organization of the social institutions common to a particular culture" (Bonfenbrenner, 1979:8). The balance theory model is a hypothesis about ongoing social-psychological processes in stepfamily functioning. This aspect of the model is most useful to mental health professionals working with distressed families.

Once an understanding is obtained of the ongoing socialpsychological processes affecting the socially-valued outcomes of stepfamily adjustinent and self-esteem, then attention can turn to the macrosystem factors in urban life which facilitate or hamper the attainment of these outcomes through their impact upon the socialpsychological processes. In particular, the inclusion of the nonresident (absent) parent in the balance theory analysis can provide information relevant to the issue of joint custody. In addition, if the balance theory analysis proves to be useful for understanding 
stepfamily functioning, it can be modified and extended to other family relationship systems, including grandparents or other significant persons outside the household.

\section{ORGANIZATION OF THIS REPORT}

Chapter II presents a selective review of the literature, develops the balance theory analysis of stepfamily functioning, and formulates the hypotheses derived from the analysis to empirically test the theoretical model. Chapter III describes the methodological procedures perforined to test the hypotheses. In Chapter IV, the results obtained in the hypothesis-testing are presented. Finally, Chapter $V$ discusses the implications of the results, identifies the limitations of the research, and suggests directions for future work on the topic. 
CHAPTER II

\section{A BALANCE THEORY OF STEPFAMILY ADJUSTMENT}

In this chapter, stepfamily literature is reviewed selectively to develop the rationale for the balance theory analysis of stepfamily adjustment. The development of balance theory is presented, followed by a review of applications of the theory to family processes. Variables are culled from the social network literature to assess the extrafamily relationships with the nonresident natural parent. Lastly, the balance theory analysis is developed, and the hypotheses are presented.

\section{STEPFAMILY RESEARCH}

As the incidence of divorce and remarriage has increased, social scientists have begun to study stepfamilies. An annotated bibliography (Walker, Brown, et al, 1979) cites a moderate number of demographic and clinical (but fewer empirical) studies of stepfamily functioning. The findings are mixed, with some studies reporting that stepfamilies function less adequately than first families, while others report that stepfamilies work at least as well.

Some studies reported negative findings. Bowerman and Irish (1962), in a study which employed questionnaire data from a large random sample of junior and senior high school students, found that stepfamilies were more likely to contain stress, ambivalence, and low cohesiveness than first families. In another large, random survey 
study, Rosenberg (1965) reported that youth suffered a marked loss of self-esteem when a stepfather entered the family, especially if the children were older when one of the natural parents left. Similarly, in a random survey sample, Langner and Michael (1963) found that children from stepfamilies were less well adjusted.

In contrast, other studies did not report negative findings. Burchinal (1964) studied high school students living in a stepfamily situation and found no significant detrimental effects from that family structure. Wilson, Zucker, et al (1975) came to similar conclusions after having looked carefully at a number of social and psychological characteristics. Bohannan (1975) found that stepchildren considered themselves to be as happy, as successful, and as achieving as firstfamily children. He concluded that children in stepfamily households got along as well with their stepfathers as first-family children did with their natural fathers. Bernard (1971), in her now classic study, concluded that many stepfamily relations are healthy and mutually supportive. And Duberman (1975), in a random sample of 88 stepfamilies, reported that $64 \%$ rated themselves as having "excellent" relationships.

Variables Associated With Stepfamily Adjustment

Mixed findings such as these pose a challenge to researchers to discover the particular variables involved in successful stepfamily functioning. Both Bernard (1971) and Duberman (1975) found that the attitudes of ex-spouses, relatives, and friends were associated with the quality of stepfamily relationships. In particular, Duberman found that the nonresident natural parent had a detrimental effect upon 
stepparent-stepchild relationships. Stark (1983), in a descriptive study of ten self-described successful stepfamilies, reported that one significant characteristic of these families was a lack of animosity between the stepfamily and the absent natural parent.

Clinical experience suggests

that there is a positive correlation between the degree of acceptance and understanding by the present parental figures of the absent biological parents and the emotional well-being of the child.

(Visher \& Visher, 1979: 20)

Research evidence supports this statement. Lutz (1983) reported that adolescents rated the following as the most stressful aspects of living in a stepfamily: a) experiencing one natural parent talking negatively about the other; and b) feeling caught in the middle between the two natural parents. Similarly, Koren, Lahti, et al (1983) found that for children, dissatisfaction with the stepfamily is related to the tendency of members of the current family to criticize the absent parent and to compare the current family with the former one.

A good marital relationship is associated with successful stepfamily adjustment. Anderson (1983) reported that functional stepfamiles have a strong marital bond. Duberman (1975) found that when the marital relationship was good, family integration was rated high and relationships between stepparents and stepchildren were reported as excellent.

The quality of the stepchild-stepparent relationship appears to be important in stepfamily adjustment. Koren, Lahti, et al (1983) reported 
that communication between stepparent and stepchild was a key factor in family adjustment, with the most important aspect being the support that the stepparent gave to the stepchild. Anderson (1983) in her comparison of functional and dysfunctional stepfamilies found greater positive stepchild-stepfather involvement in functional families; dysfunctional stepfamilies demonstrated an extremely strong natural parent-child relationship to the exclusion of the stepparent. The complexities of stepfamily interactions are illustrated further by Lutz's (1983) finding that adolescents rate as highly stressful "liking a stepparent more than your natural parent of the same sex."

To summarize, stepfamily adjustment is associated with a strong marital bond and positive stepparent-stepchild relationships. The attitudes of significant others toward the stepfamily are associated with the quality of stepfamily relationships. Relationships with the nonresident parent are particularly important for the child. Adolescents report considerable stress related to the issue of divided loyalties between the nonresident natural parent and the parental figures in the stepfamily.

\section{Urban Context}

These personal relationships are imbedded in a social-cultural context. Returning to Bronfenbrenner's $(1977,1979)$ ecological framework, the intrafamily relationships are the microsystem, and the extrafamily relationships are the mesosystem. Both are imbedded within and affected by the broader social-cultural context or macrosystem, defined as "overarching patterns of ideology and organization of the 
social institutions common to a particular culture" (Bronfenbrenner, 1979: 8). A complete understanding of stepfamily adjustment entails learning about the influence of these macrosystem variables upon the quality of stepfamily relationships. The literature contains much discussion based upon clinical and personal experience about the possible impact of macrosystem variables upon stepfamily relationships, but empirical research evidence is meager. A brief discussion of such variables follows.

Societal guidelines are lacking in regard to stepfamilies. Legal and nonlegal norms and kinship terminology are inadequate. The terms "stepchild" and "stepparent" have negative connotations. There are no accepted norms for the stepparent-stepchild relationships; both parent and child struggle with the confusion and ambiguity. The stepparent has no legal relation to the child, resulting in a sense of impermanence to the relationship. There are no kinship terms or norms in regard to the extended kinship system in the remarriage situation. Each stepfamily must negotiate its own particular solutions for these relationships.

Frequently, the stepfamily must cope with legal encumbrances from a previous divorce. These may include custody, visitation rights, and child support payments. Recurring interactions around these issues between the nonresident natural parent and stepfamily members influence stepfamily adjustment. Reaves (1982), in a study of stepfamily and noncustodial parent interaction, reported these findings: a) stepfamily satisfaction for the natural mother was predicted by her satisfaction with child support payments from the noncustodial 
natural father, and b) self-esteem of the children ranging from 13-17 years of age was predicted by the stepfather's satisfaction with the child support payments. More research which examines the associations between macrosystem influences such as the effects of legal procedures and decisions and stepfamily adjustment variables would be valuable to further an understanding of the whole interconnected ecological system. Another nacrosystem influence is the opportunities for interaction between the nonresident natural parent and the stepfamily provided by the urban milieu. Does urban residential mobility discourage the maintenance of relationships between the child and the nonresident parent? Perhaps modern transportation and communication technologies make geographic distance unimportant.

Questions such as these regarding the influence of the urban social-cultural context on stepfamily relationships await research attention.

Rationale for Using Balance Theory

Stepfamily research to date has tended to focus on dyadic relationships: the stepparent-stepchild dyad, the marital dyad, the exspousal dyad, the natural parent-child dyad, or the noncustodial parent-child dyad. Although information about these dyadic relationships is valuable, the recurring theme of divided loyalties in stepfamilies suggests the potential fruitfulness of a theoretical approach which looks at triads. With balance theory, both dyads and triads can be incorporated into the analysis. 


\section{BALANCE THEORY}

Balance theory originated with Heider's formulation of a system of relationships descriptive of an individual's cognitive field. Newcombe subsequently modified the theory to make it more applicable to interpersonal relationships and social fields. Other scholars formalized the theory using concepts from the mathematical theory of graphs (H. Taylor, 1970).

Balance theory analyzes relations between people. Relations may be positive (+) or negative $(-)$. Two types of relations are included in this research. Sentiment relations are affective feelings about others. Unit relations are feelings of belonging in the same family household. It is assumed that relations tend toward a balanced state; this assumption is the balance theory. Imbalance results in a state of tension for the persons involved with stress toward change in one of the relations.

\section{Balanced States}

A dyad is balanced if the relations between the two persons are all positive or all negative. Two persons who reciprocate liking for each other (or, alternatively, disliking for each other) demonstrate a balanced state. Another example of a balanced dyad is the following "I live with a person whom I like." This example is a positive sentiment relation and a positive unit relation.

Disharmony results when relations of different signs exist. "I dislike my stepparent with whom I live" is an example of an imbalanced 
dyad with a negative sentiment relation and a positive unit relation. Similarly, "I dislike John even though he likes me" is also an imbalanced dyad.

A triad is balanced if the relations between the persons are all positive, or if two of the relations are negative and one is positive. Examples of balanced triads are the following: a) "The friend of a friend is a friend." All relations are positive (see Figure 2A). An example in stepfamily relationships is the situation in which the natural parent, stepparent, and child all feel positively about each other. b) Or, "the enemy of my friend is my enemy too." This is the classic "two against one" situation in which two persons are friends and share a distike of a third person. Two relations are negative, and one relation is positive (as snown in Figure 2B). An example of this balanced triad is the situation in which the parental figures in a stepfamily join in a shared dislike of the nonresident natural parent.

A triad is imbalanced when two of the relations are positive and one is negative, as in Figure $2 C$. This is the uncomfortable situation of divided loyalties in which "my two friends dislike each other." It is also the situation of a child whose two natural parents do not get along. There will be pressure for the child to reject one or the other parent to restore the triad to the balanced pattern shown in Figue $2 \mathrm{~B}$. If the child's relationship is strongly positive with both parents, the situation is extremely stressful. Hess and Camara's (1979) finding that parental discord following divorce was an important contributor to child stress and Lutz's (1983) data in which adolescents rated "feeling caught 
in the middle between the two natural parents" as very stressful are both in accordance with balance theory.

Frequently, the stepparent, natural parent, and child triad begins in the unbalanced pattern shown in Figure $2 \mathrm{C}$ with a positive marital dyad, a positive natural parent-child dyad, and a negative stepparentchild dyad. The imbalance can be resolved by a change in any of the dyads toward either of the balanced patterns. The pattern in Figure $2 A$ is the preferred resolution for the stepfamily.

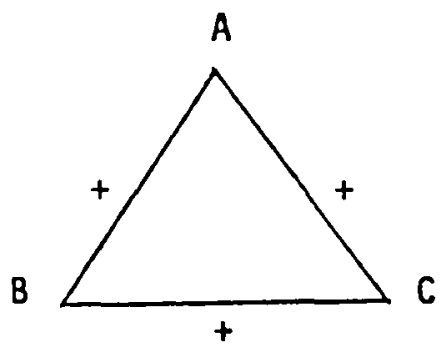

A. Balanced Triad

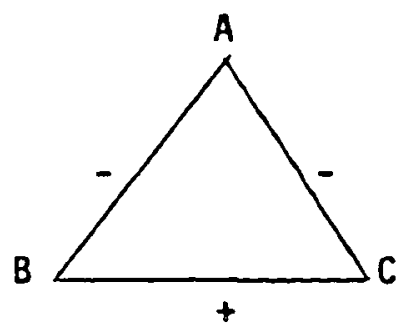

B. Balanced Triad

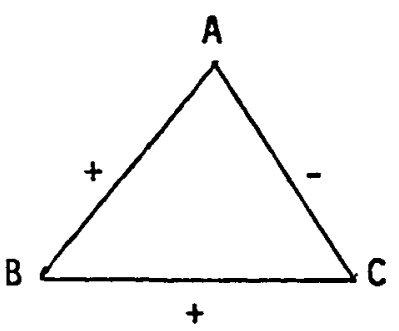

C. Unbalanced Triad

Figure 2. Balanced and unbalanced triads.

\section{Graph Theory Model of Balance}

Cartwright and Harary (1956) first translated the basic concepts of Heider's model into those of the mathematical theory of graphs. In graph theory, each person is represented by a point, and each relation is represented by a line between the appropriate points. Positive relations receive a $(+)$ value, and negative relations receive a $(-)$ value. 
Figure 3 is a graph of a relationship system. A path is two or more lines connecting consecutive points on a graph. In Figure 3 , the lines $A B$ and $B C$ are a path from $A$ to $C$. A cycle is any path that returns to the point of origin. Hence, $A B, B C, C A$ form a cycle representing a triad. A balanced system of relationships, or a balanced cycle, is one in which the algebraic product of the signs of the lines is positive. This can be verified by multiplying the signs in the balanced triads in Figures $2 A$ and $2 B$. In an imbalanced system, the algebraic product of the signs is negative. Again, this can be verified by riultiplying the signs in the unbalanced triad in Figure $2 \mathrm{C}$.

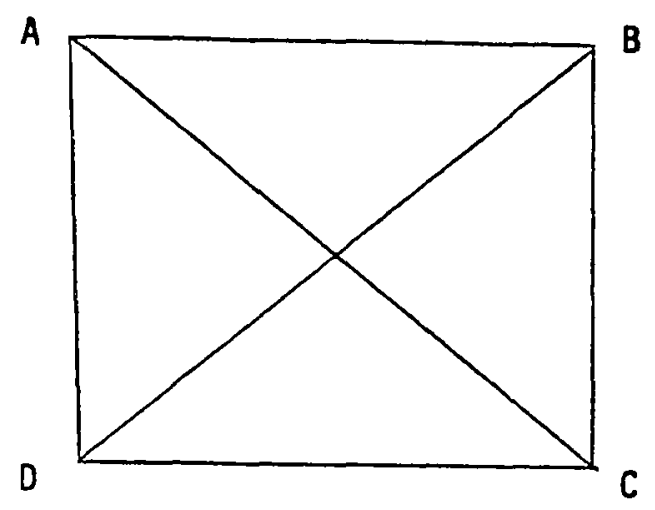

Figure 3. Relationship system.

A completely balanced graph of a set of relationships is one in which all the cycles in it are balanced. However, all the cycles in a graph may not be balanced. Therefore, balance indices have been developed to measure the degree of balance of a graph based upon the 
ratio of positive cycles to total number of cycles in the graph. The calculation is described in detail in Chapter III, Research Methodology.

Balance Theory Applications

Balance theory has been applied to phenomena in the social sciences as diverse as international relations (Harary, 1983) and fairy tales (Auster, 1980). H. Taylor (1970) provides an excellent review of the earlier work on interpersonal relations. A more recent review of balance as utilized in the psychological literature is presented in Cartwright and Harary (1979). McLemore (1973) applied balance theory to the mother, father, and child triads in a family to derive implications for understanding the child's position in the family. Hoffman (1981) discusses the contribution that balance theory makes to family therapy theory.

W. Taylor (1970) applied the graph-theoretic model of balance developed by Cartwright-Harary (1956) to a four-member family seen in a clinical setting to simplify an understanding of the family's organization. He defined a balanced family as one that remains intact, though not necessarily unstressed, and an unbalanced family as one which tends toward balanced arrangements through the addition of a helper, the expulsion or withdrawal of a member, or change in the quality of a dyad. He showed that in a family with negative dyads, isolating (scapegoating) one member is the least stressful balance arrangement. His empirical data of the therapeutic process supported the balance theory analys is. W. Taylor's (1970) work suggested to this researcher the 
possibility of a balance theory analysis of stepfamily adjustment including four persons in the relationship system: the stepparent, the natural parent, the child, and the nonresident natural parent.

\section{BALANCE MODEL OF THE STEPFAMILY SYSTEM}

The system of relationships between the nonresident parent, the resident natural parent, the stepparent, and the child is represented by a graph (see Figure 4). Two types of relations are depicted. Unit relations, defined as members residing within the same household, are one type; the sign of these relations is given in the illustrative graph in Figure 4A. Sentiment, or affective relations, are the second. Sentiment relations may be either positive or negative and vary with each family. The two types of relations are combined into a single system of relationships. This is shown diagrammatically by superimposing the two separate graphs over each other to make a single graph (see figure 4C). At any particular time, a cycle representing a set of relationships is either balanced or unbalanced, with tension consequences for the involved individuals. In the graph shown in Figure $4 A$, the cycle AP, $C H, R P$ is balanced for unit relations with two negative relations and one positive relation $(-)(-)(+)=(+)$.

\section{Unit Relations}

According to Heider (1958: 176), "separate entities comprise a unit when they are perceived as belonging together." Traditionally, nuclear family members are seen as a unit when they reside in the same household. For this reason, a positive unit relation was defined as 


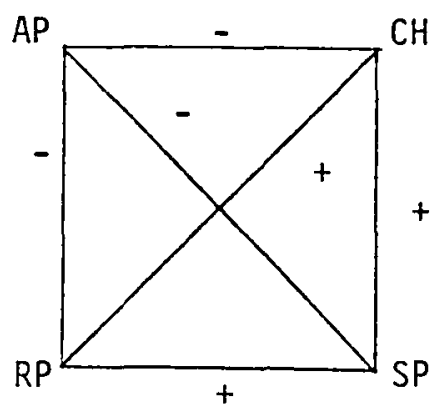

Unit Relations

$4 A$

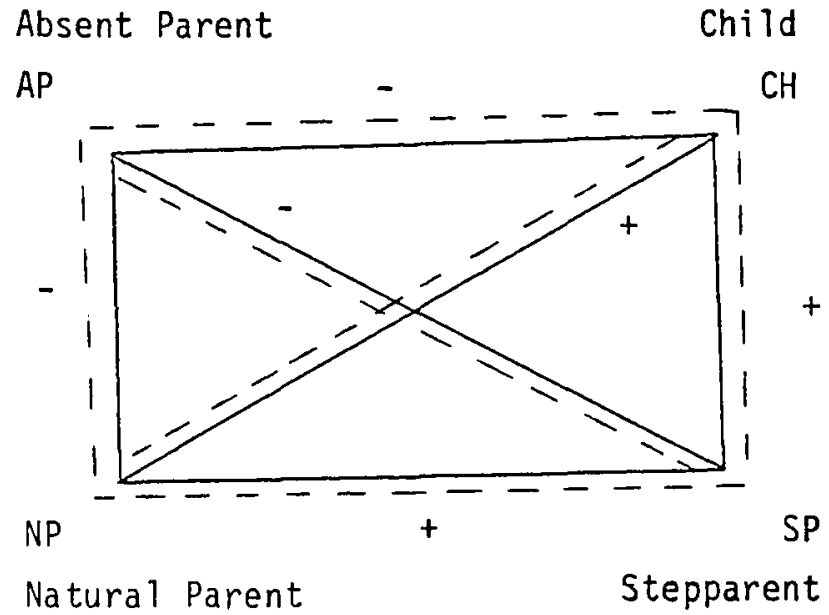

Unit and Sentiment Relations Combined

$4 \mathrm{C}$

Unit

Sentiment

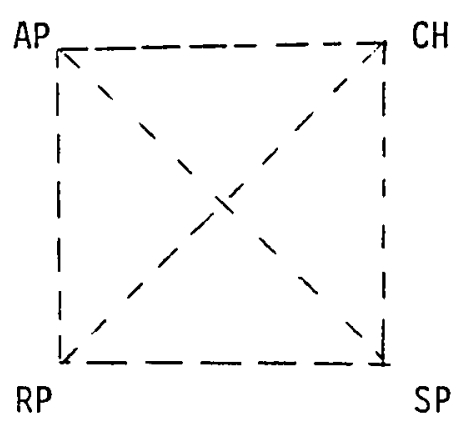

Sentiment Relations

Figure 4. Stepfamily relationship system depicting both unit and sentiment relations. 
residing in the same household with another family member; a negative unit relation was defined as not residing in the same household. Divorce and remarriage alter the traditional family residential arrangements, resulting in confusion and ambiguity about what configuration constitutes a family (Visher and Visher, 1979). Defining a positive unit relation as one in which members reside in the same household and a negative unit relation as one in which a household is not shared assumes that the traditional idea about family structure still influences stepfamily members' feelings.

\section{Sentiment Relations}

A sentiment relation refers to the way one person feels about another. In this research, the assumption is made that the overall quality of the dyadic relationship may be labeled either positive or negative. Different approaches were used for assessing the intrafamily sentiment relations and the extrafamily sentiment relations. The quality of the intrafamily sentiment relations between the stepparent, natural parent, and child was assessed based upon approaches to understanding intrafamily communication. The operationalization of the intrafamily sentiment relations is described in Chapter III, Methodological Procedures.

The quality of the extrafamily sentiment relations with the nonresident parent is based upon variables for understanding interpersonal relationships suggested in the social network literature. This choice was made in the search for ways to conceptualize "family" relationships for which there are no traditional role behaviors. The 
persons involved are finding new ways of maintaining relationships; it is hoped that the use of social network variables will describe the quality of these relationships.

Child-Absent Parent Dyad. The social network literature was searched for variables which would be useful for assessing the quality of the sentiment relation between the child and the nonresident natural parent. Different authors suggest the use of different variables. Fischer (1977) suggests frequency of contact, duration of the relationship, and intimacy as the indicators of the "depth, intensity, or quality of a relation." Bronfenbrenner (1979) focuses on the importance of reciprocity, balance of power, and affectivity in interpersonal relationships.

Cochran and Brassard (1979) discuss the relational characteristics of content, reciprocity, and intensity together with the time-space considerations of frequency and regularity of contact and continuity through historical time. The content of the relationship refers to what happens when the two persons are together; content categories 1 isted are exchange of goods and services, information sharing, recreation, and emotional support. An awareness of which activities are engaged in and how many different kinds of activities are part of the relationship are both of importance to an understanding of it. Intensity "refers to the relative willingness of the child to forego other considerations in order to" participate in the give and take of the relationship. The basis for intensity, or the degree of commitment to the relationship, may lie in obligation, that is, the societal expectations imposed upon 
the relationship. It may also lie in affect, i.e., the positive or negative feelings assigned to the other member of the dyad. The influence of any particular relationship depends on the combination of the dyadic factors discussed above.

Drawing upon the network literature, particularly Cochran and Brassard's discussion, dyadic factors were selected which seemed most appropriate for understanding the relationship, if any, between the teenage child and the nonresident parent. Content, intensity, the basis for intensity in obligation and/or affect, and satisfaction were chosen as relational characteristics important for ascertaining the presence of a positive relationship between the child and the absent parent. A positive relationship would be characterized by positive affect and supportive activities. Time-space considerations of frequency of contact, freedom of access (or the ease with which the child could initiate the contact), and regularity of contact were selected as factors which facilitate, or reflect the existence of, a positive relationship. The last factor selected was the degree of continuity in the relationship from the time the former family was intact to the present.

Resident Parent-Absent Parent Dyads. The next concern was the sentiment relations between the two resident parents in the stepfamily, and the nonresident parent. It was expected that these interactions would center primarily on concerns related to the child, and this was the primary focus. The relationships between the stepfamily parents and the nonresident parent are positive to the degree to which they are 
characterized by trust, positive orientation, and goal consensus regarding concerns related to the child. Additionally, the dyadic variables of frequency of contact, intensity, satisfaction, and the obligation basis for the relationship were included as important for understanding the relationship between the stepfamily parents and the nonresident parent.

The operationalization of the extrafamily sentiment relations is described in detail later in the chapter on methodology.

Development of the Hypotheses

The system of stepfamily relationships represented in a graph such as that presented in Figure $4 C$ may be completely balanced, or not. Frequently, it is not. The complexities of stepfamily life often preclude the possibility of balance in all the cycles in the graph. A frequent source of imbalance is the cycle representing the nonresident natural parent, the resident parent, and the child. Often, the child has positive sentiment relations with both natural parents, while the natural parents have a negative sentiment relation; this is the $(t)$ $(+)(-)=(-)$ pattern of imbalance. Also, when the child has a positive sentiment relation with the nonresident parent together with the negative unit relation from residing in a different household, an unbalanced state occurs: $(+)(-)=(-)$. These states of imbalance result in tension for the members of the stepfamily. This tension may be manifested in family members' feelings about the stepfamily. In general, the expectation is that the degree of balance of the relationship system will be associated with stepfamily adjustment as 
indicated by family members' degree of satisfaction with family life, feelings of acceptance, notions about expected permanence of the stepfamily and individual self-esteem.

The entire graph may be the focus of interest if attention is directed toward the total system of relationships. Or the focus of interest may be upon particular cycles representing a particular set of relationships. The degree of balance index may be used to measure the degree of balance of the total system including all cycles, or it may be modified to measure the degree of balance of a subset of cycles. One modification used in this research involves the concept of local balance, which is the degree of balance considering only cycles passing through a given point representing a particular person. Thus, local balance provides a way to look at the balance of the relationship system from the perspective of each family member.

Initially taking the child's perspective, the following specific hypotheses are proposed:

1. A high degree of local balance for the child will be associated with the child's feeling accepted by the stepfamily and satisfied with the stepfamily; i.e., positive correlations are expected between the child's local degree of balance index and the child's feelings of acceptance and of family satisfaction. 
2. A high degree of local balance for the child will be associated with a high level of self-esteem. Thus, a positive correlation is expected between the child's local degree of balance index and self-esteem.

Analogously, the following hypotheses are proposed for the resident parent and for the stepparent:

3. A high degree of local balance for the resident parent will be associated with a feeling of acceptance in the stepfamily and a high level of family satisfaction. Thus, a positive correlation is expected between the resident parent's local degree of balance index and feelings of acceptance in and satisfaction with the family.

4. A high degree of local balance for the resident parent will be associated with high self-esteem as evidenced by a positive correlation between the resident parent's local degree of balance and self-esteem.

5. A high degree of local balance for the stepparent will be associated with feelings of acceptance in the family and with family satisfaction. Again, positive correlations are expected between the stepparent's local degree of balance index and feelings of acceptance and satisfaction with the family. 
6. A high degree of local balance for stepparents will be associated with self-esteem. A positive correlation is expected between the stepparent's local degree of balance index and self-esteem.

Lastiy, a hypothesis is proposed in regard to family members' expectations about the permanence of the stepfamily. Since the departure of any family member would disrupt the family, permanence is expected to be related to the balance of the total relationship system rather than to the balance of only those relationships in which a particular family member is involved directly. Therefore, the following hypothes is is proposed:

7. A high degree of balance in the total graph will be associated with each family member's expectations that the stepfamily will be permanent. Thus, positive correlations are expected between the total degree of balance index and individual family members' expectations about family permanence.

The following chapter describes the methodological procedures used to empirically test these hypotheses. 


\section{CHAPTER III}

\section{RESEARCH METHODOLOGY}

This research uses data collected by the Stepfamily Project in their third assessment and shares its sample and data collection procedures. These procedures are described in this chapter. Analysis of the data was a four-stage process. Initially, the scales for measuring the dyadic sentiment relations were developed. Secondly, the degree of balance indices were calculated. Thirdly, the scales measuring stepfamily adjustment and self-esteem were developed. Lastly, the hypotheses were tested by computing Pearson correlations between the degree of balance indices and the stepfamily adjustment and self-esteem scales.

\section{THE STEPFAMILY PROJECT}

The Stepfamily Project was a longitudinal study over a period of eighteen months of the adjustment of new stepfamilies with older children. Newly-formed stepfamilies who had at least one resident child between the ages of 9 and 18 were assessed three times at nine-month intervals. The stepparent, natural parent, and child together came to the interviews at the Regional Research Institute and were assessed

\footnotetext{
1

"The Adjustment of New Stepparent Families," funded by the Administration for Children, Youth, and Families, Office of Human Development Services (\#90-CW-603) 1980-1983.
} 
through use of a series of questionnaires, a behavioral interaction task, and an interview. The stepfamilies' interaction and communication, their feelings about themselves, their attitudes toward stepfamily issues, the problems they experienced, the resources they used, and the nature of their social networks were topics included in the data collected.

\section{SAMPLE SELECTION PROCEDURES}

The sample consisted of stepfamilies who met the following criteria: 1) The family had formed within the previous year. The adult couple did not need to be legally married, but must be maintaining a household together. 2) The family had a child between the ages of nine and eighteen who was willing to participate in the data collection process.

Volunteer stepfamilies were recruited through a publicity campaign including newspaper advertisements, public service announcements on radio and television, and a brochure distributed to county marriage license bureaus and other public agencies. A total of 66 families were recruited over a period of approximately one year.

\section{Sample Characteristics}

The 66 stepfamilies had been together for an average of 3.9 months. They had an average of 2.6 resident children. The husband's mean age was 36.6 , the wife's mean age was 33.7 years, and the mean age of the child who participated in the data collection process was 13.2 years. 
Thirty-one of the children were girls, and 35 were boys. The sample was primarily middle-class, Caucasian, and well-educated.

Data Collection Procedures

The data were collected in assessment interviews administered at the Regional Research Institute by a single interviewer. Each family was assigned to an interviewer who was the contact for that family throughout the entire study. The family was paid a $\$ 25.00$ honorarium for each interview in which they participated. The assessment procedure was similar in each of the three interviews, consisting of an introductory period, an initial questionnaire administration, the behavioral interaction task, a second questionnaire administration, and lastly an interview. ${ }^{2}$ The procedure took between an hour and a half and two hours to complete. The interaction task and the interview were tape recorded on cassettes by way of a microphone leading to an adjoining room.

The data for the research reported in this dissertation were collected in the third assessment interview. At the close of the interview, families were given the questionnaires pertaining to their relationships with the nonresident parent (together with a brief explanatory cover letter) and requested to complete them and return them in the stamped addressed envelope provided. Approximately one month later, a follow-up letter with additional questionnaires was mailed to

2

A detailed description of these procedures is available in Koren, Lahti, Sadler, and Kimboko, 1983. 
those families who had not responded. Within the week, a telephone follow-up was made to the nonrespondent families. Of the 47 families who participated in the third interview, 37 returned the questionnaires. These 37 comprise the research sample.

\section{MEASUREMENT OF SENTIMENT RELATIONS}

Constructing the balance variables was a two-step process. The first step was the measurement of the dyadic sentiment relations in the stepfamily system of relationships. The second step was calculation of the indices of balance. This section describes the procedures of questionnaire development and scale construction used to measure the sentiment relations. Different procedures were followed for the measurement of the intrafamily sentiment relations and for the extrafamily sentiment relations with the nonresident parent. The intrafamily sentiment relation measures were based upon day-to-day communication measures within the household which were combined into sentiment relation scales. The measurement of the extrafamily sentiment relations was based upon social network variables thought to describe relationships with persons residing outside the household. Each procedure will be described in turn. The following section will describe the calculation of balance indices.

Intrafamily Sentiment Relation Scales

Communication Subscales. The Stepfamily Project was interested in viewing relationships among individual family members because the stepfamily literature places considerable emphasis on such 
relationships. Moreover, it stresses good communication as the primary means of building and maintaining these relationships. Accordingly, measures were developed for the day-to-day communication at home among family members. These measures were questionnaire ratings of communication behaviors with other family members. The items asked about the frequency of discrete events and were based on seven-point Likert scales ranging from "more than once a day" to "once a year or less." From these questionnaire ratings, the Stepfamily Project constructed subscales to measure support, conflict, and avoidance. Adults were given a marital communication questionnaire and a parent-child communication questionnaire. From the marital communication questionnaire, the following subscales were constructed: marital support, marital conflict, and marital avoidance. Marital support concerned the degree to which a spouse communicated with the marital partner in a manner likely to enhance the relationship; a sample item is "My spouse tells me he/she is happy with something I've done." Marital conflict concerned the degree to which friction and discord occurred between spouses; a sample item is "My spouse criticizes or blames me for something." Marital avoidance concerned the degree to which one spouse avoided or ignored the other; a sample item is "My spouse refuses to discuss a complaint with me and instead gives me the 'silent treatment'."

From the parent-child communication questionnaire querying the parents about child behaviors, these subscales were constructed: child support, child conflict, and child avoidance. These were defined in a 
manner similar to the marital communication subscales although item content differed somewhat. Each measure was obtained from both the natural parent and the stepparent yielding subscales for child support of stepparent, child conflict with stepparent, child avoidance of stepparent and likewise subscales for child support of the natural parent, child conflict with the natural parent, and child avoidance of the natural parent.

Children were given a questionnaire asking about communication with both their stepparent and natural parent. Six subscales were derived from the communication questionnaire given to the child: stepparent support (of child) and natural parent support (of child), stepparentchild conflict and natural parent-child conflict, and stepparent avoidance (of child) and natural parent avoidance (of child). The definitions were the same as those for the parents, although item content differed. The items for each of these scales are listed in Appendix A.

Reliability of the communication subscales was assessed by evaluating the internal consistency of the items with Cronbach's alpha coefficient. The coefficients were computed using the SPSS Reliability program and are presented in Table I; this table is also a useful summary of the communication subscales used in constructing the measures of dyadic sentiment relations between stepfamily members.

Sentiment Relation Scales. These communication subscales measuring support, conflict, and avoidance were the basis for the measurement of intrafamily sentiment relations. Scores for each of the subscales 
listed in Table I were computed by summing the constituent items and dividing by the number of items. It was these scores which were combined into measures of the sentiment relations.

TABLE I

REL IABILITY OF THE COMMUNICATION SUBSCALES

Subscale

Marital support (natural parent)

Marital conflict (natural parent)

Marital avoidance (natural parent)

Marital support (stepparent)

Marital conflict (stepparent)

Marital avoidance (stepparent)

Stepparent support (of child)

Stepparent conflict (with child)

Stepparent avoidance (of child)

Natural parent support (of child)

Natural parent conflict (with child)

Natural parent avoidance (of child)

Child support (of stepparent)

Child conflict (with stepparent)

Child avoidance (of stepparent)

Child support (of natural parent)

Child conflict (with natural parent)

Child avoidance (of natural parent)

$\begin{array}{cc}\text { Alpha } & \text { Number of } \\ \text { Coefficient } & \text { Items }\end{array}$

.79

.85

.62

.89

.92

.81

.80

.83

.73

.54

.74

.62

.92

.80

.79

.86

.88

.67
7

11

4

7

11

4

6

6

4

6

6

4

10

6

3

10

6

3

The conflict and avoidance scores were added together and divided by two; this computation yielded a negative communication score. The negative communication score was subtracted from the support score to yield a measure of the quality of the relationship based upon the quality of communication. A formula for this computation follows:

$$
\begin{aligned}
& \text { SENTIMENT }=\text { SUPPORT }-\left(\frac{\text { CONFLICT }+ \text { AVOIDANCE }}{2}\right) \\
& \text { RELATION }
\end{aligned}
$$


Six scales were computed in the above manner to assess the sentiment relations between stepfamily members from the perspective of each individual family member. The marital relation is measured from the perspective of both the natural parent and the stepparent; the natural parent-child relation is measured from the perspective of both the natural parent and the child; similarly, the stepparentchild relation is measured from the perspective of both parties. Since balance theory requires a simple + or - measure, scale scores were dichotomized at 0 , the midpoint, to classify a sentiment relation as positive or negative.

In summary, the following scales were obtained: natural parent Inarital relation, stepparent marital relation, child's relation with the stepparent, stepparent's relation with the child, child's relation with the natural parent, and natural parent's relation with the child.

As is described later, analyses were done using a single measure of the sentiment relation between stepfamily members rather than two measures from each party's perspective. This approach does not provide for dyadic relationships which are non-reciprocal; that is, relationships which one party views positively, but the other party does not. Rather, it assumes that an overall measure of the relationship is adequate. For these analyses, the two scales measuring the relation from each party's perspectives were combined. For example, the scale score for the natural parent marital relation was added to the scale score for the stepparent marital relation to yield the overall score for the marital relation. Again, the scale scores were dichotomized at 0 , 
the midpoint, to classify a sentiment relation as positive or negative. Thus, for those analyses there were only three scales, one for each dyadic relationship in the stepfamily. Means, standard deviations, and computer names for all sentinent relation scales may be found in Appendix B.

Summary. From questionnaires asking about day-to-day communication behaviors, subscales were built to measure support, conflict and avoidance in the dyadic relationship as perceived by each party. The support, conflict, and avoidance subscales were combined into intrafamily sentiment relation scales.

Sentiment Relation Measures with the Nonresident Parent

Measurement of the sentiment relations with the nonresident parent differed in several respects from that for the intrafamily sentiment relations. Questionnaires were developed by this researcher to assess thase extrafamilial realtionships, and a scale was constructed from the items to measure the sentiment relation. Each measure is a single scale rather than an additive composite of three subscales. The item content differed from that of the communication questionnaires used to measure the intrafamily sentiment relations. Items were based on variables culled from the social network literature which would describe a relationship with a person who does not reside in the same household. Lastly, the relations were viewed solely from the perspective of the stepfamily members. Information was not available from the nonresident parent. 
Questionnaire Development. Different questionnaires were developed for each stepfamily role to describe the dyadic relationship with the nonresident parent. Thus, there were three instruments: the child questionnaire, the natural parent questionnaire, and the stepparent questionnaire. Each questionnaire was based upon the conceptual variables selected to understand that particular dyadic relationship. The previous chapter contains a discussion of that selection. Items were written which were expected to be valid operational definitions of those variables. The items have five point scales.

The Natural Parent Questionnaire was based upon the following conceptual variables. The extent to which the natural parent trusted the ex-spouse and felt the two of them had similar goals in regard to the child was inportant. This statement is illustrative of item content: "When my child sees his absent parent, I feel he/she is in good hands," with response options ranging from "strongly disagree" to "strongly agree" through the midpoint "undecided." Another important concern was the presence of a positive attitude or affect toward the exspouse. An example of an item assessing that variable is the following: "I enjoy seeing or talking with my ex-spouse" with response options from "never" to "always" through the midpoint "sometimes." Other conceptual variables were the frequency of contact, satisfaction with the relationship, and commitment to mantaining the relationship.

The Stepparent Questionnaire was based upon the same conceptual variables except that commitment by the stepparent to maintaining the relationship was not included. 
The Child Questionnaire was based upon some different conceptual variables. Frequency of contact, positive affect, satisfaction with the relationship, and commitment to the relationship were variables which overlapped with the adult questionnaires. The content of the activities the child and the nonresident parent shared was of interest. Following is an illustrative item sampling content of the relationship. "I talk with this parent about my feelings and problems," with response items ranging from "never" to "always." The kind of relationship the child had with his nonresident parent previously was assessed to evaluate continuity in the relationship. Lastly, the predictability of contact and the freedom of access to contact with the nonresident parent were assessed. Appendix $C$ presents the conceptual variables upon which each questionnaire was based, the corresponding questionnaire items, and the actual instruments.

Scale Construction. To form the scales measuring the sentiment relations with the nonresident parent, the following steps were taken:

1. To assess the sentiment relation between the child and the nonresident parent, the items from the child questionnaire were intercorrelated; and the correlation matrix was examined for a first assessment of the internal consistency of the proposed items. The same procedure was followed with the natural parent questionnaire items and the stepparent questionnaire items. Items with negative correlations were reflected. Items with excessive missing data were excluded. The three items querying about continuity in the relationship from the time the former family was intact to the present were eliminated from the 
child questionnaire for this reason. Otherwise, missing data were minimal.

2. Reliabilities of the proposed scales were assessed by evaluating the internal consistency of the items with Cronbach's alpha coefficient using the SPSS Reliability program. Based upon the itentotal correlations and the alpha that would result by removing each item (one at a time) from the scale, the frequency of contact item was dropped from the proposed scale to measure the sentiment relation between the stepparent and the nonresident parent. Similarly, the satisfaction item was eliminated from all three proposed scales. Apparentiy, it is possible to feel satisfied with a variety of kinds of relationships with a nonresident parent--from no contact to a close relationship. With these changes, satisfactory reliabilities were obtained for all three scales: sentiment relation between the child and nonresident parent with $r=.91$; sentiment relation between the natural parent and the nonresident parent with $r=.91$; and sentiment relation between the stepparent and the nonresident parent with $r=.88$. The final items for each scale are listed in Appendix A.

3. The individual scores for each sentiment relation are the mean scale score computed by suming the constituent items and dividing by the number of items. This procedure maintained the original item metric of 1 to 5 . Scores were dichotomized at 3 , the midpoint, to classify a particular sentiment relation as positive or negative. Summary of Sentiment Relation Measurement. The intrafamily sentiment relations were measured in a two-step process. Subscales 
measuring day-to-day communication behaviors of support, conflict, and avoidance were combined to measure the sentinent relations. The sentiment relation was measured from the perspectives of both parties in the dyad resulting in these six sentiment relation scales: the natural parent's view of the marital relation, the stepparent's view of the marital relation, the child's view of the stepparent-child relation, the stepparent's view of the stepparent-child relation, the child's view of the natural parent-child relation, and the natural parent's view of the natural parent-child relation. For some analyses, the perspective of both parties in the dyad were combined into a single sentiment relation measure of the dyad.

The sentiment relations with the nonresident parent were measured by scales constructed from questionnaires based upon variables describing relationships with persons who are not household members seen daily. The relations are viewed solely from the perspective of the stepfamily members resulting in three such sentiment scales: the nonresident parent-natural parent (ex-spouse) relation, the nonresident parent-stepparent relation, and the nonresident parent-child relation.

\section{INDICES OF BALANCE CALCULATION}

The degree of balance of the stepfamily system of relationships was calculated in different ways to explore the value of including different relations in the analysis. Two separate issues were explored. The first issue concerned the validity of including unit relations in addition to the sentiment relations in the balance calculation. As was 
previously discussed in Chapter II, unit relations are defined as a shared residence in the same household. Thus, the unit relations with the nonresident parent are negative, and the unit relations between stepfamily members are positive.

The second issue concerned lack of reciprocity, or asymmetric relations. A relation is symmetric if both parties feel similarly. That is, if $A$ likes $B, B$ also likes $A$. A single line between $A$ and $B$ with a positive (+) sign represents the relationship. An asymmetric relation is a relationship in which the two parties feel differently about each other; although A likes B, B does not like $A$. This could be represented by two directed lines--a positive (+) line from $A$ to $B$ and a negative $(-)$ line from $B$ to $A$. Is a single-signed line adequate representation of a relation, or do two directed lines add predictability? .

Four different methods of calculating the degree of balance were used, starting most simply and adding complexity. Initially, balance was computed based upon single sentiment lines representing the relations. Secondly, balance was computed with two directed lines representing the sentiment relations between the stepfamily members, thus providing a more complete representation of asymmetric or nonreciprocal relationships. The third method of balance calculation added unit relations to the single sentiment relations. Lastly, unit relations were included in the more complex representation of the sentiment relations. Each method is described in turn, using a graph of a single family to illustrate the procedures. 


\section{Single Sentiment Balance Indices}

As was presented in Chapter II, the stepfamily system of relations is represented by a graph in which a point represents a family member and the signed line between two points represents the relation between the two family members. A positive relation is represented by a $(+), a$ negative relation by a $(-)$. Figure 5 presents a graph of a relationship system.

The concept of cycle is central to the computation of balance indices. To define cycle, the concept of path is helpful. A path is

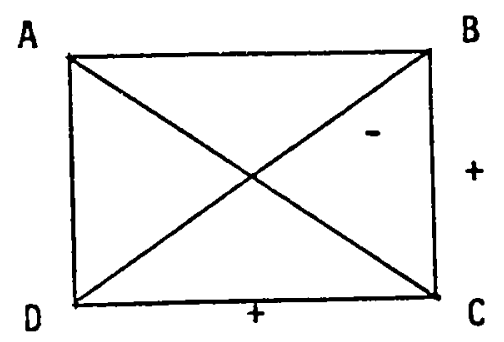

Figure 5. A signed relationship system.

two or more lines connecting consecutive points in a graph. In figure 5 , the lines $A B$ and $B C$ form a path from $A$ to $C$. A cycle is any path that returns to the point of origin. Hence, in Figure 5, the lines $A B$, $B C$ and $C A$ form a cycle representing the triad.

A cycle, and the system of relations it represents, is balanced if the algebraic product of the signs of the lines is positive. The cycle is unbalanced if the product is negative. In Figure 5, the cycle $B C$, $\mathrm{CD}$, $\mathrm{DB}$ is an unbalanced cycle: $(+)(+)(-)=(-)$. A graph is 
completely balanced if and only if all of its cycles are balanced. However, the degree of balance of a graph can be calculated as the ratio of positive or balanced cycles to the total number of cycles in the graph. Cartwright and Harary (1956) present this simple formula for the degree of balance of a graph:

$$
\begin{gathered}
\qquad B(G)=\frac{ \pm c(G)}{c(G)} \text { where } \\
+c(G)=\text { the number of positive cycles in the graph, and } \\
c(G)=\text { the total number of cycles in the graph. }
\end{gathered}
$$

The degree of balance calculation upon single sentiment relations will be described using the graph of a stepfamily system appearing in Figure 6 . The graph can be decomposed into four triangles $(6 \mathrm{~B}, 6 \mathrm{C}, 60$, $6 E)$, representing the four cycles contained in the graph. The triangles have been given labels appropriate to the system members and will be referred to by those labels in further discussions throughout this report. For example, $6 E$ is labeled new triad because the system members are the members of the new stepfamily: child, stepparent, and natural parent. The baiance of each cycle is computed and also appears in Figure 6: adult triad $(-),(-)(+)=(+)$, rival triad $(-)(+)(+)=$ $(-)$, new triad $(+)(+)(+)=(+)$, and old triad $(-)(+)(+)=(-)$. Total balance of the family system, that is, the degree of balance of the entire graph, is a simple calculation. There are four cycles contained in the figure. Two of them, adı!lt triad and new triad are balanced and positive; therefore 


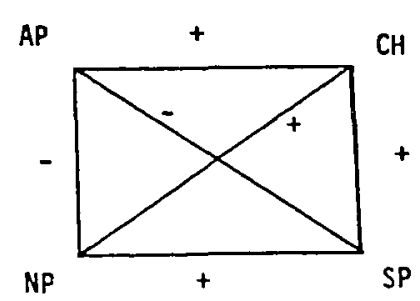

6A. The Total System.
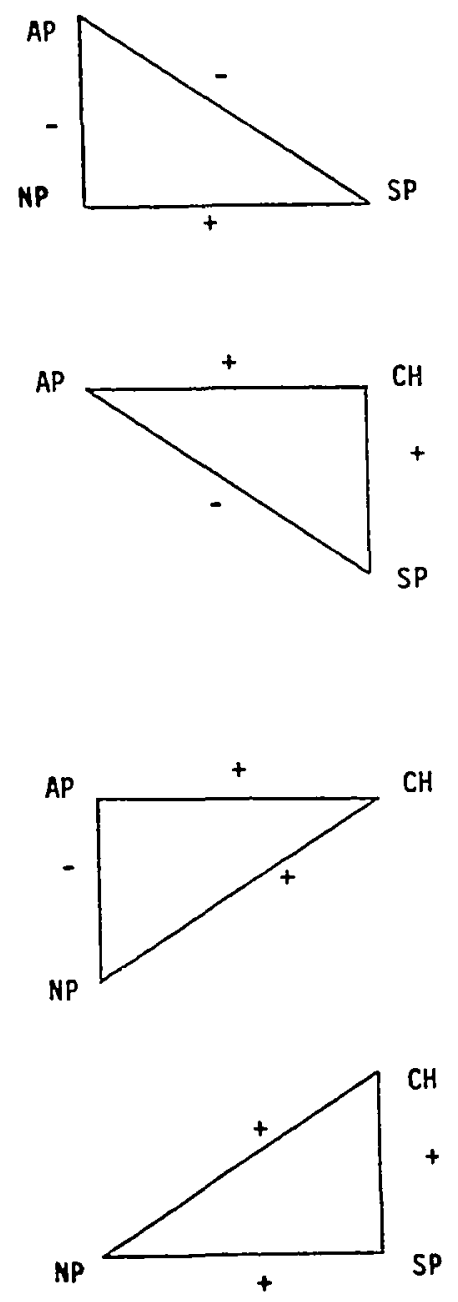

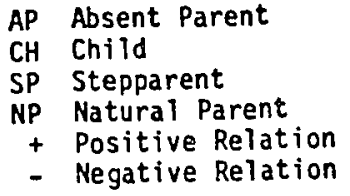

68. Adult triad is balanced.

$(-)(-)(+)=(+)$

6C. Rival triad is unbalanced.

$(+)(+)(-)=(-)$
6D. 01d triad is unbalanced.

$(+)(+)(-)=(-)$

5E. New triad is balanced.

$(+)(+)(t)=(+)$

Figure 6. A stepfamily system of sentiment relations. 


$$
b(G)=2 / 4=.50
$$

Local balance is the degree of balance considering only cycles passing through a given point. Thus, local balance for the child is calculated including only those cycles of which the child is a member. The child is a member of the rival triad, new triad, and old triad. The degree of balance calculation is as follows: total number of cycles is three of which only one, new triad, is balanced and positive. Therefore

$$
b(G)=1 / 3=.33
$$

The procedure is similar for the local balance of the natural parent and of the stepparent. Table II summarizes these degree of balance calculations for a stepfamily.

There is another cycle in the graph. It is the path which is the perimeter of the rectangle, i.e., the path connecting the four corner points of the rectangle. The cycle is called a 4-cycle because it contains four lines. This cycle was omitted from the balance calculations because of a serious problem in its use.

In Figure $7 \mathrm{~A}$, the 4 -cycle is an unbalanced cycle: $(+)(+)(+)(-)$ $=(-)$. If the same system of relationships is represented as in Figure $7 \mathrm{~B}$ with the points representing the stepfamily members placed in different positions in the graph, the 4-cycle is now a balanced cycle: $(-)(-)(+)(+)=(+)$. The degree of balance indices calculated from Figure $7 A$ differ from those calculated from Figure $7 B$ because in the count of positive cycles, Figure $7 B$ has one more positive cycle than Figure 7A. Yet, both figures represent the identical system of 


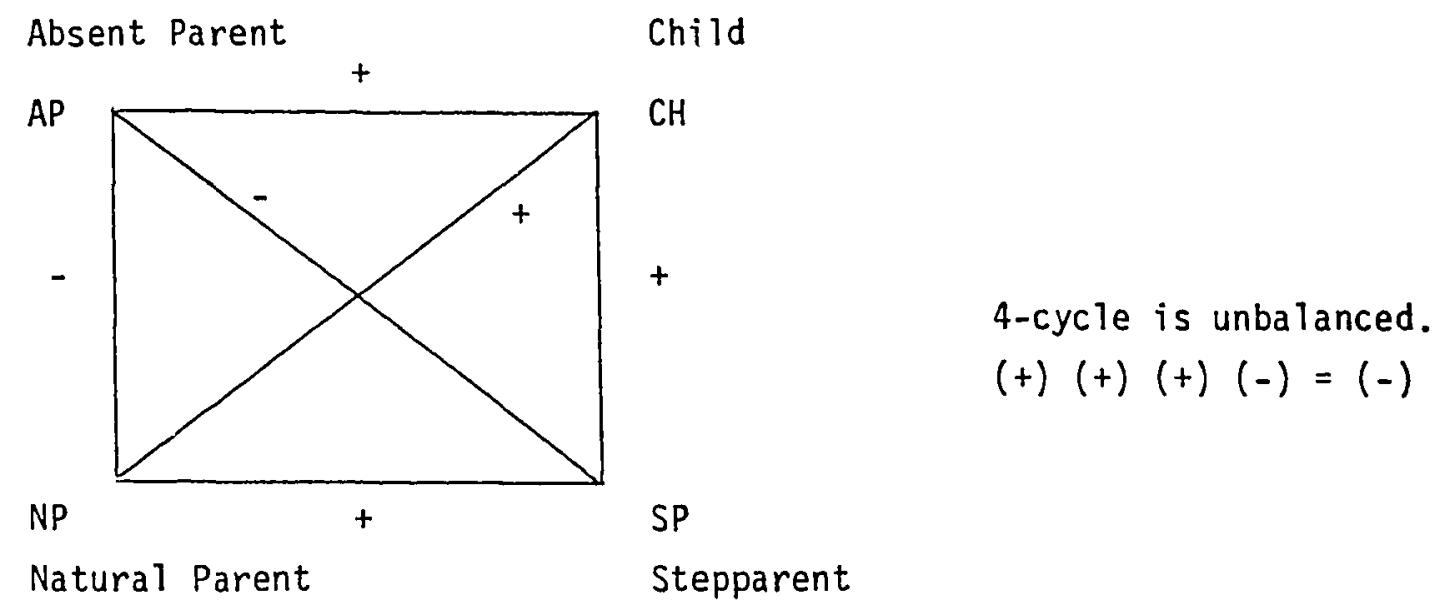

7A. Unbalanced 4-Cycle.

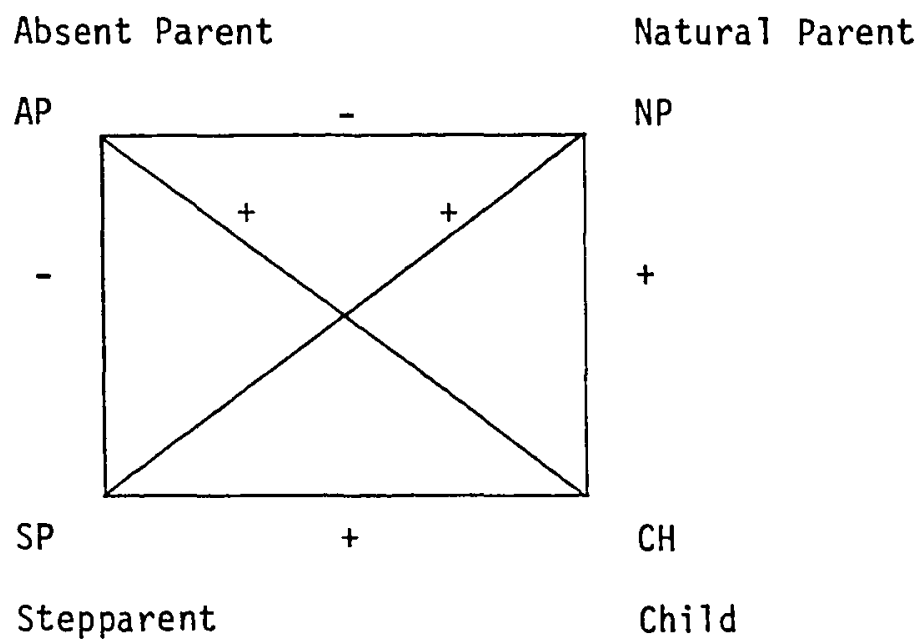

4-cycle is balanced.

$(-)(-)(+)(+)=(+)$

7B. Balanced 4-Cycle.

+ Positive Relation

- Negative Relation

Figure 7. Illustration of the difficulty with the degree of balance index using four cycles. 


\section{TABLE II}

\section{DEGREE OF BALANCE CALCULATIONS WITH SIMPLE SENTIMENTS}

Local bälance for child

Rival triad -

New triad $+\quad$ Balance $=1 / 3=.33$

old triad -

Local balance for stepparent

Rival triad -

New triad $+\quad$ Balance $=2 / 3=.67$

old triad +

Local balance for resident parent

New triad +

Old triad -

Adult triad -

Balance $=2 / 3=.67$

Total balance

New triad $\quad$ i

Old triad -

Adult triad +

Balance $=2 / 4=.50$

Rival triad -

stepfamily relationships. Thus, the inclusion of the 4-cycle in the balance calculations would result in degree of balance indices which are not unique to a particular relationship system, but differ arbitrarily with the choice of the position of the points representing the stepfamily members. Because of this difficulty, 4-cycles were not included in the balance calculations in this research.

Balance Indices With Directed Lines

Figure 8 presents a stepfamily system with directed lines between the natural parent, stepparent, and child. There is a line directed 


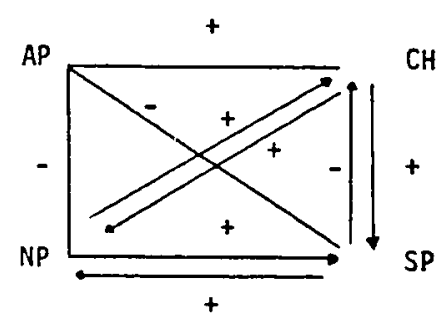

8A. Total System.
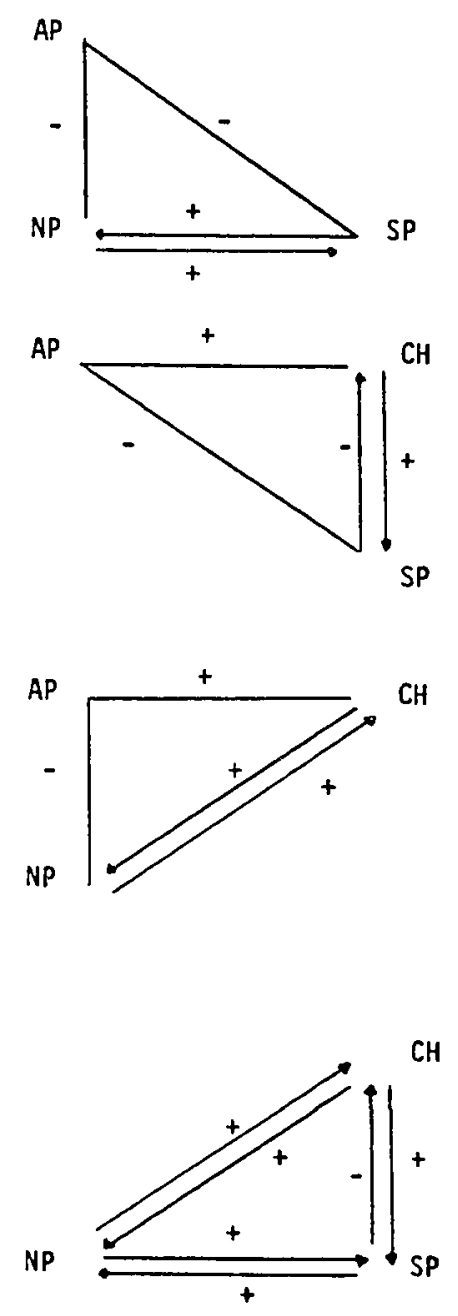

8B. Adult triad with one 2-cycle and two 3-cycies

8C. Rival triad with one 2 -cycle and two 3-cycles 2-cycle and two 3-cycles

8E. New triad with three 2 -cycles and eight 3 -cycles

Figure 8. A stepfamily system with directed lines representing reciprocity of sentiment relations. 
from the natural parent to the child representing the natural parent's sentiment relation toward the child, together with a line directed from the child to the natural parent representing the child's sentiment relation toward the parent. Thus, the dyadic relation is represented by double lines. The path following the line from child to natural parent and back to child is a cycle. Cycles representing both parties' perspective on a dyadic relation are termed 2-cycles because the cycle consists of two lines. The cycles representing triads are termed 3-cycles because the cycle consists of three lines.

In the degree of balance calculations, the formula and the approach of decomposing the graph into the four constituent triangles is the same as before. Increasing the number of lines to include more relations rapidly increases the number and complexity of counting cycles. Referring to Figure $8 \mathrm{D}$, there is one 2-cycle, the path $\mathrm{CH}, \mathrm{NP}, \mathrm{CH}$ from child to natural parent and back. There are two 3-cycles: the path from child $(\mathrm{CH})$ to nonresident parent (AP) to natural parent (NP) and back to child $(\mathrm{CH})$ following the directed path from NP to $\mathrm{CH}$; the second 3-cycle also connects the child, the nonresident parent, and the natural parent, following the directed path from $\mathrm{CH}$ to NP. Thus, old triad (Figure 80 ) has three cycles, one 2-cycle and two 3-cycles. The same is true for adult triad (Figure 8B) and rival triad (Figure 8C).

New triad in Figure $8 \mathrm{E}$ is more complex. There are three 2-cycles, one for each dyad. There are eight 3-cycles using all the alternate lines for the paths between the three family members. Appendix D lists these cycles together with other detail about the calculation 
of the different balance indices. Three 2-cycles plus eight 3-cycles totals eleven cycles in new triad. To summarize the count of cycles: there are three in each of rival triad, adult triad, and old triad for a sum of nine; adding the eleven cycles in new triad, brings the total to twenty cycles in the entire figure.

Balance in the 2-cycles is the algebraic product of the signs of the lines. Thus, a symmetric relation is balanced: $(-)(-)=(+)$ or $(t)(t)=(t)$. An asymmetric relation is unbalanced: $(-)(+)=(-)$. The logic of the previous method repeats itself from this point. Balance in the 3-cycles is the product of the signs of the three lines. The degree of balance for the entire figure is the number of balanced, or positive, cycles in the numerator divided by 20 , which is the total number of cycles in the entire figure:

$$
b(G)=\frac{\text { Number of positive cycles }}{20}
$$

The balance calculation for the local balance indices is based upon the triangles representing the triads in which the family member participates. Each family member participates in three triads. For example, the child participates in new triad with 11 cycles, old triad with three cycles, and rival triad with three cycles, for a total number of 17 cycles. Similarly, the stepparent and the natural parent also each participate in new triad with its 11 cycles, plus two other triads with three cycles each. The total number of cycles in the three triads is 17; therefore, the denominator in the local degree of balance formuli is 17 . 
Balance Indices Including Unit Relations

Unit relations were added first to the analysis with simple sentiments. The results are shown in Figure 9. The two lines between points represent the two types of relations, sentiment and unit, between persons. Unit relations with the nonresident parent are negative (-); unit relations among the natural parent, stepparent and child are positive $(+)$. Upon decomposing the figure into the four constituent triangles $(9 B, 9 C, 90,9 E)$, it can be seen that each is of similar complexity to that of new triad in the just-previous analysis. Each triangle contains eleven cycles. Four triangles, each with 11 cycles, equals 44 cycles in the denominator of the balance formula for the entire figure. The denominator for the local degree of balance indices is 33 .

Finally, unit relations were included in the analysis with the directed lines representing each party's sentiment relations. Figure 10 presents the system of relations entailed by that approach. The total number of cycles in the denominator of the balance formula is 87 ; the denominator for the local degree of balance indices is 70 .

The calculation of the balance of each cycle, counting the number of positive cycles, and the computation of the balance indices were obtained with the aid of a computer. The COUNT and COMPUTE statements available in SPSS were used to program the necessary procedures. These procedures are presented in Appendix D, together with the detailed listing of the cycles for each of the four methods. 


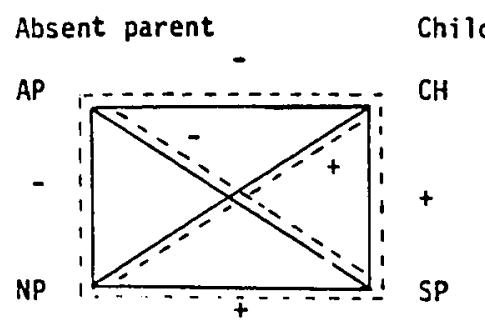

Natural Parent
Child

Stepparent

9A. Total System.

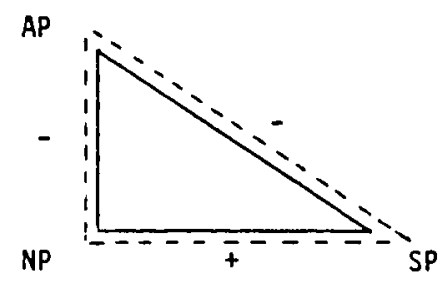

98. Adult triad.

\author{
9c. Rival triad. \\ g. Adult triad.
}

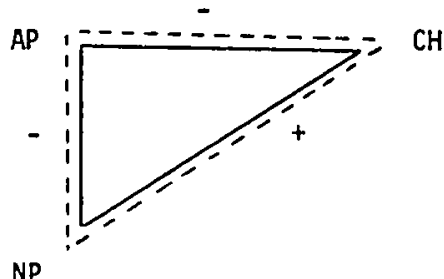

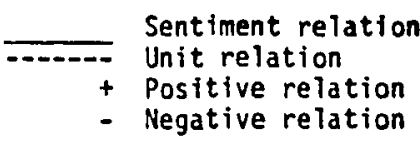

- Negative relation

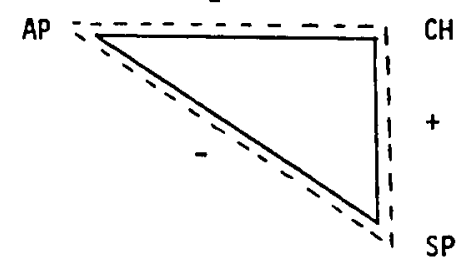

90. 01d triad.

9E. New triad.

Figure 9. A stepfamily system with sentiment relations and signed unit relations. 

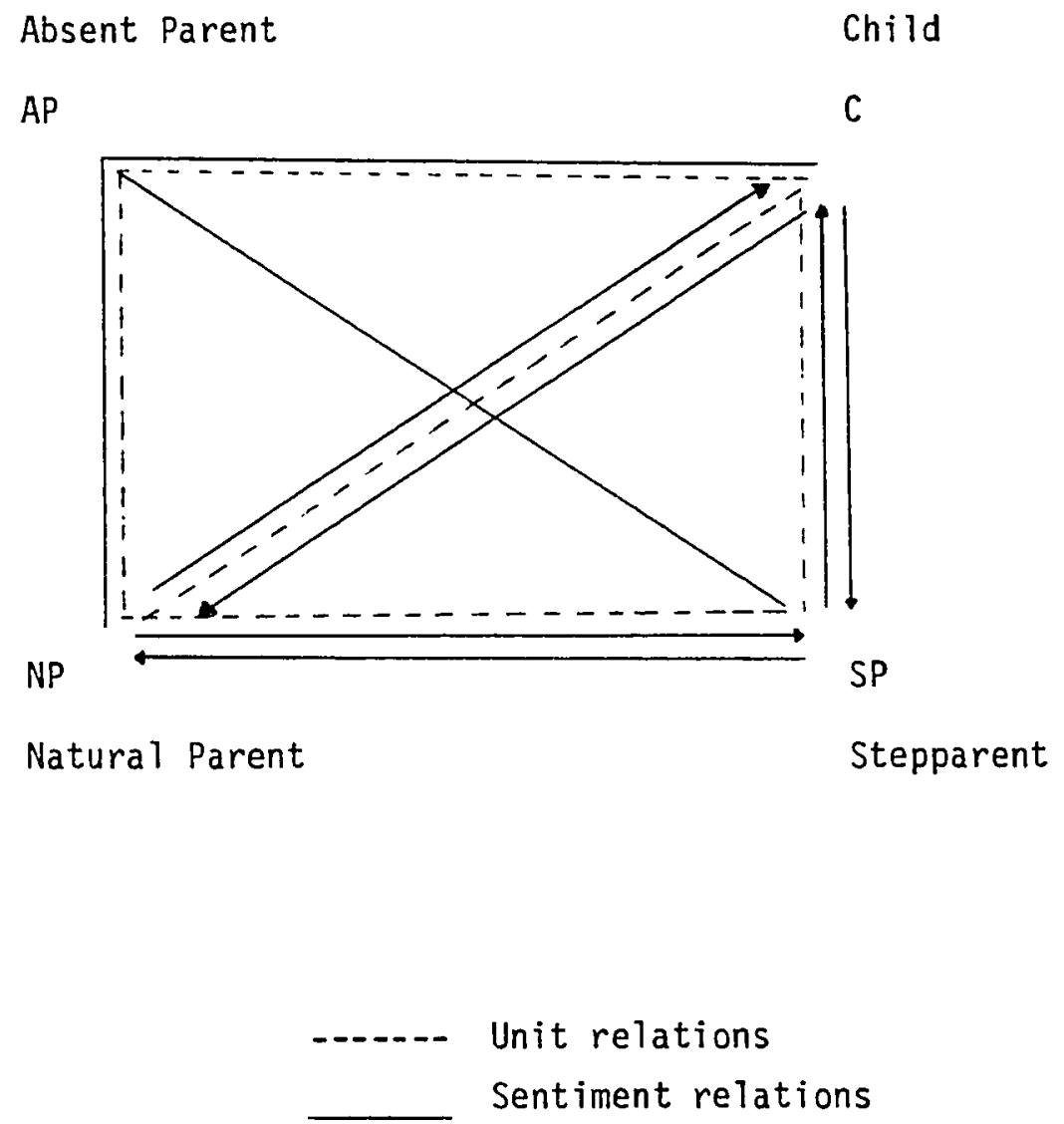

Figure 10. The stepfamily system with unit relations and directed lines representing reciprocity of sentiment relations. 


\section{MEASUREMENT OF ADJUSTMENT VARIABLES}

The Stepfamily Project was interested in studying key feelings involved in the adjustment process. Emotional issues relating to acceptance in the family by other family members become problematic in the stepfamily. The past experience of divorce and family break-up may lead to fears that the past will be repeated with the new family. An overall assessment of satisfaction with life in the stepfamily seemed a valuable indicator of adjustment. Questionnaire measures of the variables of acceptance, family satisfaction, permanence, and selfesteem were developed by the stepfamily project and are described below. The items for each scale are listed in Appendix A.

\section{Acceptance}

Acceptance concerned the extent to which a family member felt valued and appreciated by the other family members. An example of the item content is the following statement: "I feel like an intruder in my stepfamily." Response options ranged from "never" to "aiways."

\section{Family Satisfaction}

Family satisfaction is concerned with overall feelings of satisfaction with life in the family. An illustrative item is the following: "Overall, how happy are you to be a member of your family?" Response options ranged from "totally happy" to "totally unhappy."

\section{Permanence}

Permanence concerned the extent to which a family member expected 
that the family would stay together. The content is illustrated by the following item: "I worry about whether my family will 1ast," with response options from "never" to "always."

\section{Self-esteem}

Individual adjustment was represented by measuring the self-esteem of each family member. The scale included a family nember's feelings of worth and self-regard and was based upon six items from the Rosenberg Self-Esteem Scale (1966). A sample item follows: "I am able to do things as well as most other people."

Each variable was measured from the perspective of the natural parent, the stepparent, and the child. The resultant scales measured the child's sense of acceptance in the family, the child's satisfaction with the family, the child's expectations about the permanence of the stepfamily, and the child's self-esteem. The same scales were available for the natural parent and for the stepparent. Thus, there were twelve adjustment scales in all. Individual scores were the mean scale scores. Reliabilities of the scales were assessed by evaluating the internal consistency of the items with Cronbach's alpha coefficient using the SPSS Reliability program, and the coefficients are presented in Table III. Reliabilities are good, with two exceptions: natural parent acceptance (.63) and natural parent self-esteem (.61). Means, standard deviations, and computer names appear in Appendix B. 
TABLE II I

RELIABILITY OF THE ADJUSTMENT SCALES

Scale

\begin{tabular}{c} 
Alpha \\
Coefficient \\
\hline
\end{tabular}

Number of Items in Scale

Child

acceptance

.80

.76

family satisfaction

.90

permanence

.71

3

self-esteem

3

6

Natural Parent

acceptance

family satisfaction

permanence

self-esteem

.63

.88

.96

.61

3
3
3
6

Stepparent

acceptance

family satisfaction

permanence

self-esteem

.85

.88

.96

.87

HYPOTHESIS TESTING PROCEDURES

Pearson correlations $(r)$ were calculated between the balance indices and the adjustment variable scale scores to test for the hypothesized associations. Balance, as computed by each of the four methods (single sentiment relations, directed sentiment relations, single sentiment with unit relations, and directed sentiment with unit relations), was used in the Pearson correlations. The size of the 
correlations obtained with each method were compared to evaluate which method yielded the stronger associations with the adjustment variables. Correlations at the .05 level of significance were accepted as evidence for the hypothesized association between a balance index and an adjustment variable. 


\section{CHAPTER IV}

\section{RESULTS}

Sentiment relation scales were constructed to measure the quality of the dyadic relationships included in this balance theory analysis. Scale score distributions are presented to describe the variation found in the quality of these relationships.

Twelve hypotheses were stated relating balance of relations in the stepfamily system to the adjustment of the new stepfamily and to individual self-esteem. Four hypotheses are statements from the perspective of the child, four are from the perspective of the stepparent, and four are from the perspective of the resident natural parent. In this chapter, the results of tests on these hypotheses are presented. The inclusion of unit relations, single sentiment relations, and directed sentiment relations was explored using four different methods of balance calculation. The relative strengths of association with the adjustment variables found for the balance indices calculated by these four methods are compared. Descriptive case material is presented to illustrate both balanced and unbalanced family systems. Exploration of a plausible alternative hypothesis to balance is presented. Discussion of the results is deferred to Chapter $V$. 


\section{SENTIMENT RELATION SCALE SCORES}

Intrafamily Sentiment Relations

The possible range of the intrafamily sentiment relation scales is from -6 to +6 . The lowest obtained score was -2.8 , and the highest obtained score was 5.7. The scores at the lower end of the scale did not occur. Scores were dichotomized at 0 , the midpoint, into positive and negative sentinent relations.

For the marital dyad, only one score, a -1.3 on SMREL (the scale measuring the stepparent's marital sentiment relation), was negative. Most scores were in the 2 to 4 range. For the natural parent-child dyad, scores tended to be slightly lower with most scores in the 1 to 3 range. One child scored negatively on CNPREL (the scale measuring the child's natural parent sentiment relation) with a score of -.1 , while three natural parents had negative sentiment relations in the parentchild relationship. Scores on the sentiment relation scales for the stepparent-stepchild dyad were more variable than the sentiment relation scores for the natural parent-child dyad. Seven stepparents had negative sentiment relation scores. Three stepchildren had negative sentiment relation scores, while three scored over +5 . The means, standard deviations, and frequency distributions for these sentiment relation scales appear in Appendix B.

\section{Extrafamily Sentiment Relations}

The possible range of scores on the scales measuring sentiment relations with the nonresident parent is from 1 to 5 . The obtained 
scores ranged over the entire scale from a low of 1.0 to 4.7 . Scores were dichotomized at 3.0 , the midpoint, into positive and negative sentiment relations.

The stepparent's sentiment relation with the nonresident natural parent was negative, except in four cases. Eleven of the natural parents displayed positive sentiment relations with their ex-spouses. The majority of the children had positive sentiment relations with their absent parents; there were eight cases with negative sentiment relations. Again, the means, standard deviations, and frequency distributions of these scales appear in Appendix B.

\section{CHILD HYPOTHESES}

Three of the hypotheses were statements relating the child's local degree of balance to feelings indicative of stepfamily adjustment or to self-esteem. The fourth hypothesis dealt with the balance of the total fanily system.

\section{Local Degree of Balance}

Hypothesis 1. A high degree of local balance for the cinild will be associated with a high feeling of acceptance in the stepfamily by the child. Imbalance will be associated with little feeling of acceptance in the family. Thus, a positive correlation is expected between the balance index and the child's acceptance scale.

States of imbalance are assumed to be a source of tension for the focal person. This tension is manifested in the person's feeling a lack of acceptance in the stepfamily. 
Pearson correlations were calculated between the balance indices and the child's acceptance scale to test the hypothesis. As can be seen in Table IV, the correlations were significant for three of the four methods of computing degree of balance, while the correlation approached significance for the fourth. These data support the hypothesis that the degree of local balance for the child is associated with the child's feeling of acceptance in the stepfamily.

The strength of association is greater when balance is calculated using two directed lines to represent both family members' sentiments in a dyadic relation $(r=.50, p=.001)$ rather than a single line to summarize the relation $(r=.26, p=.063)$. This pattern suggests the value of the more precise method of representing a dyadic relation. In the sample of 37 , five of the child-stepparent relations are asymmetric, and four of the child-resident natural parent relations are asymmetric. The use of a method for calculating balance which includes these asymmetries strengthens the association found between balance and the child's acceptance scale.

The pattern of correlation shows that the strength of association is greater when unit relations are included in determining the balance of the system of relations. Adding unit relations to the analysis with single line sentiment relations increases the correlation with the child's acceptance scale from a non-significant one $(r=.26)$ to a significant one $(r=.41, p=.006)$. Similarly, adding unit relations to the directed line sentiment relation analysis increases the correlation from $r=.50, p=.001$ to $r=.54, p=.000$. 
TABLE IV

CORRELATIONS BETWEEN BALANCE INDICES AND

ADJUSTMENT SCALES FOR THE CHILD

\begin{tabular}{|c|c|c|c|c|}
\hline $\begin{array}{l}\text { Balance } \\
\text { Index }\end{array}$ & Acceptance & $\begin{array}{c}\text { Family } \\
\text { Satisfaction }\end{array}$ & $\begin{array}{l}\text { Self- } \\
\text { Esteem }\end{array}$ & Permanence \\
\hline $\begin{array}{l}\text { Single } \\
\text { Sentiment } \\
\text { Relations }\end{array}$ & $\begin{array}{l}.26 \\
p=.063\end{array}$ & $p \stackrel{.20}{=} .112$ & $\begin{array}{l}.02 \\
\text { n.s. }\end{array}$ & $p \stackrel{.42}{=} .005$ \\
\hline $\begin{array}{l}\text { Single } \\
\text { Sentiment } \\
\text { and Unit } \\
\text { Relations }\end{array}$ & $p \stackrel{.41}{=} .006$ & $p \stackrel{.35}{=} .018$ & $\begin{array}{l}-.03 \\
\text { n.s. }\end{array}$ & $p \stackrel{.42}{=} .005$ \\
\hline $\begin{array}{l}\text { Directed } \\
\text { Sentiment } \\
\text { Relations }\end{array}$ & 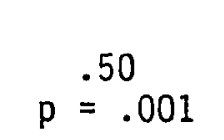 & $\mathrm{p}=.54$ & $\begin{array}{l}.22 \\
\text { n.s. }\end{array}$ & $p \stackrel{.44}{=} .003$ \\
\hline $\begin{array}{l}\text { Directed } \\
\text { Sentiment } \\
\text { and Unit } \\
\text { Relations }\end{array}$ & $p \stackrel{.54}{=} .000$ & $\begin{array}{l}.58 \\
\mathrm{p}=.000\end{array}$ & $\begin{array}{l}.16 \\
\text { n.s. }\end{array}$ & $p \stackrel{.45}{=} .002$ \\
\hline
\end{tabular}

Hypothesis 2. A high degree of local balance for the child will be associated with a high sense of satisfaction with the stepfamily by the child. Imbalance will be associated with dissatisfaction with the stepfamily. A positive correlation is expected between the balance index and the child's family satisfaction scale.

Again, the assumption underlying this hypothesis is that imbalance is a source of tension for the child; this tension manifests itself in the child's sense of satisfaction with the stepfamily.

Pearson correlations were calculated between the different balance indices and the child's family satisfaction scale. The correlations are 
significant for three of the four balance indices (see Table IV), thus providing support for the hypothesis that the child's local degree of balance is associated with the level of the child's family satisfaction. Inspection of the correlations of the different balance indices with the child's family satisfaction scale in Table IV shows the same pattern of correlations obtained with the child's acceptance scale: the strength of the association is greater with directed 1 ines than with a single sentiment line; adding unit relations to the analysis increases the strength of the association. This congruence strengthens the conclusions stated above regarding the value of representing dyadic relations with two directed lines and including unit relations in the child's balance measures.

Hypothesis 3. A high degree of local balance for the child will be associated with high self-esteem.

The tension assumed to result from imbalance in the stepfamily is expected to be associated with feelings of adjustment in the family for the child. These feelings of adjustment in turn are expected to affect and be affected by self-esteem. The hypothesis was tested by computing Pearson corralations between the balance indices and the self-esteem scale. The correlations were all non-significant (see Table IV). Thus, the data do not support the hypothesis of an association between balance and the child's self-esteem.

Total Degree of Balance

The fourth hypothesis is concerned with the balance of the entire 
figure. This means that all of the relations are included in the balance index rather than only those relations in which the child is a direct participant.

Hypothesis 4. A high degree of "total" balance of the system will be associated with high expectations about the permanence of the new stepfamily. Imbalance will be associated with concern about the future permanence of the stepfamily. A positive correlation is expected between the balance index for the entire graph and the child's permanence scale.

The tension which is the result of imbalance is expected to be felt by the child as concern about the permanence of the new stepfamily. Since stepfamily permanence could be disrupted by any family member, the child's evaluation of permanence is expected to include the relations among all family members. For this reason, the balance of the entire family, rather than local balance of the child, is the balance index assumed to be associated with the child's permanence scale.

Table IV presents the Pearson correlations computed to test this hypothesis. The correlations are significant, thus supporting the hypothesis of an association between "total" balance and the child's sense of stepfamily permanence. The four correlations for the different methods of calculating balance are virtually identical $(r=.42, r=.42$, $r=.44, r=.45)$. It appears that the strength of the association between "total" balance and the child's sense of permanence is indifferent to the method used to calculate the balance index.

Summary

The data support the hypotheses regarding associations between 
balance and the child's feelings, which are indicative of adjustment to the stepfamily. The child's feeling of acceptance and sense of family satisfaction are associated with local degree of balance; the child's sense of permanence of the stepfamily is associated with total system balance. The data do not provide evidence for an association between balance and the child's self-esteem.

Use of the method of calculating balance which represents asyminetric relations results in substantially higher correlations between balance and the child's adjustment scales. The inclusion of unit relations in the balance index also results in higher correlations.

\section{Case Illustration}

A description of the family situation of the child with the lowest balance index will give more life and meaning to the abstract idea of balance. All three family members feel positively about the nonresident parent. The marital bond is strong and positive. Both Sue (a fictitious name) and her stepfather report that their relationship is difficult and filled with conflict and avoidance behaviors. The relationship between sue and her natural parent is asymmetric. The mother reports that the relationship with Sue is difficult, with conflict and a high frequency of avoidance behaviors by Sue, while Sue reports a more positive picture of her relation with her natural parent. Sue states with anger that her parents do not trust her, while her father, the nonresident parent, says that she "has a good head on her shoulders." The mother suggests that Sue has become closer to her absent father; however, Sue indicates that she can't see him often 
enough. Sue offers a threat to run away if the stepfamily situation does not improve for her and expresses an interest in outside counseling help.

The stepfamily parents express concern over how to improve the family for the daughter, but the strength of their relationship sustains them while Sue feels unaccepted in the family.

Figure 11 depicts graphically this family system. The absent parent-child dyad, absent parent-stepparent dyad, and ex-spousal dyad are all positive. The stepparent-stepchild dyad is symmetric and negative. The natural parent-child dyad is asymmetric, with a negative directed line from the parent to the child, but a positive directed line from the child to the parent. The dyadic relations (2-cycles) are balanced except for the natural parent-child dyad.

Once again, the graph is decomposed into its constituent triangles to simplify discussion. Adult triad, which does not include the child, is completely balanced with all cycles, both dyadic and triadic being balanced. However, the triads in which the child participates have varying degrees of balance. The triadic cycles of child, absent parent, and stepparent are unbalanced in the rival triad. Again, in the old triad, the triadic cycle with the absent parent, natural parent, and child is imbalanced in terms of the parent's feeling about the cinild. In the new triad, the cycles representing the stepfamily parents' feelings toward the child are balanced in the $(-)(-)(+)$ pattern of shared negative feelings about the child; the cycles representing the child's feelings about the parents are imbalanced in the $(+)(+)(-)$ 

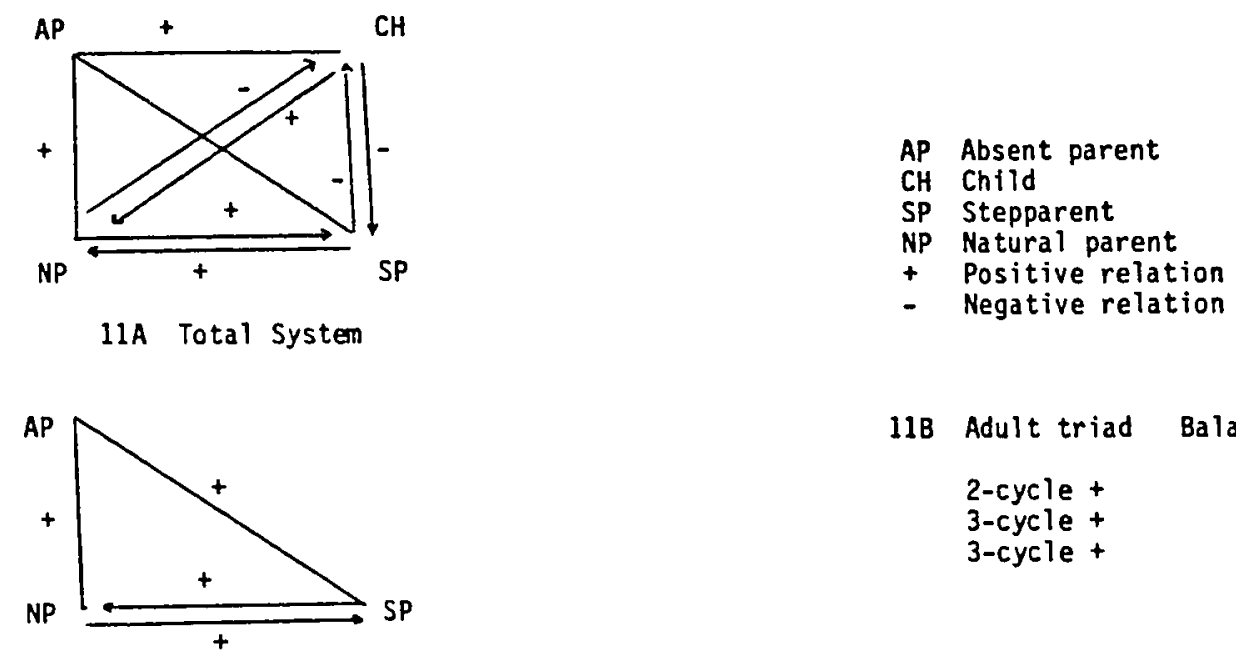
$11 B$ Adult triad Balance $\frac{3}{3}$
2-cycle +
3-cycle +
3-cycle +

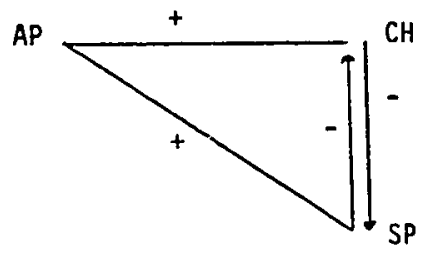
11C Rival triad Balance $\frac{1}{3}$ 2-cycle + 3-cycle - 3-cycle -
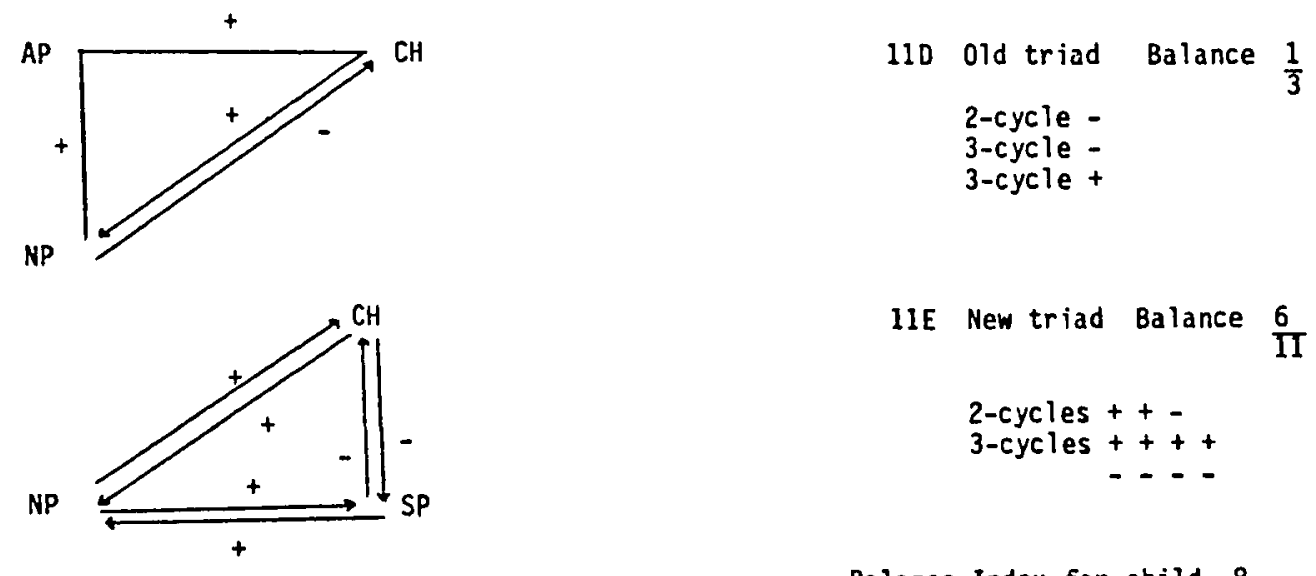

Balance Index for child $\frac{8}{17}=.47$

Figure 11. Stepfamily system with directed lines with low degree of balance index for child. 
pattern.

Sue participates in many imbalanced cycles, resulting in tension for her. In addition, she is the isolate in the balanced triads within the stepfamily. This position, although contributing to the family system, possibly also stresses her as an individual. At this particular point in time, the family, though stressed, remains intact.

\section{STEPPARENT HYPOTHESES}

The four hypotheses which are statements from the stepparent's perspective parallel in substance those presented above from the child's perspective.

\section{Local Degree of Balance}

Hypothesis 5. A high degree of local balance for the stepparent will be associated with a high feeling of acceptance in the stepfamily. Imbalance will be associated with little feeling of acceptance in the family.

To test this hypothesis, Pearson correlations were computed between the stepparent's local degree of balance indices and the stepparent acceptance scale. All four correlations are positive and significant (see Table $V$ ).

The pattern of the correlations presented in Table $V$ shows that representing asymmetric relations substantialiy increases the strength of the associations. The inclusion of unit relations does not appear to result in stronger associations between balance and feelings of acceptance in the family. 
TABLE V

CORRELATIONS BETWEEN BALANCE INDICES AND

ADJUSTMENT SCALES FOR THE STEPPARENT

Balance Index

Single Sentiment Relations

Single Sentiment and Unit

Relations

Directed

Sentiment

Relations

Directed

Sentiment and Unit

Relations

\section{Acceptance}

Family Satisfaction
SelfEsteem

Permanence

$$
p \stackrel{.44}{=} .004
$$

$p \stackrel{.47}{=} .002$

$-.03$

n.s.
.43
$p=.004$

$$
p \stackrel{.46}{=} .002
$$

.44

$p=.003$ $p \stackrel{.67}{=} .000$

$p=.000$ $p=.59$
$-.15$

n.s.

.19

n.s.

.53

$p=.000$

.16

n.s.
.36

$p=.016$

Hypothes is 6. A high degree of local balance for the stepparent will be associated with a high sense of satisfaction with the stepfamily by the stepparent. Imbalance will be associated with dissatisfaction with the stepfamily.

The hypothesis was tested by computing Pearson correlations between the stepparent's local degree of balance indices and the stepparent family satisfaction scale. As can be seen in Table $V$, the correlations are positive and significant. The hypothesis is supported by the data.

The same pattern of correlations found between the balance indices and the acceptance scale is repeated here. In fact, the correlations 
are very similar. The strength of association between balance and family satisfaction is stronger when asymmetric relations are represented in the balance index. The inclusion of unit relations reduces the correlations slightly.

Hypothesis 7. A high degree of local balance for the stepparent will be associated with high self-esteem.

None of the correlations between the balance indices and selfesteem reaches significance, as shown in Table $V$. The data do not support the hypothesis of an association between balance and selfesteem.

Total Degree of Balance.

Hypothesis 8. A high degree of "total" balance of the system will be associated with high expectations about the permanence of the new stepfamily by the stepparent. Imbalance will be associated with concern about the future permanence of the stepfamily.

Pearson correlations were computed between the balance indices for the entire system of relations and the stepparent permanence scale to test this hypothesis. The correlations presented in Table $V$ are all significantly positive. Again, the data support the hypothesis of an association between the balance of the entire system of relations and a permanence scale, in this case, the stepparent permanence scale.

\section{Summary}

The hypothesis regarding associations between balance and feelings indicative of the stepparent's adjustment in the stepfamily are 
supported by the data. The pattern of the correlations between the balance indices calculated by the different methods and the stepparent acceptance, family satisfaction, and permanence scales is similar throughout. The correlations are higher when asymmetric relations are represented in the balance index, while the inclusion of unit relations results in slightly lower correlations. The data do not support the hypothesis of an association between balance and self-esteem.

\section{NATURAL PARENT HYPOTHESES}

The substance of the four hypotheses from the perspective of the resident natural parent paraliel those presented previously for the child and stepparent.

\section{Local Degree of Balance}

Hypothesis 9. A high degree of local balance for the natural parent will be associated with a high feeling of acceptance in the stepfamily. Imbalance will be associated with little feeling of acceptance in the stepfamily.

As was done before, Pearson correlations were computed between the local degree of balance for the natural parent and the natural parent acceptance scale to test the hypothesis. These correlations are presented in Table VI.

None of the correlations are significant, although of the two balance indices in which asymmetric relations are represented, the correlations of $r=.27, p=.055$ and $r=.26, p=.060$ approach significance. The data do not support the hypothesis of an association 
between balance and the natural parent's feelings of acceptance in the family.

TABLE VI

CORRELATIONS BETWEEN BALANCE INDICES AND ADJUSTMENT

SCALES FOR THE NATURAL PARENT

Balance

Acceptance

Family

Self-

Index

Satisfaction

Esteem

Permanence

Single

Sentiment

.20

.36

.13

$p=.014$

n.s.

.45

Relations

n.s.

$p=.007$

Single

Sentiment

and Unit

Relations

.19

$p \stackrel{.27}{=} .055$

$-.13$

.28

n.s.

n.s.

$p=.007$

Directed

Sentiment

$p \stackrel{.27}{=} .055$

.40

$p=.007$

.06

.40

Relations

$p=.055$

n.s.

$p=.007$

Directed

Sentiment

and Unit

Relations

$p \stackrel{.26}{=} .060$

$p \stackrel{.36}{=} .015$

$-.06$

.31

$p=.03$

Hypothesis 10. A high degree of local balance for the natural parent will be associated with a high sense of family satisfaction. Imbalance will be associated with dissatisfaction with the stepfamily.

Three of the four Pearson correlations computed to test this hypothesis were significant: $r=.36, p=.014 ; r=.40, p=.007$; $r=.36, p=.015$. The fourth correlation of $r=.27, p=.055$ 
approaches significance. These data provide support for the hypothesis of an association between local balance of the natural parent and family satisfaction, but the strength of the association seems to be weaker than it was for the stepparent and the child.

The representation of asymmetric relations in the balance index results in higher correlations, but the increase is less than for the child and stepparent. The inclusion of unit relations in the balance calculation lowers the size of the correlation. Table VI presents these correlations.

Hypothesis 11. A high degree of local balance for the natural parent will be associated with high self-esteem.

The Pearson correlations between the balance indices and selfesteem in Table VI are not significant. Once again the data do not support the hypothesis of an association between balance and selfesteem.

Total Degree of Balance

Hypothesis 12. A high degree of "total" balance of the system will be associated with high expectations about the permanence of the new stepfamily by the natural parent. Imbalance will be associated with concern about the future permanence of the stepfamily.

The hypothesis was tested by computing Pearson correlations between the "total" balance indices and the natural parent permanence scale. As can be seen in Table VI, the correlations are positive and significant. These data offer consistent support for the hypothesis of 
an association between balance and the sense of stepfamily permanence by the natural parent.

The representation of asymmetric relations in the balance index makes little difference in the size of the correlation; the inclusion of unit relations lowers the correlations slightly.

\section{Summary}

The hypotheses regarding associations between balance and the natural parent's family satisfaction and sense of stepfamily permanence are supported by the data. In this, the results are consistent with those for the child and stepparent. The hypothesis relating local degree of balance to the natural parent's feeling of acceptance in the family was not confirmed. Again, the hypothesis relating balance to self-esteem was not confirmed.

Similar to the results for the stepparent, the inclusion of the unit relation in balance calculations lowers the correlations slightly. There was not a consistent pattern in regard to the effect of the representation of asymmetric relations upon the size of the correlations.

Overall, the strength of the associations between balance and the natural parent's feelings about stepfamily adjustment were weaker and less consistent than those for the child and the stepparent.

Case Illustrations

Unbalanced Family. This family has the lowest total balance index in the sample, with both parents having the lowest local degree of 
balance index for a stepparent and for a natural parent. All of the intrafamily relations are asymmetric. The stepfather reports negatively about both the marital relation and his relation with his stepdaughter, describing the high frequencies of conflict and avoidance behaviors and low frequencies of support. The mother reports lack of support in the marital relation, but lesser frequencies of conflict and avoidance. The mother reports much conflict and avoidance in the relation with her daughter, but also high rates of support. The daughter reports positively about her relations with both parents and feels accepted in the family. Both parents are dissatisfied with family life. The stepfather moved out for a brief separation on their first anniversary.

Problems seen by the stepfather include the division of household responsibilities, with the daughter feeling that she "does it all." The stepfather sees the daughter's behavior as another problem source; the daughter responds to the stepfather "yours too." There are conflicts over the allocation of time between work and family for both parents.

The stepfather feels they all choose to remain with the family, including the daughter, who could go live with the nonresident father. The daughter reports a positive relation with the nonresident father, but says she wouldn't want to stay there because she doesn't like the schools and would miss her friends. The mother says she wants the daughter to live with her and that she has legal custody. The parents are seeking family counseling.

Balanced Family. This is a description of one of the families with a completely balanced system of relations. There is no contact by any 
family member with the nonresident parent of the child. All of the relations between stepfamily members are positive and symmetric. The nother views the relations slightly less positively than the boy or the stepfather, but laughs and says she lets things like finances bother her more. The couple married six months after the stepfather moved in, which gave the mother more security. The stepfather has a son who visits for the weekend every two weeks. Initially, this visitation was difficult for the mother, but relationships have improved greatly. The stepfather has deliberately chosen to limit interaction with both his mother and his ex-wife because both relationships are disruptive to the stepfamity.

The couple have decided to seek custody of the stepfather's son because they feel the custodial mother "enjoys the single life" in ways that are detrimental to the boy, while they now have a good stable family unit to offer him.

\section{ALTERNATE HYPOTHESIS EXPLORATION}

The data appeared to provide strong support for the hypothesis of an association between balance and family members' feelings indicative of stepfamily adjustment, but the possibility remained at this point that the correlations found could be accounted for by an alternative confounding variable. Perhaps the adjustment scales were associated, not with system balance, but rather with the number of positive sentiment relations in the system. To explore this alternative hypothesis, the variable positivity was defined and correlated with the 
adjustment scales. Specifically, child's positivity was the number of positive dyadic relations in which the child participated; this was correlated with the child's acceptance, family satisfaction, and selfesteem scales. Total positivity, or the total number of positive sentiment relations in the entire family system, was correlated with the child's permanence scale. Parallel analyses were performed with the stepparent and the natural parent data.

The correlations between the positivity variables and the stepfamily adjustment scales were compared with the corresponding correlations between the balance indices and the stepfamily adjustment scales. The balance indices usea in this comparison were the indices which represented asymmetric relations, but did not include unit relations. These indices were chosen because they were the indices with the strongest associations with the stepfamily adjustment scales for the parents.

In all cases, the correlations between the positivity variables and the stepfamily adjustment scales were lower than the corresponding correlations between the balance indices and stepfamily adjustment scales. The differences are most marked for the permanence scales. Table VII presents a comparison of these correlations. The data do not support the alternative hypothesis.

The hypothesis of an association between balance and self-esteem was not supported by the data. However there is evidence for a weak association between the number of positive sentiment relations to which a family member is party and self-esteem. The correlation between the 
TABLE VII

COMPARISUN OF CORRELATIONS OF ADJUSTMENT SCALES

WITH BALANCE AND WITH POSITIVITY

$\begin{array}{lcc}\begin{array}{l}\text { Stepfamily Adjustment } \\ \text { Scales }\end{array} & \begin{array}{c}\text { Correlation With } \\ \text { Balance }\end{array} & \begin{array}{c}\text { Correlation With } \\ \text { Positivity }\end{array} \\ \text { Child } & & .41 \\ \text { Acceptance } & .50 & .42 \\ \quad \begin{array}{c}\text { Family Satisfaction } \\ \text { Permanence }\end{array} & .54 & .12 \\ \text { Stepparent } & .44 & .45 \\ \text { Acceptance } & & .53 \\ \text { Family Satisfaction } & .66 & .19 \\ \text { Permanence } & .67 & \\ \text { Natural Parent } & .53 & .10 \\ \text { Acceptance } & & .26 \\ \text { Family Satisfaction } & & .11 \\ \text { Permanence } & .27 & \\ \text { Self-Esteen } & .40 & .32 \\ \text { Child } & .40 & .37 \\ \text { Stepparent } & & \\ \text { Natural Parent } & .22 & \end{array}$

child positivity and self-esteem is $r=.32, p=.028$; the correlation between natural parent positivity and self-esteem is $r=.37, p=.012$; both correlations reach significance. The correlation between stepparent positivity and stepparent self-esteem approaches significance with $r=.24, p=.078$.

The alternative hypothesis was not supported by the data for the stepfamily adjustment measures but resulted in new information in regard 
to the self-esteem measures.

\section{OVERALL SUMMARY OF RESULTS}

The data consistently support the general hypothesis of an association between the balance of the stepfamily system of relations and stepfamily members' feelings which are indicative of the adjustment of the new stepfamily. The associations are stronger for the child and the stepparent than for the natural parent. Feelings of acceptance in the family and family satisfaction are associated with local degree of balance. Expectations about stepfamily permanence are associated with the total balance of the entire system. It was possible to reject the alternate hypothesis that the associations were with the number of positive relations in the system rather than with system balance.

Representing asymmetric relations in the balance index calculation results in stronger associations with the stepfamily adjustment variables than when they are omitted.

The inclusion of unit relations results in stronger associations with the stepfamily adjustment variables for the child, but not for the parents.

The data do not support the hypothesis of an association between balance and self-esteem of the family members. There is evidence of a weak association between self-esteem and the number of positive family relations the person maintains. 
CHAPTER $V$

DISCUSSION

The purpose of this research was to develop and empirically test a balance theory analysis of stepfamily relationships and adjustment and, in the process, to further knowledge about stepfamilies. The hypothesized associations were found between balance in the relationship system and family members' feelings indicative of the adjustment of the new stepfamily. The strength of the associations varied both with the method of calculating the balance index and with family member. The hypothesized associations between balance and self-esteem were not found. Possible explanations for these results will be discussed. Implications of the findings for balance theory, for clinical practice, and for policy will be discussed together with directions for future research.

\section{BALANCE THEORY ANALYSIS}

Balance in the stepfamily system of relationships consistently was associated with family members' feelings of family satisfaction, acceptance in the family, and expected permanence of the family. This suggests that the formation of a balance in relationships among family members (including the absent natural parent) is important for the adjustment of the new stepfamily. This entails establishing either a mutual like or a mutual dislike in dyadic relationships since 
reciprocated feelings constitute the balanced state for dyads. It also entails resolving the frequently-found conflicting loyalties which constitute the imbalanced triadic pattern, $(-)(+)(+)$. To the degree that balance is attained, tension is minimized and family members' feelings of adjustment are enhanced.

The associations between balance and the family adjustment measures were stronger for the child and the stepparent than for the natural parent. This may be because of the lower internal consistency of the natural parent measures, both for the communication subscales and for the acceptance adjustment scale.

The balance index was calculated in different ways to explore the value of including asymmetric relations and unit relations in the analysis. Discussion of the results of this exploration follows.

Asymmetric Relations

Asymmetric relations are dyadic relationships in which the two parties do not reciprocate the same sentiment (feeling). Ore person feels positively $(+)$, while the other person feels negatively $(-)$. Use of directed lines for sentiment in the balance index calculation made possible the inclusion of such asymmetric relations in the analysis. Representation of asymmetric relations in the balance resulted in stronger associations between balance and the stepfamily adjustment measures.

Reciprocated feelings constitute the balanced state in dyadic relationships. Asymmetric relations are imbalanced $(+)(-)=(-)$. The imbalance of the asymmetric relations generates tension. Use of a 
method to represent such relations in the balance index provided a means for including variability in tension owing to the presence or absence of asymmetric relations in the system. This increased precision improved the predictability of the adjustment measures.

The increase was less for the natural parent than for the child and stepparent. This may be because in this sample there are fewer cases in which the natural parent is a party in an asymmetric dyadic relation.

Unit Relations

The role of unit relations in stepfamily balance is ambiguous. Inclusion of unit relations in the balance model did not add to the prediction of adjustment feelings for the adults. However, it was a significant influence for the child.

Thus, the unit relation is more complex than originally conceptualized. The assumption underlying the unit relation was that the traditional idea of a nuclear family sharing a household would influence states of balance. In addition, Heider (1958) points out that proximity and interaction, both of which occur in sharing a household, are frequently unit-forming factors. For these reasons, living in the household was defined as a positive (+) unit relation based upon structure, and not living in the household was defined as a negative (-) unit relation. Because including unit relations in the balance model did not add to the prediction of adjustment feelings for the stepfamily parents, these definitions may not be valid for the adults.

There are ambiguities in the unit relation (Heider, 1958) in that absence of unit formation could be either indifference, which might be 
more accurately represented by a 0 , or an active resistance to the idea of belonging together, which seems to fit the negative $(-)$ representation. Or alternatively, the negative representation may involve the feeling that nuclear family members ought to live together, but cannot because of altered circumstances. The more subtle differentiation could give a better picture of individual family situations. Beyond that, intuitively there seems to be a different quality to the idea of a negative unit relation with the absent natural parent for the stepfamily parents who have chosen to form the new household than for the child who possibly had little choice about the situation. The original idea of imbalance in a positive sentiment relation with a parent with whom a household is not shared seems intuitively to be a better description of the child's situation. Possibly, an individual assessment of each family member's feeling in regard to the unit relation is needed as was accomplished for the individual assessment of the sentinent relation.

There are interesting implications in the finding that, for the child, unit relations influence balance. If unit relations are included in the balance model, a completely balanced relationship system is possible only when the sentiment relations with the absent parent are negative. This can be seen by looking at the graphs of a cycle (shown in Figure 12) consisting of the absent parent, resident parent, and child. When the unit relations (shown with a solid line) are assumed to be fixed by structure, the negative sentiment relations (shown with a broken line) are the only values which balance the graph completely. In 
Figure 12A, the mixed cycles, which consist of the negative unit relations and the negative sentiment relation, are balanced: $(-)(-)=$ $(+)$. The mixed cycles in Figure 128 , which consist of a negative unit relation and a positive relation, are unbalanced: $(-)(+)=(-)$. Thus, positive sentiment relations with the absent parent result in imbalance in the relationship system.

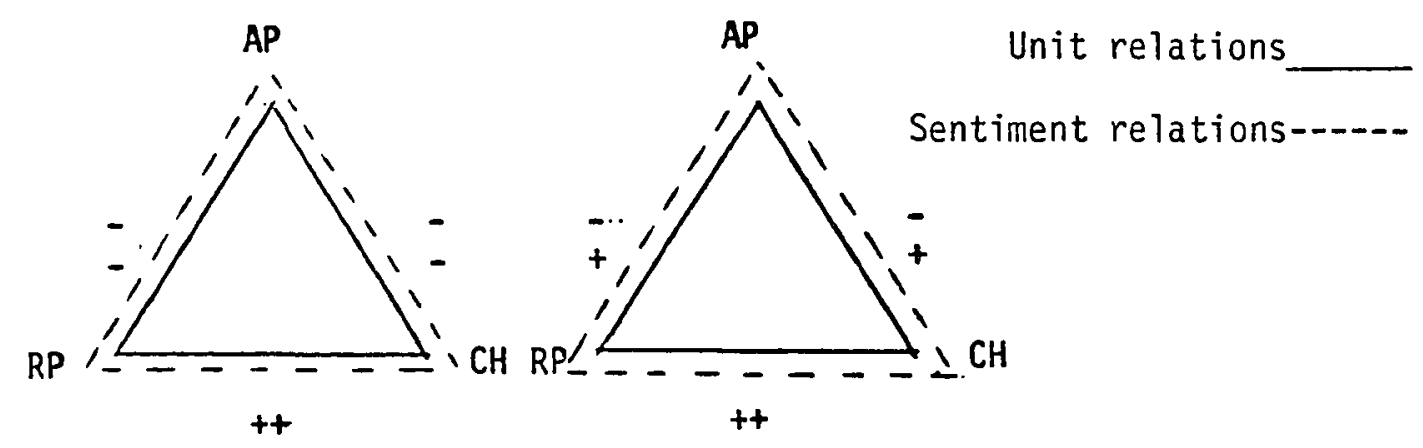
A. Balanced System
B. Partially Balanced System

Figure 12. Absent parent, resident parent, and child triads.

The evidence indicates that this analysis has different implications for stepfamily parents than for stepfamily children. Unit relations do not appear to influence balance for adults; thus, the imbalance of a positive sentiment relation with the nonresident parent is not a tension source for them. However, since unit relations defined by structure appear to influence balance for the child, the imbalance created by a positive relation with the absent biological parent is a source of tension which is associated with feelings of adjustment in the stepfamily. 


\section{Self-Esteem}

Balance in the stepfamily relationship system was not associated with family members' self-esteem as had been hypothesized. The expectation had been that the degree of tension felt in the family relationships would be associated with family members' feelings of selfworth. The evidence did not support this hypothesis.

Rather, self-esteem was associated with the number of positive sentiment relations to which the family member was a party. This finding provides an explanation for the lack of association between balance and self-esteem. Balanced states may involve negative sentiment relations. It appears that, for self-esteem, engaging in positive relationships is the important factor (rather than balance and its associated tension levels).

This suggests the desirability of the family system's attaining balanced states composed of positive sentiment relations. This will not only enhance family members' feelings indicative of family adjustment, but also their feelings of self-worth.

\section{LIMITATIONS OF THE RESEARCH}

The conclusions drawn about the relationship between stepfamily system balance and adjustment are subject to both the sample and measurement limitations in the research. The sample is small, nonrandom, primarily middle class, Caucasian, with well educated parents. These sample characteristics limit the generalizability of the results in that families with other characteristics may differ. The 
role of the unit relation, in particular, is likely to differ in samples from other social contexts. This is because the significance of sharing a household for feelings of belonging to a family probably varies with the social-cultural norms about familial living arrangements.

Measurement of both the sentiment relations and the adjustment variables is based on self-report data alone. The use of other measurement methods such as behavioral observation or interviews would have provided a data base not limited by the characteristics of a single measurement method. This is not as serious a problem for the sentiment relations scales, which are phenomenological variables, as it is for the stepfamily adjustment scales. Other objective-measurement methods for the adjustment variables would be a desirable addition to assess validity of those measures.

The correlational results presented demonstrate an association between stepfamily system balance and family members' feelings indicative of adjustment. This is the first step. The results do not, however, address the issue of the causal nature of these associations. The influences as presented in the balance model are reciprocal, dynamically complex, and affected by variables external to the relationship system. This issue awaits research.

IMPLICATIONS OF THE RESULTS

Research Implications

The ability of the balance theory analysis to predict family members' feelings of family satisfaction, acceptance in the family, and 
expected permanence of the family adds to the credibility of the balance theory when it is applied to social-motivational phenomena. This application to stepfamily adjustment focused upon dyadic and triadic relationships based upon the balance theory hypothesis that imbalance in those relations would generate tension. Findings support the usefulness of balance theory for understanding interpersonal relations which have affective import.

The research did not address directly a second aspect of balance theory, the hypothesis that imbalance leads to change in relationships in the direction of balance. This would involve investigating the process of stepfamily adjustment and change. The empirical validation of the balance theory analysis in this research suggests the potential fruitfulness of applying the balance model to that complex adjustment process. The following aspects of the model appear to yield useful hypotheses.

Imbalance in the relationship system results in forces toward change in the dyadic relations comprising the system. Research into the balance process has examined the variables involved in predicting which relations will change in the move toward balance. The evidence $(H$. Taylor, 1970) predicts change toward reciprocity in dyadic relations and change toward positive relations. This puts the attainment of balanced states and stepfamily adjustment in an optimistic light.

But change toward balance does not always occur. Change is less likely to occur in relations involving a strong commitment to the other person involved in the relationship. Thus, a child may be reluctant to 
alter the sentiment relation with the absent natural parent to attain a balanced state. Or there may be a reluctance to change a positive sentiment relation to a negative one in order to attain balance.

Both of these reasons for the lack of change toward balance are illustrated in the case of Sue described in Chapter IV. She could move toward balance by changing her positive sentiment relation with her mother to a negative one. This would balance the natural parent-child dyad and the triadic cycles in the stepfamily. Yet this move would require both change from a positive to a negative relation and change in a long-standing relationship of much importance.

Finally, family members may engage in alternate strategies other than change in dyadic relations to cope with the tension resulting from imbalance. The balance literature (Taylor, 1970) speculates about the possibility of these alternatives. A person may deny the presence of imbalance in the relationship system. Or a person may decrease the importance of a relationship, thus opening the way for later change toward balance. Or a family member may simply "grin and bear it."

Other interesting research questions are posed by negative sentiment relations in the stepfamily. If the balance pattern attained involves the triadic pattern consisting of two negative relations and a positive one, (-) (-) (+), what coping strategies does the isolated family member adopt? Again, the case of Sue is illustrative. She is the isolated member of the stepfamily, except for those cycles in which her positive sentiment toward her mother is represented. She "copes" 
with threats to run away and with the expressed wish for outside help. Further, is there a point at which a family will collapse from too many negative relations, regardless of balance? Research with samples of distressed stepfamilies could address these questions.

Balance Theory Model Limitations. There were limitations in this application of a balance theory model to stepfamily adjustment. First, as was described in Chapter III, Research Methodology, the 4-cycle could not be included in the balance index because the balance index was not unique to a particular relationship system, but differed arbitrarily with the choice of the position of the points representing the stepfamily members.

Thus, the graph-theoretic approach is limited to a dyadic and triadic analysis. Intuitively, it seems reasonable that the greater the cycle length, the less effect the cycle will have. But this argument does not eliminate the desirability of the inclusion of longer cycles in an analysis. The problem needs attention from balance theory researchers.

Second, the relations represented in the graph were dichotomized as negative or positive, and each was given a weight of one. The relative strengths of the relations were ignored, as was the possibility of indifference. Research exploring the use of a balance index which expresses the degree of balance in terms of the strengths of relations would be a desirable extension.

Lastly, this research was limited to four family members, thus truncating the relationship system for some families. Extension of the 
system to include at a minimum other resident children and other absent natural parents where they exist would be very desirable. The size of the family system and the composition of the nembers undoubtedly varies with each family situation. Research is needed to identify the range of members significant to the family system.

Ecological Perspective. Bronfenbrenner's $(1977,1979)$ ecological framework guided this research conceptually. That framework suggested looking outside the family household-to further understanding of events occurring within the household boundary. The mesosystem level in his framework involves relationships with persons outside the family household microsystem. In this way, the concept of a mesosystem level directs attention to social network approaches which focus upon informal relationship systems. Inclusion of relationships with a significant person outside the stepfamily household was helpful for understanding family adjustment. The fact that the expected associations were found is evidence that the variables culled from the social network literature did describe the nature of those extrafamily relationships. Such social network approaches can be fruitfully applied to other research efforts to provide an understanding of family functioning.

Bronfenbrenner's ecological framework also points to the importance of macrosystem factors in urban life for an understanding of stepfamily adjustment. How does the urban social-cultural context influence stepfamily relations? Legal arrangements such as visitation, custody, child support payments, and the legal responsibilities of stepparents form part of that context. Research is needed which looks at the effect 
of legal arrangements upon family members' relationships, including their affective feelings toward each other (sentiment relations) and their perceptions of what constitutes a family (unit relations). Another important topic is the impact of societal attitudes regarding remarriage as manifested in interactions with school personnel, peers, neighbors, and other persons with whom family members interact. Finally, societal norms internalized by family members may influence the balance process.

\section{Policy and Clinical Implications}

Although this research did not address directly policy or clinical issues, the findings provide information relevant to these areas.

Clinical. The balance theory of the social-psychological processes occurring in stepfamily relationship systems provides a conceptual model for mental health professionals to use in understanding such families. A look at the balance or imbalance of a given cycle indicates those relationships among family members which are likely to be stressful. A look at the number of negative sentiment relations in which a family member is involved pinpoints another possible source of stress, while the number of positive sentiment relations indicates possible sources of strength. This information may provide a basis for exploring specific relationships with the goal of targeting interventions to ameliorate family and individual stress.

Policy. The findings suggest the possibility of tradeoffs in visitation and joint custody arrangements. Such arrangements are advocated as mechanisms for maintaining positive relationships between 
the child and both natural parents. This is desirable in that a child's continuation of a positive primary relationship with both parents after divorce is important for both social and school adjustment (Hess and Camara, 1979). Yet, for the child, maintenance of the positive sentiment relation with the absent parent results in an imbalance in the stepfamily relationship system. Imbalance is associated with less favorable feelings and adjustment. Thus, to the extent that visitation and/or joint custody arrangements do promote positive sentiment relations with the absent parent, the child's adjustment within the new stepfamily may be more difficult.

The balance process may be affected by social-cultural variables. The imbalance of the negative unit relation and the positive sentiment relation may be eliminated for the child as societal norms regarding family life alter to encompass the realities of remarriage households.

\section{SUMMARY}

Balance theory was used to develop a conceptual model with which to analyze the complex dyadic and triadic relations, both within the family household and with the nonresident natural parent. Hypotheses derived from the model about family members' feelings of adjustment in the stepfamily were validated empirically. The ability of the balance theory analysis to predict family members' feelings of family satisfaction, acceptance in the family, and expected permanence of the family adds to the credibility of balance theory when applied to interpersonal systems with affective import. It also adds to the body 
of knowledge concerning patterns of relationships which accompany adjustment in stepfamilies.

Research implications of the results are that balance theory analysis is potentially useful for furthering knowledge about the process of adjustment in stepfamilies. The balance model can be extended to include relationships with other significant persons outside the family household (such as grandparents), both in stepfamilies and in first families.

Clinical implications are that the balance model is potentially useful for guiding the planning of interventions to ameliorate distress in stepfamilies.

Policy implications of the results point to the possibility of tradeoffs in custody issues. Joint custody, while providing the benefit of continuing relationships with both natural parents, also may make more difficult the child's adjustment in the stepfamily. 


\section{REFERENCES}

Abelson, R. D. Whatever became of consistency theory?

Personality and Social Psychology Bulletin, 1983, 9, 37-54.

Anderson, J. Interaction and relationship patterns in functional and dysfunctional intact families and stepfamilies. Dissertation Abstracts International, 1983, 44, (4-B), 1225.

Auster, C. J. Balance theory and other extra-balanced properties: an application to fairy tales. Psychological Reports, $1980,47,183-$ 183.

Bernard, J. Remarriage: a study of marriage. New York: Russell \& Russe11, 1971.

Bohannan, P. Stepfathers and the mental health of their children. La Jolla, California: Western Behavioral Sciences Institute, 1975.

Bowerman, C. E. \& Irish, D. P. Some relationships of stepchildren to their parents. Marriage and Family Living, 1962, 24, 113-121.

Bronfenbrenner, U. Toward an experimental ecology of human development. American Psychologist, 1977, 32, 513-531.

Bronfenbrenner, $U$. The ecology of human development. Cambridge, Mass.: Harvard University Press, 1979.

Burchinal, L. G. Characteristics of adolescents from unbroken, broken, and reconstituted families. J. of Marriage and the Family, 1964, 26, 44-51.

Cartwright, D. and Harary, F. Structural balance: a generalization of Heider's theory. Psychological Review, 1956, 63, 277-293.

Cartwright, D. and Harary, F. Balance and clusterability: an overview. in P. Holland and S. Leinhardt (eds.) Perspectives on social network research. New York: Academic Press, 1979.

Cochran, M. and Brassard, J. Child development and personal social networks. Child Development, 1979, 50, 601-616

Duberman, L. The reconstituted famiiy: a study of remarried couples and their children. Chicago: Neison-Hall Publishers, 1975.

Fischer, C. Networks and places. New York: Free Press, 1977. 
Furstenberg, F. Reflections on remarriage. J. of Family Issues, 1980, $\underline{1}, 443-453$.

Glick, P. C. Remarriage: some recent changes and variations. J. of Family Issues, $1980, \underline{1}, 455-478$.

Goode, W. J. After divorce, Glencoe, Illinois: Free Press, 1956.

Harary, F. Consistency theory is alive and well. Personality and Social Psychology Bulletin, 1983, 9, 60-63.

Heider, F. The psychology of interpersonal relations. New York: John Wiley \& Sons, 1958.

Hess, R. \& Camara, K. Post-divorce family relationships as mediating factors in consequences of divorce for children. J. of Social Issues, 1979, 35, 79-96.

Hetherington, E. M., Cox, M. \& Cox, R. Play and social interaction in children following divorce. J. of Social Issues, $1979, \underline{35}, 26-49$.

Hoffman, L. Foundations of family therapy. New York: Basic Books, Inc., 1981.

Keshnet, J. From separation to stepfamily: a subsystem analysis. J. of Family Issues, 1980, 1, 517-532.

Kompara, D. R. Difficulties in the socialization process of stepparenting. Family Relations, 1980, 29, 69-73.

Koren, P., Lahti, J., Sadler, C. \& Kimboko, P. The adjustment of new stepfamilies: characteristics and trends. Final report, July 1983, Regional Research Institute, Portland State University, OHDS/ACYF Grant \#90-CW-603.

Langner, T. S. \& Michael, S. T. Life stress and mental health. New York: Free Press, 1963.

Lee, G. Effects of social networks on the family. In W. Burr, R. Hill, I. Nye, \& I. Reiss (Eds.), Contemporary theories about the family (Vol. 1). New York: Free Press, 1979.

Lindsay, J. S. Balance theory: possible consequences of number of family members. Family Process, 1976, 15, 245-249.

Lutz, P. The stepfanily: an adolescent persepective. Family Relations: J. of Applied Family and Child Studies, 1983, 32, 367375. 
McLemore, C. W. Applications of balance theory to family relations. of Counseling Psychology, 1973, 20, 181-184.

Reaves, J. R. Stepfamily and non-custodial parent interaction. Dissertation Abstracts International, 1982, 43 (6-B), 2000.

Rosen, R. Children of divorce: what they feel about access and other aspects of divorce experience. J. of Clinical Child Psychology, $1977, \underline{6}, 24-26$.

Rosenburg, Morris. Society and the adolescent self-image. Princeton: Princeton University Press, 1965.

Santrock, J. W. Warshak, R., Lindbergh, C. \& Meadows, L. Children's and parents' observed social behavior in stepfather families. Child Development, 1982, 53, 472-480.

Stark, K. J. A descriptive study of ten self-defined successful stepfamilies. Dissertation Abstracts International, 1983, 43 (124), 4058-4059.

Taylor, H. Balance in small groups. New York: Von Nostrand, Reinhold, 1970.

Taylor, W. R. Research on family interaction I: static and dynamic models, Family Process, 1970, 9, 221-232.

Visher, E. B. \& Visher, J. S. Stepfamilies: a guide to working with stepparents and stepchildren. New York: Brunner/Mazel, 1979.

Walker, L., Brown, H., Crohn, J., Rodstein, B., Zeisel, E., \& Sager, C.J. An annotated bibliography of the remarried, the living together and their children. Family Process, 1979, 18, 193-212.

Walker, K. N. \& Messenger, L. Remarriage after divorce: dissolution and reconstruction of family boundaries. Family Process, 1979, 18, 185-192.

Walker, K., Rogers, J., \& Messinger, L. Remarriage after divorce: a review. Social Casework, 1977, 58, 276-285.

Wilson, K. L., Zucker, L., McAdams, D. C., \& Curtis, R. L. Stepfathers and stepchildren: an exploratory analys is from two national

surveys. J. of Marriage and Family, 1975, 37, 526-536. 
APPENDIX A

SCALE ITEMS 


\section{Marital Support}

Scale: more than about several several about several once a

once a once times times once a times year or

day a day a week a month month a year less

Items: - My spouse tells me he/she is happy with something I've done.

- My spouse says something that makes me laugh.

- My spouse pays attention to me when I am saying something.

- My spouse gives me hugs, kisses, or other physical signs of affection.

- My spouse offers to help me do something.

- My spouse acknowledges something I have to say.

- My spouse specifically tells me he/she loves or cares about me.

\section{Marital Conflict}

Scale: Inore than about several several about several once a

once a once times times once a times year or

day a day a week a month month a year less

Items: - My spouse criticizes or blames me for something.

- My spouse lectures me about a problem.

- My spouse brings up a complaint about me in front of friends or at other embarrassing times.

- My spouse tells me he/she is unhappy or annoyed with me for something I've done.

- My spouse says that my emotions and feelings are unreasonable.

- My spouse brings up old problems that have already been discussed and resolved.

- My spouse brings up a complaint when I am especially tired or hungry. 
- My spouse and I have minor misunderstandings or moments of bickering.

- My spouse and I have arguments.

- When we have an argument, one of us hits or physically abuses the other.

- When we have an argument, my spouse brings up unrelated issues or complains.

\section{Marital Avoidance}

Scale: more than about several several about several once a

once a once times times once a times year or

day a day a week a month month a year less

Items: - My spouse broods about something I did and won't talk to me.

- My spouse refuses to discuss a complaint with me and instead gives me the "silent treatment."

- My spouse ignores me when I am telling him/her something.

- My spouse tells me he/she is too busy to listen to something I want to say.

Child Support

$\begin{array}{llllll}\text { Scale: more than about several } & \text { several about several once a } \\ \text { once a } & \text { once times } & \text { times } & \text { once a times year or } \\ \text { day } & \text { a day a week a month month a year less }\end{array}$

Items: My child/stepchild says something that makes me laugh.

- My child/stepchild gives me hugs, kisses, or other physical signs of affection.

- My child/stepchild tells me he/she loves me or cares about me.

- My child/stepchild tells me he/she is happy with something I've done. 
- My child/stepchild asks me about how things are going at work/school.

- My child/stepchild offers to help me do something.

- My child/stepchild tells me about how things are going at school.

- My child/stepchild pays attention to me when I'm talking to him/her.

- My child/stepchild acknowledges something I have to say.

Child Conflict

$\begin{array}{lllllll}\text { Scale: more than about several } & \text { several about several once a } \\ \text { once a } & \text { once times } & \text { times } & \text { once a times year or } \\ \text { day } & \text { a day a week a month month a year less }\end{array}$

Items: - My child/stepchild criticizes or blames me for something.

- My child/stepchild whines or argues when I tell him/her to do something.

- My child/stepchild tells me he/she is unhappy with me for something I've done.

- My child/stepchild brings up complaints about me in front of friends or at other embarrassing times.

- My child/stepchild interrupts my discussions with other family members.

- My child/stepchild and I have arguments.

Child Avoidance

$\begin{array}{lllllll}\text { Scale: } & \text { more than } & \text { about } & \text { several } & \text { several about several once a } \\ \text { once a } & \text { once times } & \text { times } & \text { once a times year or } \\ \text { day } & \text { a day a week a month month a year less }\end{array}$

Items: . My child/stepchild broods about something I did and won't talk to me. 
- My child/stepchild tells me he/she doesn't want to listen to something I'm saying.

- My child/stepchild refuses to discuss a complaint with me and instead sulks or pouts about it.

Stepparent/Natural Parent Support**

$\begin{array}{lllllll}\text { Scale: } & \text { more than } & \text { about } & \text { several } & \text { several } & \text { about several once a } \\ \text { once a } & \text { once times } & \text { times } & \text { once a times } & \text { year or } \\ \text { day } & \text { a day a week } & \text { a month month a year less }\end{array}$

Items: - My SP/NP asks me about how things are going at school/work/home.

- My SP/NP tells me he/she is happy with something I've done.

- My SP/NP says something that makes me laugh.

- My SP/NP pays attention to me when I am saying something.

- My SP/NP gives me hugs, kisses, or other physical signs of affection.

- My SP/NP acknowledges something I have to say.

Stepparent/Natural Parent Conflict

Scale: more than about several several about several once a day a day a week a month month a year less

Iterns: - My SP/NP criticizes or blames me for something.

- My SP/NP lectures me about a problem.

- My SP/NP brings up a complaint about me in front of my friends or at other embarrassing times.

- My SP/NP tells me he/she is unhappy or annoyed with me for something I've done.

- My SP/NP "butts into" my discussions with other family members. 
- My SP/NP and I have arguments.

Stepparent/Natural Parent Avoidance

Scale: more than about several several about several once a

once a once times times once a times year or

day a day a week a month month a year Tess

Items: . My SP/NP broods about something I did and won't talk to me.

- My SP/NP ignores me when I am telling him/her something.

- My SP/NP tells me he/she is too busy to listen to something I want to say.

Permanence

Scale: never seldom sometimes often always

Items: . I feel that my stepfamily might break up.*

- I worry about whether my stepfamily will last.*

- I am confident that my stepfamily will stay together.

Acceptance

Scale: never seldom sometimes often always

Items: - I feel that family members appreciate the things I do for them.

- I feel like an intruder in my stepfamily.*

- I feel accepted in my stepfamily. 
Family Satisfaction

Scale: totally very somewhat somewhat very totally satis. satis. satisfied dissatis. dissatis. dissatis. (happy) (happy) (happy) (unhappy) (unhappy) (unhappy)

Items: - Overa11, how happy are you to be a member of your family?*

- Overall, how satisfied are you with your family life as a good atmosphere for bringing up children?*

- Overall, how satisfied are you with the way your family members get along with one another?*

Self-Esteem (Rosenberg, 1966)***

Scale: strongly agree agree disagree strongly disagree

Items: - I feel that I have a number of good qualities.*

- I am able to do things as well as most other people.*

- At times I think I ain no good at all.

- On the whole, I am satisfied with myself.*

- I certainly feel useless at times.

- I take a positive attitude toward myself.*

Nonresident Parent-Natural Parent Sentiment Relations

Scale: never about once several times several times several times

Item: I see or talk with my ex-spouse. 
Scale: never rarely sometimes often always

Items: I enjoy seeing or talking with my ex-spouse.

- My ex-spouse and I help each other out.

$\begin{array}{llll}\text { Scale: never } & \begin{array}{l}\text { less } \\ \text { often }\end{array} & \begin{array}{l}\text { about the } \\ \text { same }\end{array} & \begin{array}{l}\text { more } \\ \text { often }\end{array}\end{array}$

Item: . If I had the choice, I would see or talk with my ex-spouse.

Scale: $\begin{aligned} & \text { strongly disagree undecided agree } \\ & \text { disagree }\end{aligned}$

Items: I see or talk with my ex-spouse because I have to.

- My ex-spouse and I have similar life styles.

- It is important that I see or talk with my ex-spouse for my child's sake.

- When our child sees his/her absent parent, I feel that he/she is in good hands.

- My ex-spouse and I have similar values.

- I feel that my ex-spouse is a good influence upon our child.

- My ex-spouse and I have similar ideas about child rearing practices.

- I worry about our child's well being when he/she sees his absent parent.

Nonresident Parent-Stepparent Sentiment Relations

Scale: never rarely sometimes often always

Item: . I enjoy seeing or talking with my stepchild's absent parent. 
$\begin{array}{llll}\text { Scale: never } & \begin{array}{l}\text { less } \\ \text { often }\end{array} & \begin{array}{l}\text { about the } \\ \text { same }\end{array} & \begin{array}{l}\text { more } \\ \text { often }\end{array}\end{array}$

Item: . If I had the choice, I would see or talk to my stepchild's absent parent.

Scale: strongly disagree undecided agree strongly disagree agree

Items: - My stepchild's absent parent and I have similar life styles.

- When my stepchild sees his absent parent, I feel that he/she is in good hands.

- My stepchild's absent parent and I have similar values.

- I feel that my stepchild's absent parent is a good influence upon him/her.

- My stepchild's absent parent and I have similar ideas about child rearing practices.

- I worry about my stepchild's well being when he/she sees his/her absent parent.

Nonresident Parent-Child Sentiment Relation

Scale: never about once several times several times several times a year a year a month a week

Item: - I see or talk with this parent.

$\begin{array}{llll}\text { Scale: never less } & \begin{array}{l}\text { about the } \\ \text { often }\end{array} & \begin{array}{l}\text { more } \\ \text { often }\end{array} & \begin{array}{l}\text { much more } \\ \text { often }\end{array}\end{array}$

Item: - If I had the choice, I would see or talk with this parent. 
Scale: never rarely sometimes often always

Items: - I enjoy seeing or talking with this parent.

- When I see this parent, we have dinner together or share some xind of fun activity.

- When I talk to this parent, he/she gives me useful information or advice.

- I talk with this parent about my feelings and problems.

- When I see this parent, he/she gives me things or helps me out in other ways.

Scale: strongly disagree undecided agree strongly

disagree agree

Items: - It is easy for me to see or talk with this absent parent when I want to.

- I see or talk to this parent because I have to.

- I can depend upon regular visits with this parent.

- I see or talk to this parent because I want to.

- My relationship with this absent parent is important to me.

* Scale reflected

** Separate items with respect to stepparent (SP) and natural parent (NP)

$\star \star \star$ Used with permission 
APPENDIX B

MEANS, STANDARD DEVIATIONS, AND SELECTED FREQUENCY DISTRIBUTIONS OF STUDY SCALES 
TABLE VIII

COMPUTER NAMES, MEANS, AND STANDARD DEVIATIONS OF SENTIMENT RELATION SCALES

\begin{tabular}{l} 
Scale \\
\hline Marital Dyad \\
Natural Parent \\
Stepparent \\
Combined
\end{tabular}

Natural Parent-Child Dyad

Natural Parent

Child

Combined

Stepparent-Child Dyad

\section{Stepparent-Child Dyad}

NCREL

CNDREL

NPREL

Mean

$\underline{S .0 .}$

NMREL

SMREL

MREL

3.07

3.23

6.30

1.39

1.61

2.78

Stepparent

Child

Combined

Absent Parent-Child Dyad

Ex-Spousal Dyad

Absent Parent-Stepparent Dyad
SCREL

CSCREL

SRREL

CHIREL

NATREL

STEPREL
1.84

2.72

4.56

1.19

1.29

1.98

(a)


TABLE IX

MEANS AND STANDARD DEVIATIONS OF ADJUSTMENT SCALES

Scale

Mean $\quad$ S.D.

Child

Acceptance

3.96

.91

Family Satisfaction

4.41

1.12

Permanence

4.23

2.92

.96

Self-Esteeln

.42

Stepparent

Acceptance

3.83

4.51

Family Satisfaction

Permanence

4.06

3.22

.75

Self-Esteem

.94

.87

.51

Natural Parent

Acceptance

Family Satisfaction

4.08

.70

Permanence

4.57

.98

Self-Esteem

3.96

.98

3.08

.33 


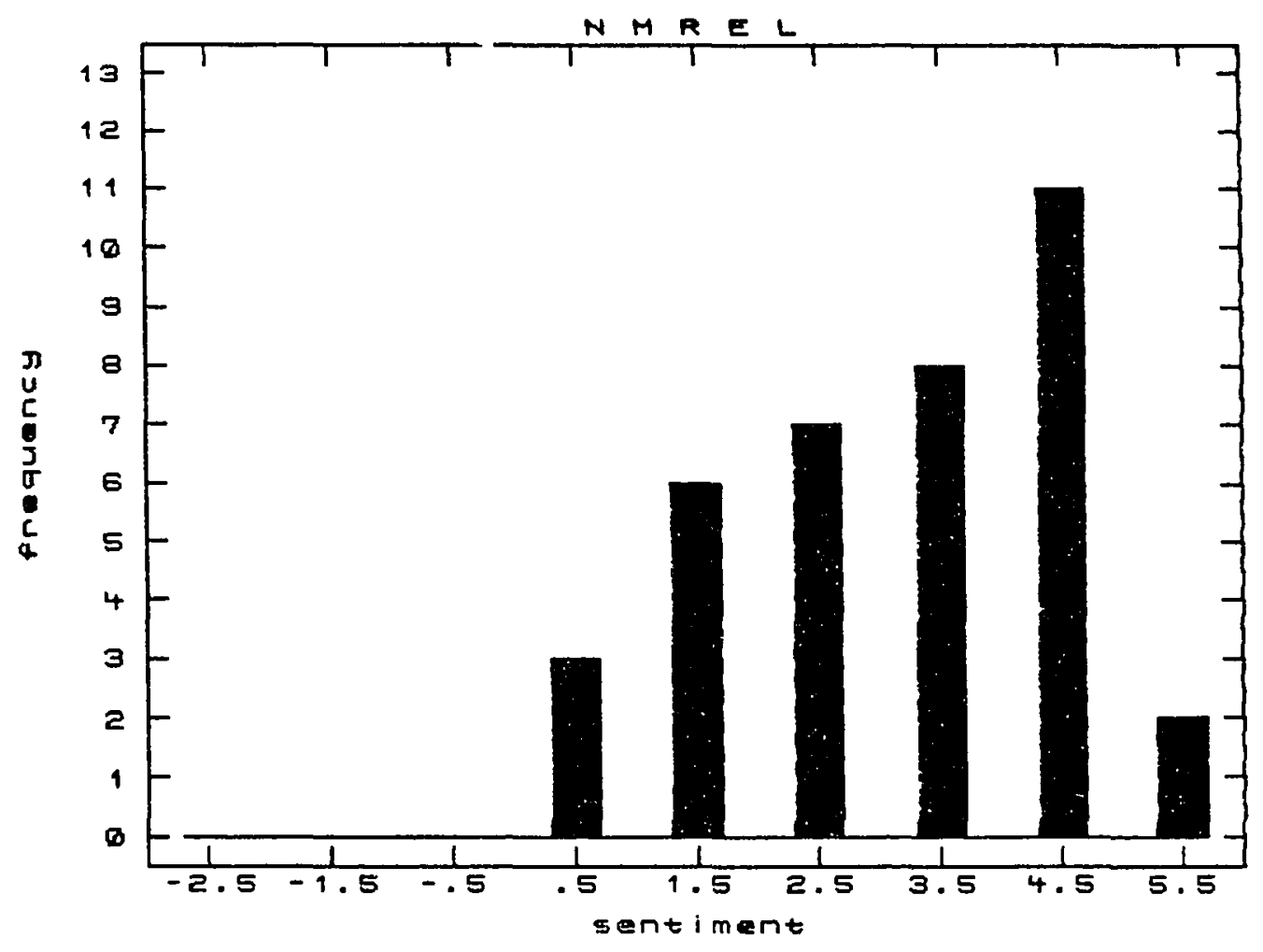

Figure 13. Frequency distribution of marital sentiment relation from natural parent's perspective (NMREL). 


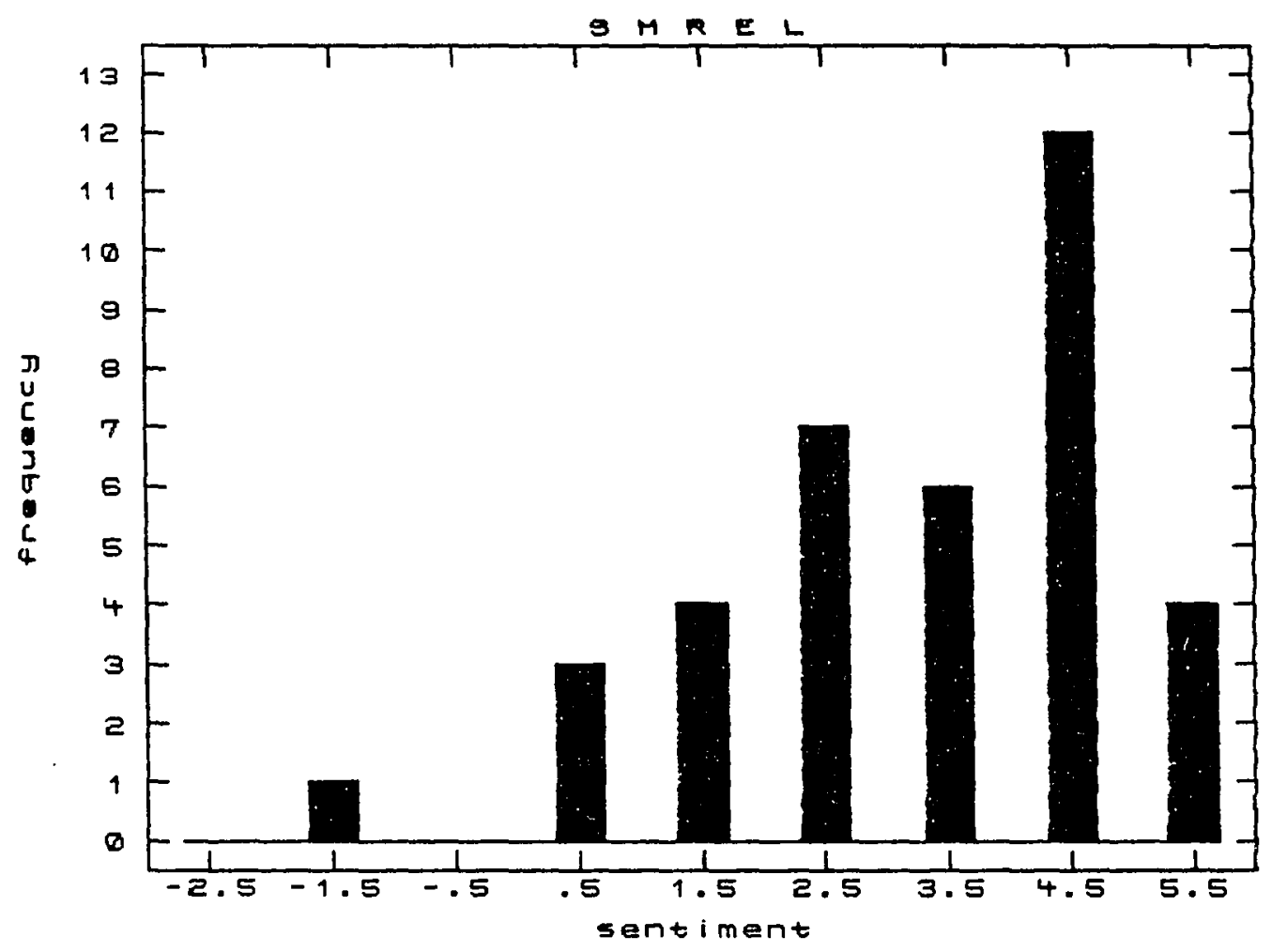

Figure 14. Frequency distribution of marital sentiment relation from stepparent's perspective (SMREL). 


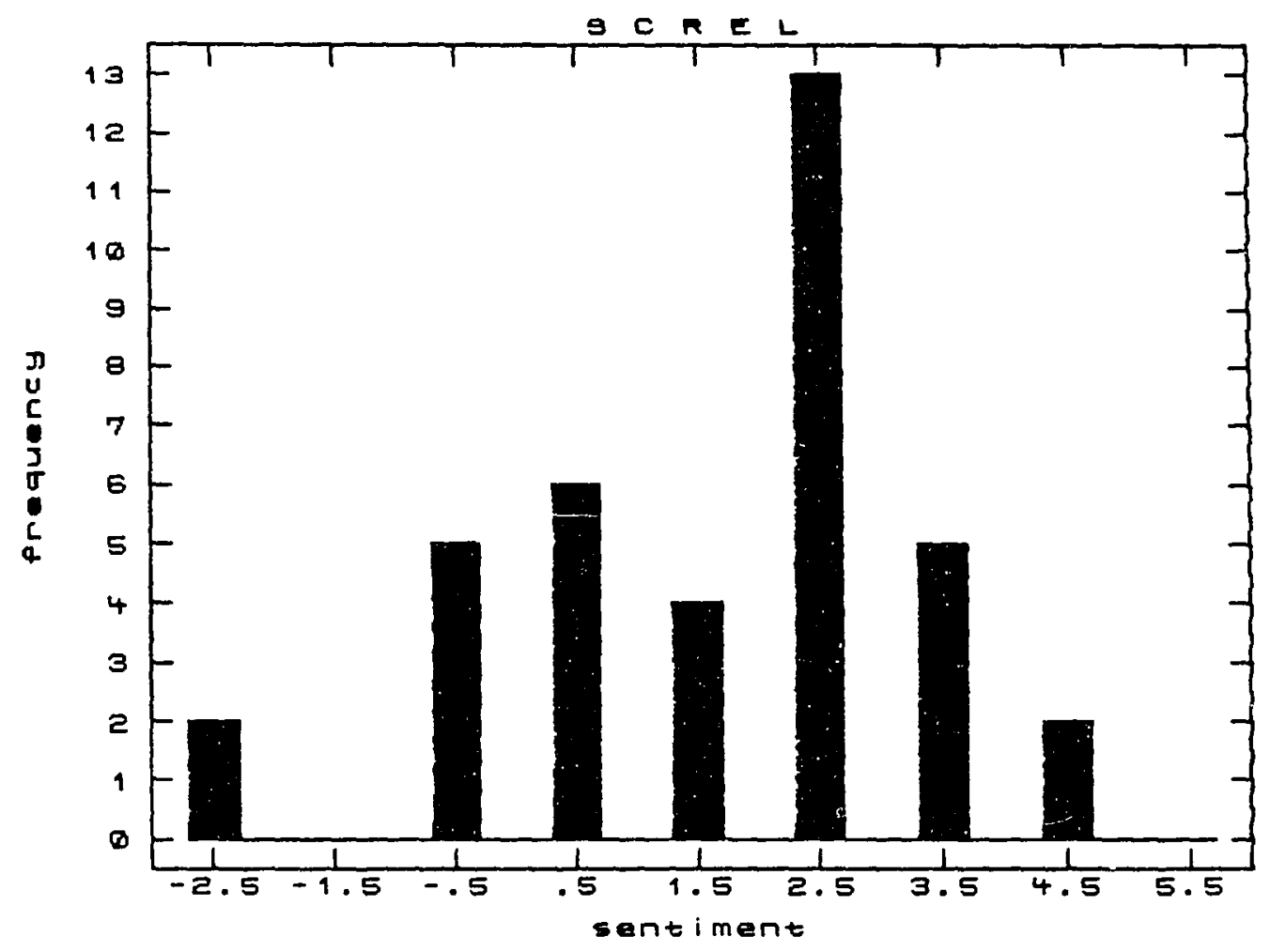

Figure 15. Frequency distribution of stepparent-child sentiment retation from parental perspective (SCREL). 


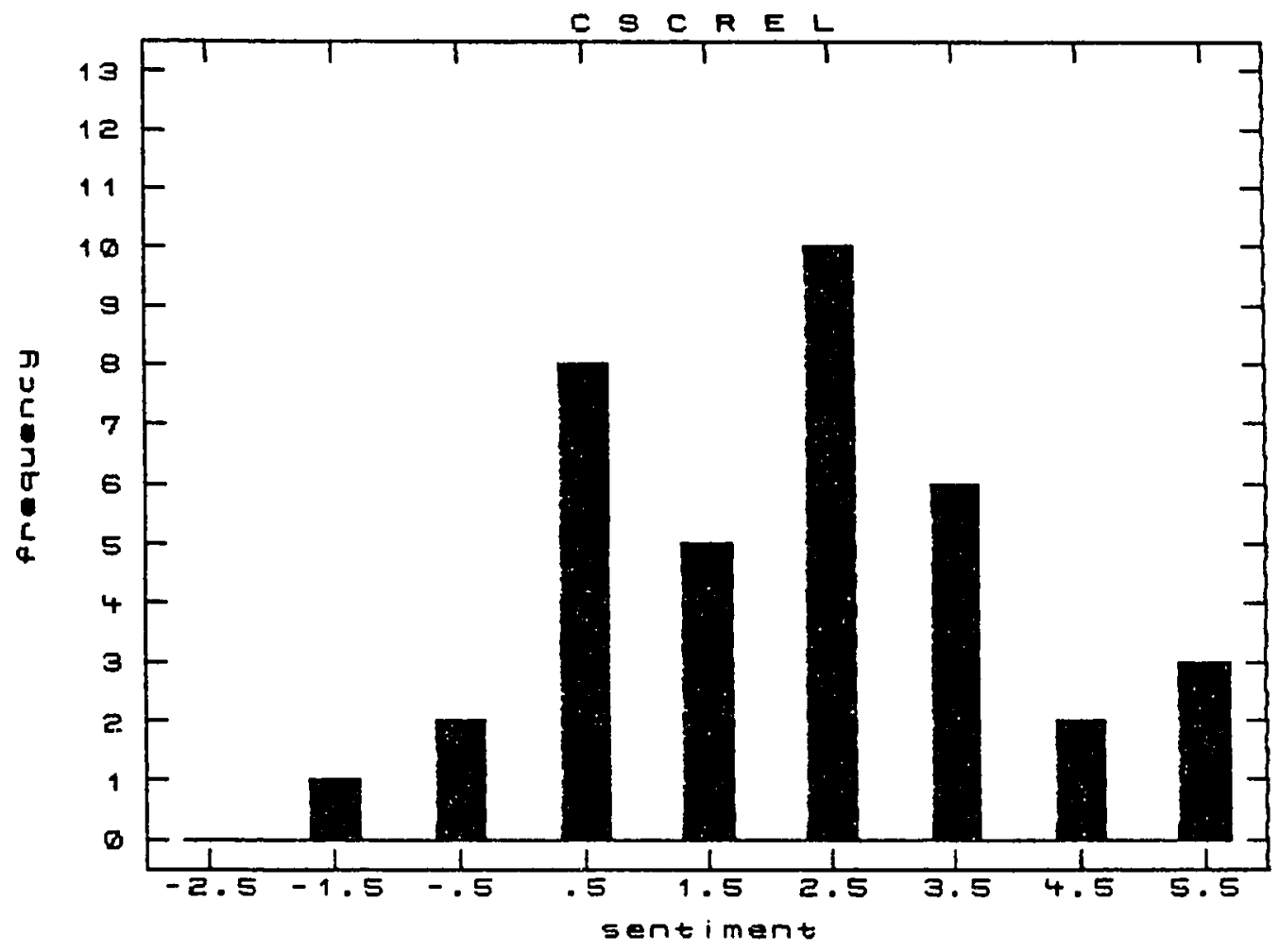

Figure 16. Frequency distribution of stepparent-child sentiment relation from child's perspective (CSCREL). 


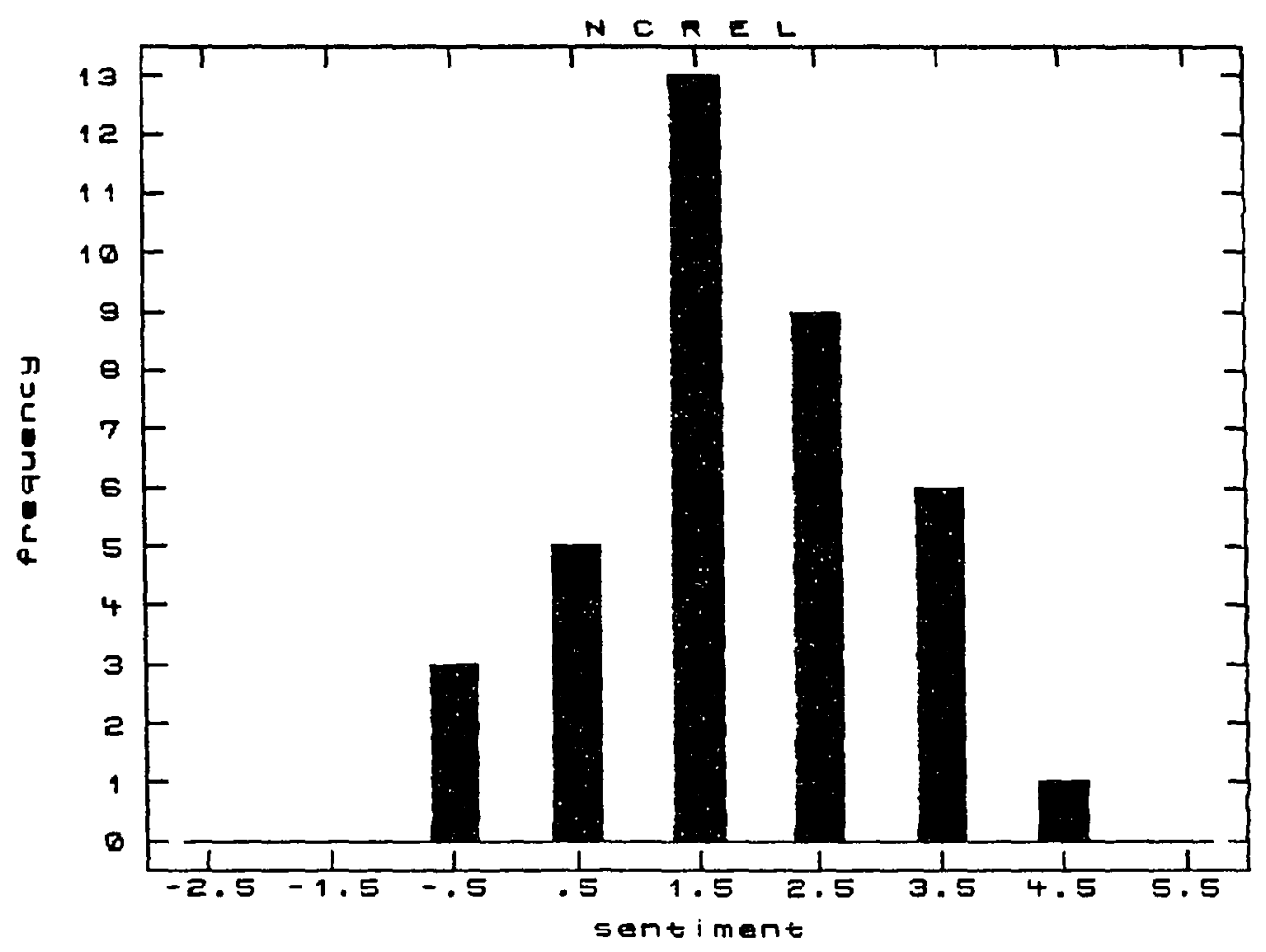

Figure 17. Frequency distribution of natural parent-child sentiment relation from parental perspective (NCREL). 


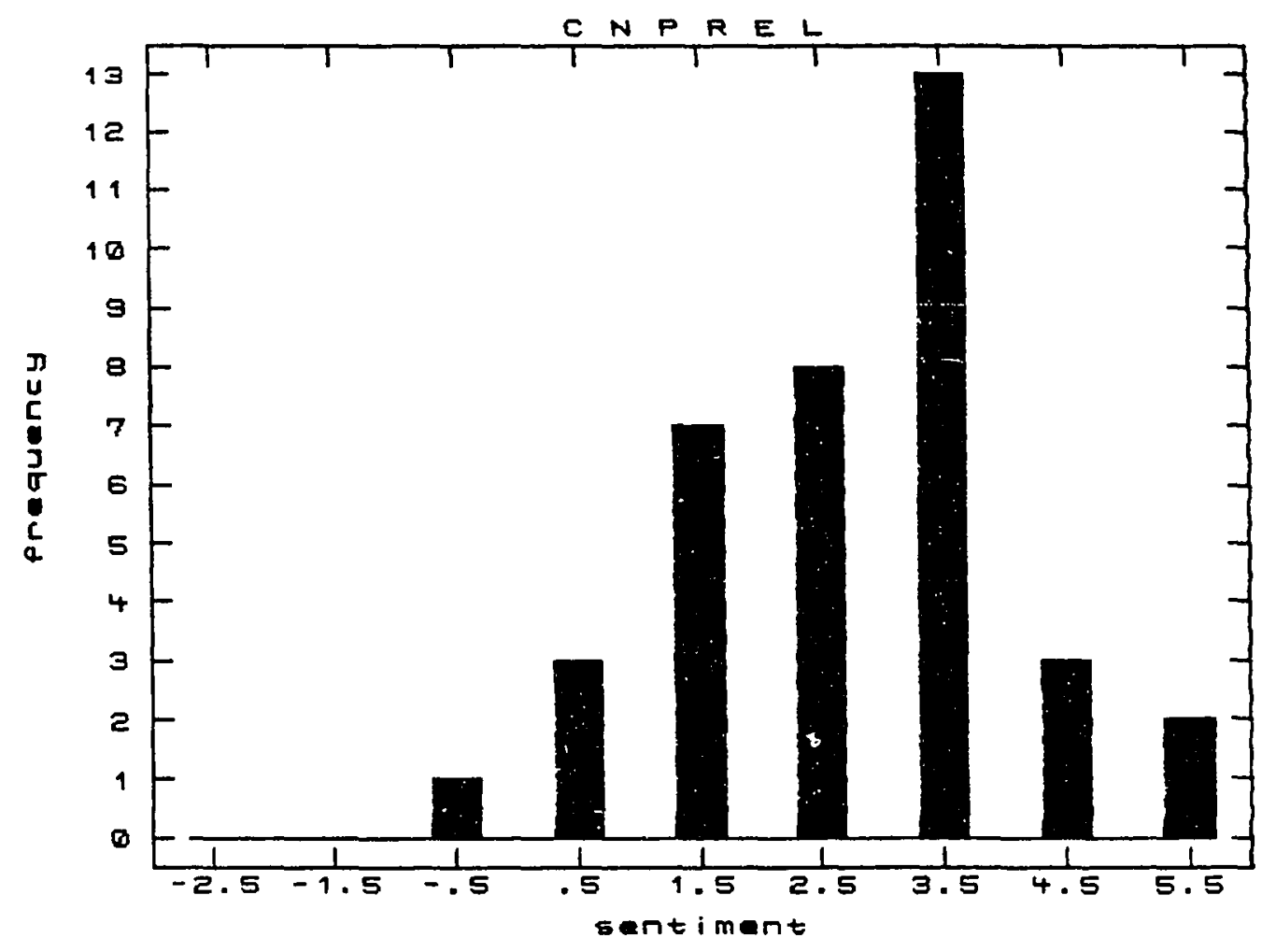

Figure 18. Frequency distribution of natural parent-child sentiment relation from child's perspective (CNPREL). 


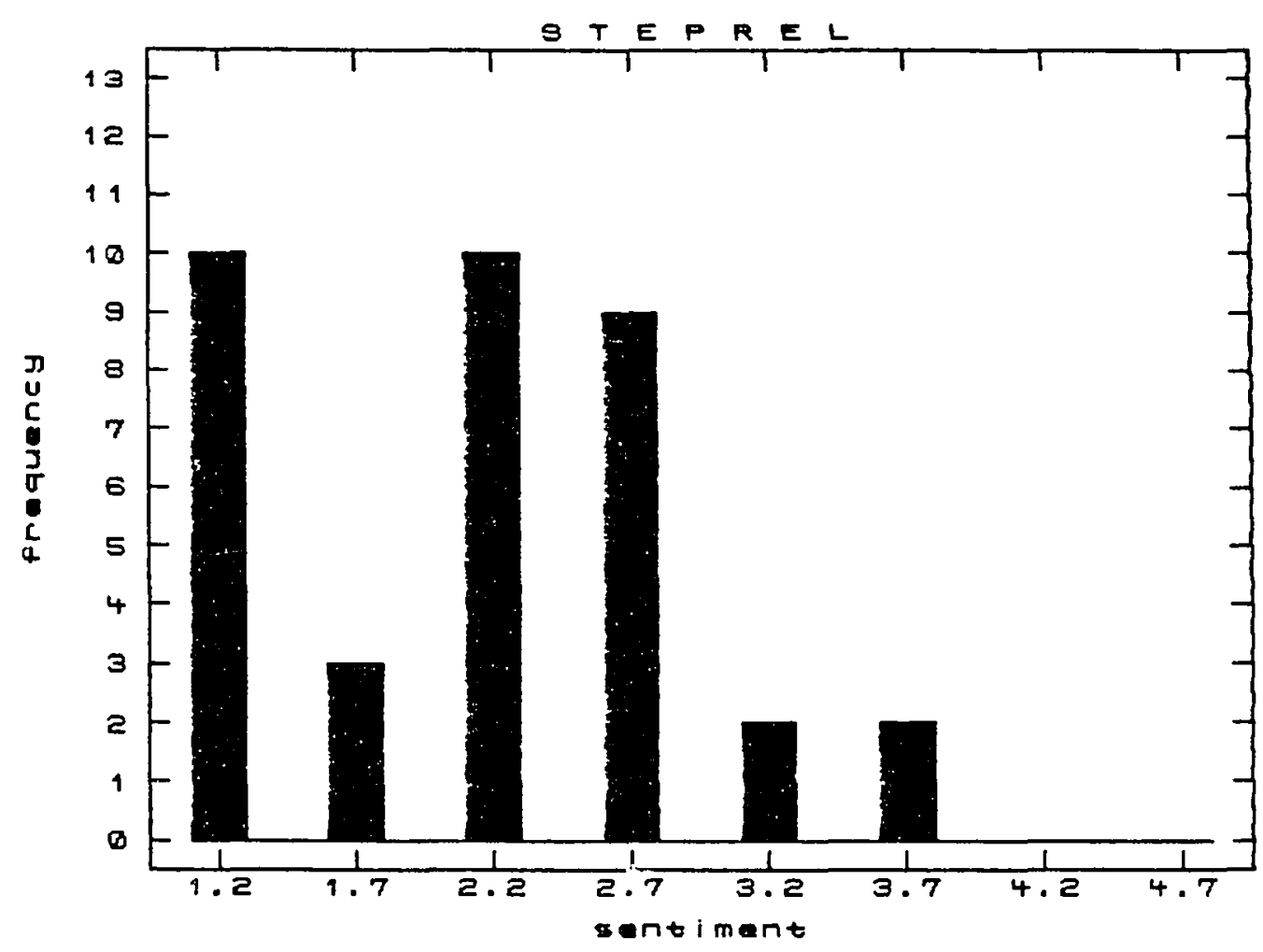

Figure 19. Frequency distribution of absent natural parent-stepparent sentiment relation (STEPREL). 


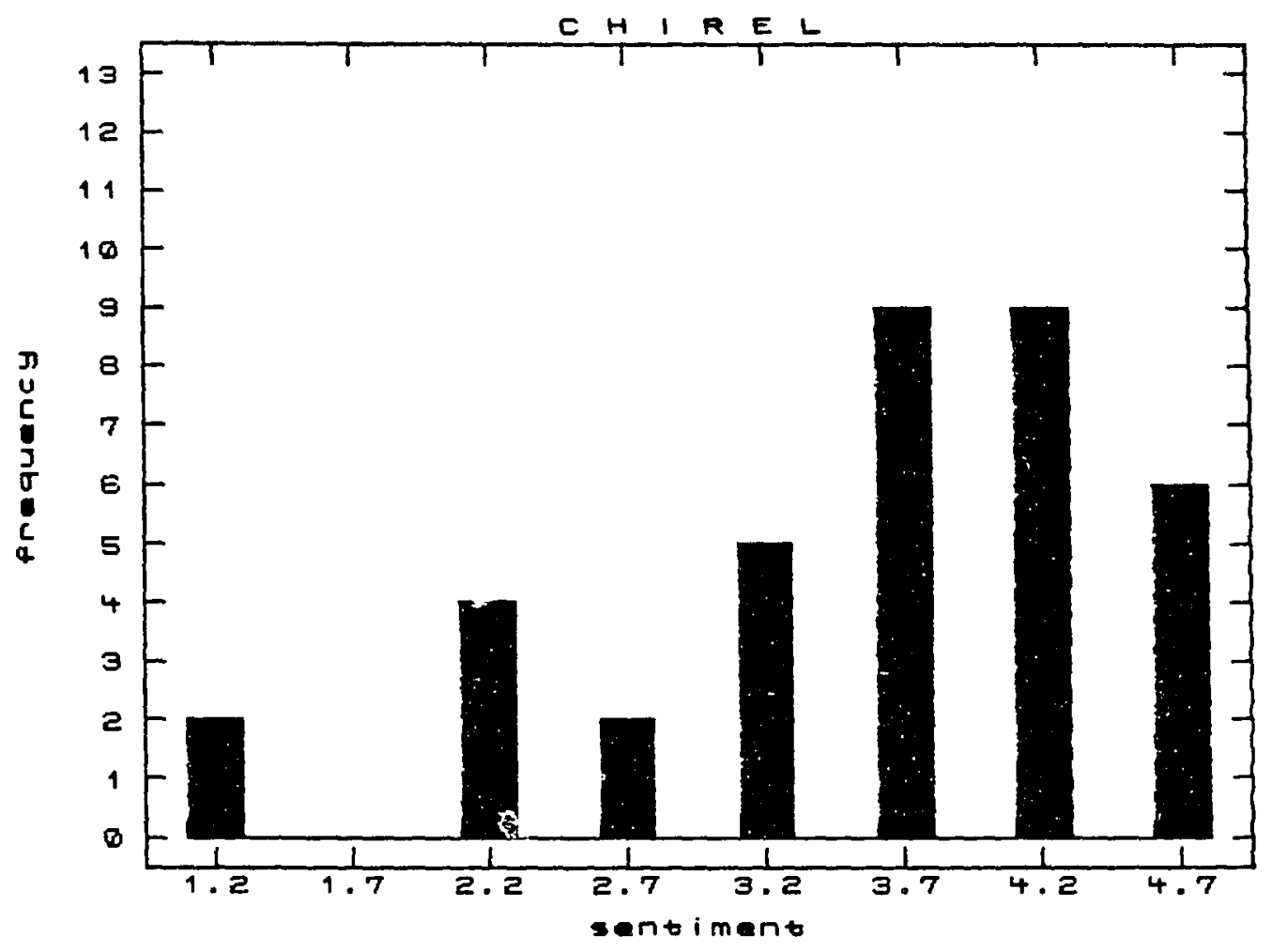
$\frac{\text { Figure } 20}{\text { relation (CHIREL). }}$ Frequency distribution of absent parent-child sentiment 


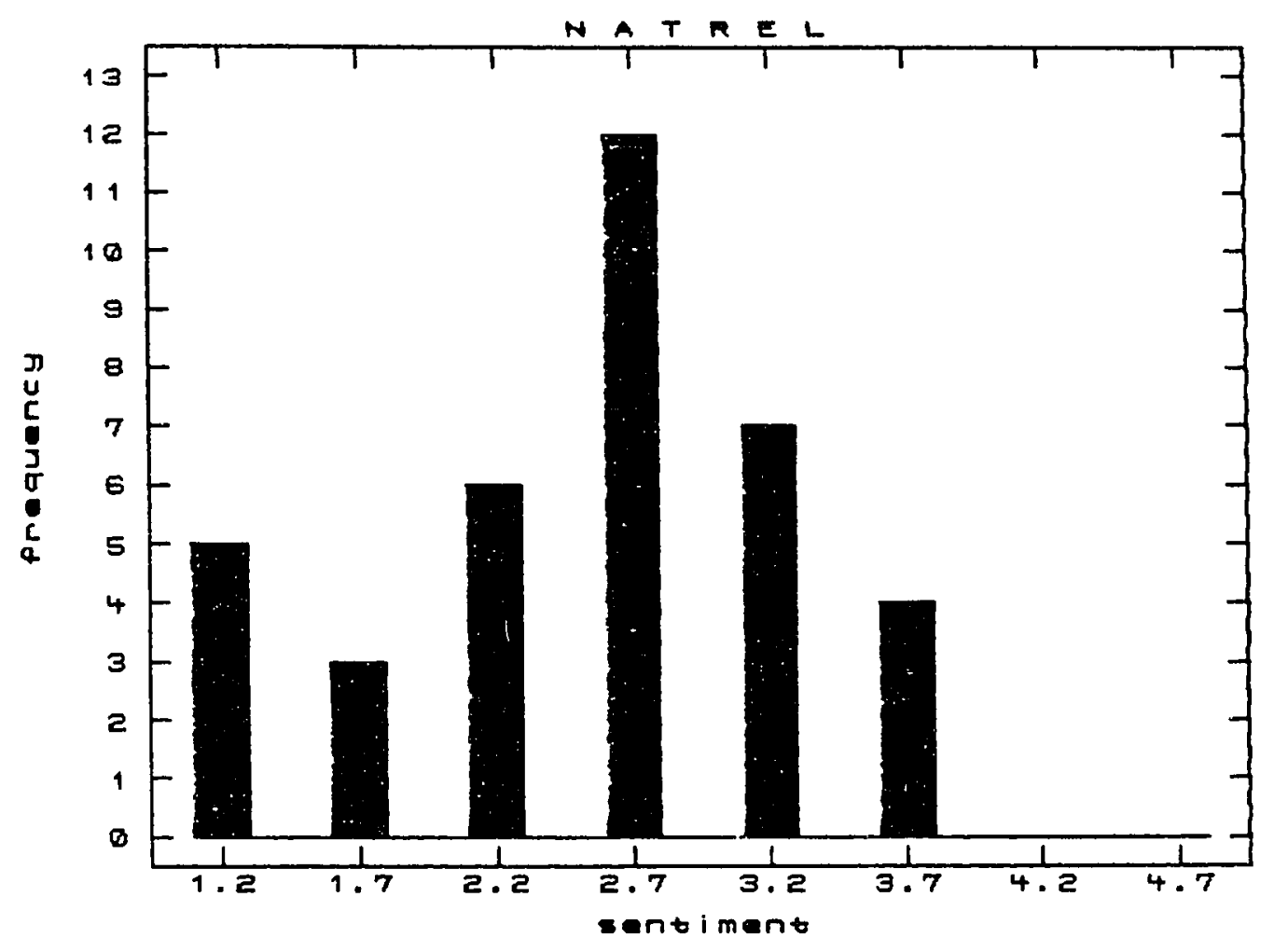

Figure 21. Frequency distribution of ex-spousal sentiment relation (NATREL). 
APPENDIX C

DEVELOPMENT OF THE NONRESIDENT PARENT QUESTIONNAIRES 
TABLE $X$

CONCEPTUAL VARIABLES WITH CORRESPONDING ITEMS IN

QUESTIONNAIRES PERTAINING TO NONRESIDENT PARENT

Variable

Questionnaire Items

Natural Parent

Trust

Goal Consensus

Satisfaction

Frequency of Contact

Positive Affect

Commitment
$9,11,13$

$7,10,12$

5

1

$2,3,4,6$

$6,8,10$

$5,7,9$

4

1

2,3

Child

Satisfaction

Frequency of Contact

Positive Affect

Commi tment

Relationship Content

Freedom of Access

Predictability

14

Continuity

1

$2,3,10,12$

13

$4,5,6,7$

9

11

$18,19,20$ 
Code \#

D S

\section{CHILD QUESTIONNAIRE}

We want to know more about your relationships with your absent parent (that is, the natural parent with whom you do NOT live) and his or her relatives. Please complete each statement by cirling the answer that best applies to you. (If the parent is deceased, start with 17.)

1. I see or talk with this parent.

$\begin{array}{llll}\begin{array}{l}\text { several } \\ \text { times/wk }\end{array} \quad \begin{array}{l}\text { several } \\ \text { times/mo }\end{array} & \begin{array}{l}\text { several } \\ \text { times/yr }\end{array} & \begin{array}{l}\text { about once } \\ \text { a year }\end{array} & \text { never } \\ \text { (If never, skip to 13.) } & & \end{array}$

2. I enjoy seeing or talking with this parent.

never rarely sometimes often always

3. If I had the choice, I would see or talk with this parent. $\begin{array}{llll}\text { never less } & \begin{array}{l}\text { about the } \\ \text { often }\end{array} & \begin{array}{l}\text { more } \\ \text { same }\end{array} & \begin{array}{l}\text { much more } \\ \text { often }\end{array}\end{array}$

4. When I see this parent, we have dinner together or share some kind of fun activity.
always
rarely
sometimes
rarely
never

5. When I talk to this parent, he/she gives me useful information or advice.
never
rarely
sometimes
often
always 
6. I talk with this parent about my feelings and problems. never rarely sometimes often always

7. When I see this parent, he/she gives me things or helps me out in other ways.
always
often
sometimes
rarely
never

8. When I see this parent, other members of my present family are with me, e.g., brother, sister.

never rarely sometimes often always

9. It is easy for me to see or talk with this absent parent when I want to.

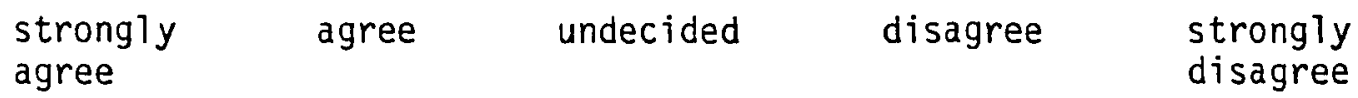

disagree

10. I see or talk with this parent because I have to.

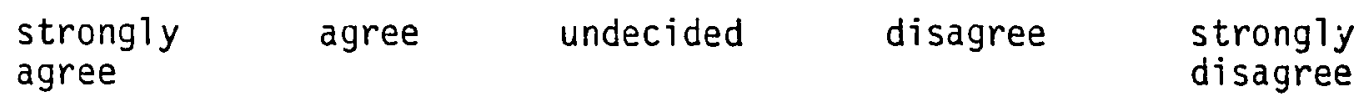

11. I can depend upon regular visits with this parent.

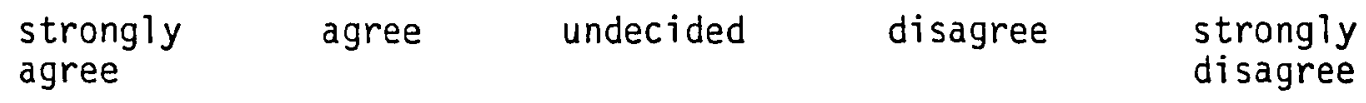

12. I see or talk with this parent because I want to.

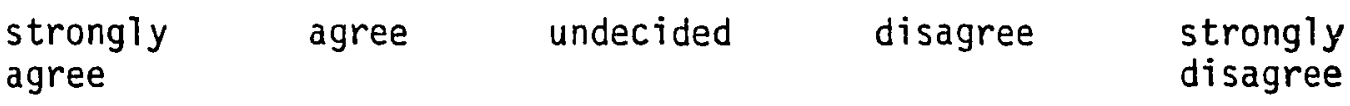


13. My relationship with this absent parent is important to me. strongly agree undecided disagree strongly agree

disagree

14. Overal1, how satisfied are you with your relationship with this absent parent?
very
satisfied satisfied undecided dissatisfied dissatisfied

15. I feel that my two natural parents now get along together. not at all slightly fair well very well

16. How far away from you does you absent parent live?

$\begin{array}{lllll}\text { under } 1 & 1-10 & 10-50 & 50-100 & \text { over } 100 \\ \text { mile } & \text { miles } & \text { miles } & \text { miles } & \text { miles }\end{array}$

17. How old were you when you stopped living with your absent natural parent?
$0-5$
$6-9$
$10-12$
$13-15$
$16-18$

18. When my former family was together, my absent parent and I did things together.
never
rarely
sometimes
often
always

19. When my former family was together, my absent parent and I got along well together. (Omit if you can't remember.)
always
often
sometimes
rarely
never 
20. When my former family was together, my absent parent understood me. (Omit if you can't remember.)

always often sometimes rarely never

21. I see or talk with my grandmother on my absent parent's side. (Omit if grandinother is deceased.)

$\begin{array}{llll}\text { several } & \text { several } & \text { several } & \text { about once } \\ \text { times/wk } & \text { times/mo } & \text { times/yr } & \text { a year }\end{array}$

22. I enjoy my relationship with this grandmother. (Omit if "never" circled above.)

$\begin{array}{lll}\begin{array}{l}\text { strongly } \\ \text { agree }\end{array} \text { agree } & \text { undecided disagree } & \begin{array}{l}\text { strongly } \\ \text { disagree }\end{array}\end{array}$

23. I see or talk to my grandfather on my absent parent's side. (Omit if grandfather is deceased.)

$\begin{array}{lllll}\text { several } & \text { several } & \text { several } & \text { about once } \\ \text { times/wk } & \text { times/mo } & \text { times/yr } & \text { a year }\end{array}$

24. I enjoy my relationship with this grandfather. (Omit if "never" circled above.)

$\begin{array}{lll}\begin{array}{l}\text { strongly } \\ \text { agree }\end{array} \text { agree undecided disagree } & \begin{array}{l}\text { strongly } \\ \text { disagree }\end{array}\end{array}$

25. Did you include any of this absent parent's relatives on the Social Network Scale? If yes, please return to that scale and identify those persons with an $A$ in the margin. 
Code \#

Mo $\quad \mathrm{Fa}$

STEPPARENT QUESTIONNAIRE

We would like to know more about your relationships with your stepchild's (that is, the child present with you in the inverview) absent parent and related kinfolk. Please complete each statement by circling the answer that best applies to you. (If absent parent is deceased, start with \#11.)

1. I see or talk with my stepchild's absent parent.

$\begin{array}{lllll}\text { several } & \text { several } & \text { several } & \text { about once } & \text { never } \\ \text { times/wk } & \text { times/mo } & \text { times/yr } & \text { a year }\end{array}$

2. I enjoy seeing or talking with my stepchild's absent parent. (Omit if "never" circled above.)

never rarely sometimes often always

3. If I had the choice, I would see or talk with my stepchild's absent parent.

\begin{tabular}{|c|c|}
\hline never & $\begin{array}{l}\text { less } \\
\text { often }\end{array}$ \\
\hline
\end{tabular}

4. Overall, how satisfied are you with your relationship with your stepchild's absent parent?

very satisfied undecided dissatisfied $\begin{aligned} & \text { very } \\ & \text { satissatisfied }\end{aligned}$
distied

5. My stepchild's absent parent and I have similar life styles. strongly agree undecided disagree strongly agree disagree 
6. When my stepchild sees his absent parent, I feel that he/she is in good hands.

$\begin{array}{ll}\begin{array}{l}\text { strongly agree } \\ \text { agree }\end{array} & \text { undecided disagree } \begin{array}{l}\text { strongly } \\ \text { disagree }\end{array}\end{array}$

7. My stepchild's absent parent and I have similar values. $\begin{array}{lll}\text { strongly agree } & \text { undecided disagree } & \begin{array}{l}\text { strongly } \\ \text { agree }\end{array}\end{array}$

8. I feel that my stepchild's absent parent is a good influence on $\mathrm{him} / \mathrm{her}$.

strongly agree undecided disagree strongly agree

disagree

9. My stepchild's absent parent and I have similar ideas about child rearing practices.

$\begin{array}{lll}\text { strongly undecided disagree } & \begin{array}{l}\text { strongly } \\ \text { agree }\end{array} \\ \text { disagree } & & \text { agree }\end{array}$

10. I worry about my stepchild's well being when he/she sees his/her absent parent.

$\begin{array}{llll}\text { strongly } & \text { agree } & \text { undecided } \\ \text { agree } & & \text { disagree } \\ \text { disagree }\end{array}$

11. I see or talk with other relitives of my stepchild's absent parent, e.g., grandparents, uncle, spouse.

$\begin{array}{lllll}\text { several } & \text { several } & \text { several } & \text { about once } & \text { never } \\ \text { times/wk } & \text { times/mo } & \text { times/yr } & \text { a year } & \end{array}$


12. I enjoy seeing or talking with my stepchild's ajsent parent's relatives. (Ömit if "never" circled above.)
never
rarely
sometimes
often
always

13. Did you include any of these relatives on the Social Network Scale? If yes, please return to that scale and identify those persons with an $A$ in the margin. 


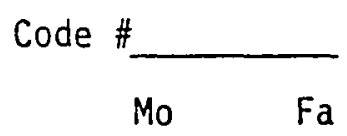

NATURAL PARENT

We want to know more about your current relationship with your ex-spouse and ex-relatives. Please complete each statement by circling the answer that best applies to you. (If your ex-spouse is deceased, start with \#14.)

1. I see or talk with my ex-spouse.

several several several about once never
times/wk times/mo times/yr a year

2. I enjoy seeing or talking with my ex-spouse. (Omit if "never" circled above.)

never rarely sometimes often always

3. If I had the choice, I would see or talk with my ex-spouse.

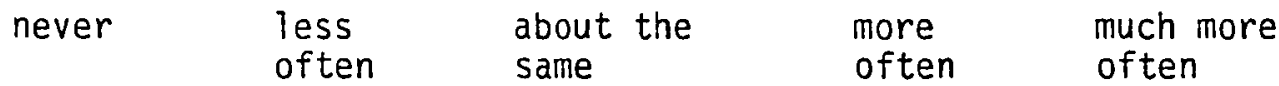

4. My ex-spouse and I help each other out.

always often sometimes rarely never

5. Overal1, how satisfied are you with your relationship with your exspouse?

$\begin{array}{lll}\text { very } & \text { very } \\ \text { satisfied satisfied undecided dissatisfied dissatisfied }\end{array}$ 
6. I see or talk with my ex-spouse because I have to. strongly agree

agree undecided disagree

strongly disagree

7. My ex-spouse and I have similar life styles. strongly disagree agree undecided strongly disagree agree

8. It is important that I see or talk with my ex-spouse for my child's sake.

strongly agree agree undecided strongly disagree

9. When our child sees his/her absent parent, I feel that he/she is in good hands.

$$
\text { strongly }
$$
agree agree undecided disagree

10. My ex-spouse and I have similar values.
strongly
disagree
agree
undecided
disagree
strongly
agree

strongly disagree

11. I feel that my ex-spouse is a good influence on our child. strongly agree

$$
\text { agree }
$$

undecided

disagree

strongly disagree

12. My ex-spouse and I have similar ideas about child rearing practices.

strongly disagree agree undecided strongly agree 
13. I worry about our child's well being when he/she sees his/her absent parent.

strongly

agree

agree

undecided

disagree

strongly

disagree

14. I see or talk with my ex-mother-in-law.

$\begin{array}{lllll}\text { several } & \text { several } & \text { several } & \text { about once } & \text { never } \\ \text { times/wk } & \text { times/mo } & \text { times/yr } & \text { a year }\end{array}$

15. Overa11, I enjoy my relationship with my ex-mother-in-1aw. (Omit if "never" circled above.)

strongly

disagree

agree

undecided

strongly

disagree agree

16. I see or talk with my ex-father-in-law.

\begin{tabular}{|c|c|c|}
\hline $\begin{array}{l}\text { several } \\
\text { times/wk }\end{array}$ & $\begin{array}{l}\text { several } \\
\text { times/mo }\end{array}$ & $\begin{array}{l}\text { several } \\
\text { times/yr }\end{array}$ \\
\hline
\end{tabular}

17. Overal1, I enjoy my relationship with my ex-father-in-law. (Omit if "never" circled above.)

strongly

agree

agree undecided

disagree

strongly

disagree

18. I see or talk with other of my ex-spouse's relatives, e.g., my exbrother-in-law, ex-husband's new spouse.

$\begin{array}{lllll}\text { several } & \text { several } & \text { several } & \text { about once } & \text { never } \\ \text { times/wk } & \text { times/mo } & \text { times/yr } & \text { a year }\end{array}$


19. I enjoy seeing or talking with these persons. (Omit if "never" circled above.)

strongly

disagree

agree

undecided

strongly agree

20. Did you included any of your ex-spouse's relatives on the Social Network Scale? If yes, please return to that scale and identify those persons with an $A$ in the margin. 
APPENDIX D

CALCULATION OF BALANCE INDICES 
This appendix presents the cycles for each balance index. The relations included in each cycle are listed by their computer names. The sentiment relation computer names were presented in Appendix B, Means and Standard Deviations of Scales. The unit relation computer names follow:

marital, MUNIT stepparent-child, SPUNIT

natural parent-child, NPUNIT

absent parent-child, CHIUNIT

absent parent-stepparent, STEUNIT

ex-spousal, NATUNIT

The cycles were named ADULT, RIVAL, OLD, and NEW, corresponding to the triangle of which they are a part.

Single Sentiment Relations

This balance index contained four cycles:

ADULT $=$ NATSENT*MSENT*STEPSEN

RIVAL-STEPSEN*CHISENT*SPSENT

NEW-MSENT*SPSENT*NPSENT

OLD-NPSENT*NATSENT*CHISENT

Directed Sentiment Relations

This balance index contained 20 cycles:

ADULTA $=$ SMSENT*NMSENT

ADULTB $=$ NATSENT*SMSENT $*$ STEPSEN

ADULTC-NATSENT*NMSENT*STEPSEN

RIVALA-SCSENT*CSCSENT

RIVALB $=$ STEPSEN*CHISENT*SCSENT

RIVALC $=S T E P S E N * C H I S E N T * C S C S E N T$

OLDA $=$ NCSENT $*$ CNPSENT

OLDB $=$ NATSENT $*$ CHISENT*NCSENT 


\author{
OLDC $=$ NATSENT $*$ CHISENT $*$ CNPSENT \\ NEWA $=$ SMSENT $*$ NMSENT \\ $N E W B=S C S E N T * C S C S E N T$ \\ NEWC $=N C S E N T * C N P S E N T$ \\ $N E W D=N C S E N T * C S C S E N T *$ SMSENT \\ NEWE $=N C S E N T * S C S E N T *$ SMSENT \\ $N E W F=N C S E N T * C S C S E N T * N M S E N T$ \\ $N E W G=N C S E N T * S C S E N T * N M S E N T$ \\ NEWH $=$ CNPSENT $*$ CSCSENT $T *$ SMSENNT \\ $N E W I=C N P S E N T * S C S E N T * S M S E N T$ \\ $N E W J=C N P S E N T * C S C S E N T * N M S E N T$ \\ NEWK $=$ CNPSENT $*$ SCSENT*NMSENT
}

Single Sentiment and Unit Relations

This balance index contained the following 44 cycles:

AADULT $=$ NATSENT $*$ NATUNIT

BADULT $=$ MSENT $*$ MUNIT

CADULT $=$ STEPSEN $*$ STEUNIT

DADULT $=$ NATSENT*MSENT *STEPSEN

EADULT $=$ NATUNI $T$ *MUNI $T$ *STEUNIT

FADULT $=$ NATUNIT*MSENT*STEPSEN

GADULT $=$ NATSENT*MUNI $T * S T E P S E N$

HADULT $=$ NATSENT $* M S E N T * S T E U N I T$

IADULT $=$ NATSENT*MUNI $T *$ STEUNIT

JADULT $=$ NATUNIT*MSENT*STEUNIT

KADULT $=$ NATUNIT*MUNI $T$ *STEPSEN

ARIVAL $=S T E P S E N * S T E U N I T$

BRI VAL $=$ CHISENT $*$ CHIUNIT

CRI VAL $=S P S E N T * S P U N I T$

DRI VAL $=S T E P S E N * C H I S E N T * S P S E N T$

ERI VAL $=S T E U N I T * C H I U N I T *$ SPUNIT

$F R I V A L=S T E U N I T * S P S E N T * C H I S E N T$

GRI VAL $=S T E P S E N * S P S E N T * C H I U N I T$

HRI VAL $=S T E P S E N * S P U N I T * C H I S E N T$

IRI VAL $=$ STEPSEN $*$ SPUN I $T *$ CHIUNIT

$J R I V A L=S T E U N I T * S P U N I T * C H I S E N T$

KRI VAL $=S T E U N I T * S P S E N T * C H I U N I T$

$A O L D=N P S E N T * N P U N I T$

$B O L D=N A T S E N T *$ NATUNIT

COLD $=$ CHISENT $*$ CHIUNIT

DOLD $=$ NPSENT *NATSENT*CHISENT

$E O L D=N P U N I T * N A T U N I T * C H I U N I T$

$F O L D=N P U N I T * N A T S E N T *$ CHISENT

GOLD $=N P S E N T *$ NATUNIT *CHISENT

HOLD $=N P S E N T * N A T S E N T * C H I U N$ IT

IOLD $=$ NPSENT *NATUNIT*CHIUNIT

JOLD $=$ NPUNIT*NATSENT *CHIUNIT 


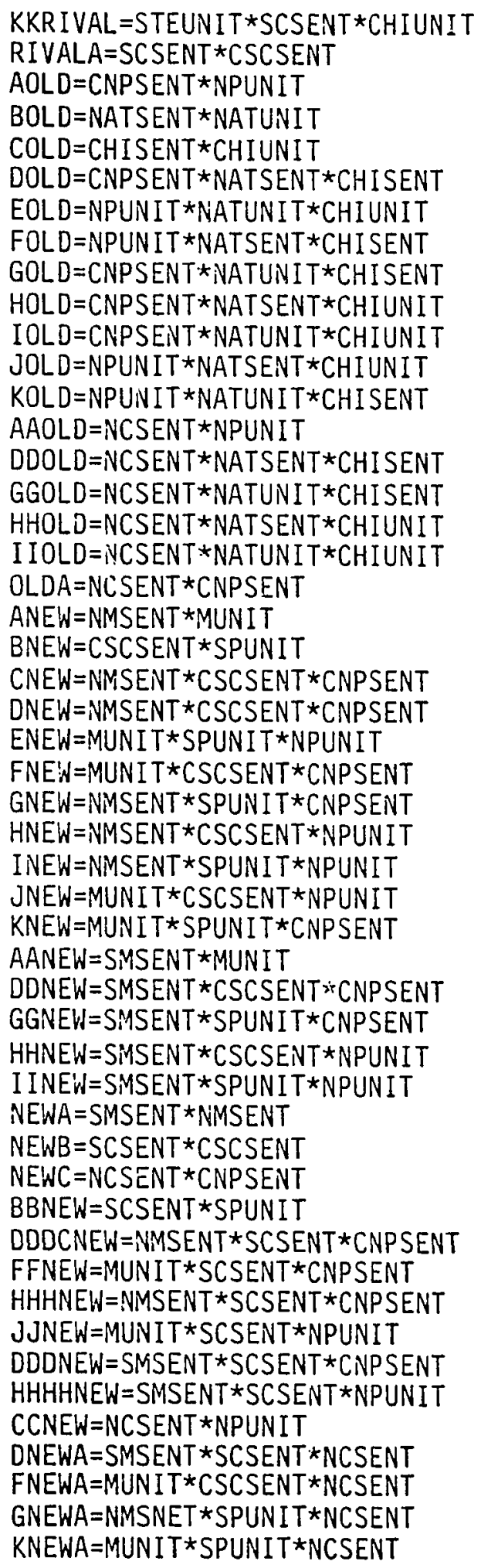




\begin{abstract}
DDNEWA $=$ SMSENT $*$ CSCSENT $* N C S E N T$
GGNEWA $=$ SMSENT*SPUNIT*NCSENT

DDDNEWA $=$ NMSNET $*$ SCSENT*NCSENT

FFNEWA $=$ MUNIT*SCSENT*NCSENT

ZDDDNEW $=$ SMSENT $*$ SCSENT $*$ NCSENT
\end{abstract}

First, the COMPUTE statement was used to obtain the algebraic product for each cycle. Secondly, the COUNT statement was used to count the number of positive cycles. Lastly, the COMPUTE statement accomplished the division required in the balance formula. 